\title{
Review Article \\ Performance Enhancing Diets and the PRISE Protocol to Optimize Athletic Performance
}

\author{
Paul J. Arciero, ${ }^{1}$ Vincent J. Miller, ${ }^{1,2}$ and Emery Ward ${ }^{1}$ \\ ${ }^{1}$ Human Nutrition and Metabolism Laboratory, Health and Exercise Sciences Department, Skidmore College, Saratoga Springs, \\ NY 12866, USA \\ ${ }^{2}$ College of Graduate Health Studies, A. T. Still University, Mesa, AZ 85206, USA
}

Correspondence should be addressed to Paul J. Arciero; parciero@skidmore.edu

Received 9 October 2014; Accepted 3 March 2015

Academic Editor: Pedro Moreira

Copyright (C) 2015 Paul J. Arciero et al. This is an open access article distributed under the Creative Commons Attribution License, which permits unrestricted use, distribution, and reproduction in any medium, provided the original work is properly cited.

\begin{abstract}
The training regimens of modern-day athletes have evolved from the sole emphasis on a single fitness component (e.g., endurance athlete or resistance/strength athlete) to an integrative, multimode approach encompassing all four of the major fitness components: resistance (R), interval sprints (I), stretching (S), and endurance (E) training. Athletes rarely, if ever, focus their training on only one mode of exercise but instead routinely engage in a multimode training program. In addition, timed-daily protein (P) intake has become a hallmark for all athletes. Recent studies, including from our laboratory, have validated the effectiveness of this multimode paradigm (RISE) and protein-feeding regimen, which we have collectively termed PRISE. Unfortunately, sports nutrition recommendations and guidelines have lagged behind the PRISE integrative nutrition and training model and therefore limit an athletes' ability to succeed. Thus, it is the purpose of this review to provide a clearly defined roadmap linking specific performance enhancing diets (PEDs) with each PRISE component to facilitate optimal nourishment and ultimately optimal athletic performance.
\end{abstract}

\section{Introduction}

At every level of athletic competition, the drive to succeed is a natural competitive instinct that requires an appropriate amount, type, and timing of exercise training and nutrient intake. This balance is important because the difference between winning and losing largely depends on the training and nutritional status of the athlete. Thus, in order for any athlete to be successful, proper training and nourishment must be a daily priority.

Specific training regimens for elite athletes are often based on the same science used to formulate exercise and nutrition recommendations for the general public. For example, governing organizations in sports medicine (American College of Sports Medicine, ACSM) and healthcare (American Heart Association, AHA; Centers for Disease Control, CDC; World Health Organization, WHO) generally promote an exercise regimen that includes a combination of (i) cardiorespiratory (aerobic) (150 minutes/week of 30-60 minutes moderateintensity 5 days/week or 20-60 minutes vigorous-intensity exercise 3 days/week); (ii) resistance (major muscle groups 23 days/week of 2-4 sets and 8-20 repetitions); (iii) flexibility (stretches held for 10-30 seconds, repeated 2-4 times 2-3 days/week); and (iv) neuromotor/functional exercise (balance, agility, coordination 20-30 minutes/day 2-3 days/week).

While the intent of these exercise recommendations is noble, the majority of the US population $(>60 \%)$ falls short in achieving them [1-3], especially among youth. It may very well be the case, exercise compliance and adherence suffers because the current recommendations are not realistic (up to 7 days of exercise per week) or compatible with many lifestyles. An additional concern with current exercise guidelines is they often lack a clear and specific connection to appropriate dietary intake recommendations.

Interestingly, the contemporary athlete (competitive and noncompetitive) no longer adheres to the traditional, narrowly defined training regimen focused on only one mode of exercise (e.g., only endurance or only resistance) but instead adheres to a multimode, integrative training model. Indeed, the challenge for most athletes today is finding the 
TABLE 1: PRISE protocol.

\begin{tabular}{|c|c|c|c|c|c|c|c|c|c|}
\hline & Exercise & Type & Work & $\mathrm{RPE}$ & Monday & Tuesday & Wednesday & Thursday & Friday \\
\hline \multirow{5}{*}{ PRISE } & Protein-pacing $(\mathrm{P})$ & $\mathrm{P}, \mathrm{A}$ & - & - & $\begin{array}{c}20 \text { grams } \times 5 \\
\text { servings }\end{array}$ & $\begin{array}{c}20 \text { grams } \times 5 \\
\text { servings }\end{array}$ & $\begin{array}{c}20 \text { grams } \times 5 \\
\text { servings }\end{array}$ & $\begin{array}{c}20 \text { grams } \times 5 \\
\text { servings }\end{array}$ & $\begin{array}{c}20 \text { grams } \times 5 \\
\text { servings }\end{array}$ \\
\hline & Resistance (R) & WB & $\begin{array}{c}2 \text { sets/exercise } \\
10-15 \text { reps }\end{array}$ & $7-9$ & WB & - & & - & - \\
\hline & Intervals (I) & $\mathrm{C}$ & $\begin{array}{c}5-7 \text { sets } \\
30 \mathrm{~s} / 4 \text { min rest }\end{array}$ & $10 / 3$ & - & $\mathrm{X}$ & REST & - & - \\
\hline & Stretching (S) & S & $\leq 60 \mathrm{~min}$ & $7-9$ & - & - & & WB & - \\
\hline & Endurance (E) & $\mathrm{C}$ & $\geq 60 \mathrm{~min}$ & 6 & - & - & & - & $\mathrm{X}$ \\
\hline
\end{tabular}

Note: P: plant-based; A: animal-based; RPE: rating of perceived effort; RT: resistance training; Sprint: sprint interval training; C: choice of exercise modality; WB: whole body exercise; S: stretching exercise; X: exercise day. Exercise modalities available for C include walking, jogging, running, cycling, swimming, elliptical, rowing, rollerblading, and cross-country skiing.

balance (time and energy) to incorporate all of the fitness components (resistance, anaerobic, aerobic, and flexibility training) into their regular training regimen, recognizing the vital importance each one contributes to their overall success. Thus, herein we propose a scientifically validated model that embraces a holistic and integrative model of exercise training that all athletes are encouraged to follow, termed "PRISE" (Table 1) [4]. The "P" is timed-daily protein-pacing intake; the " $R$ " is resistance training; " $I$ " is interval anaerobic sprint training; " $\mathrm{S}$ " is stretching (flexibility, restorative) training; and " $E$ " is endurance aerobic training and is based on 4 days of structured exercise per week (Tables 2 and 3; Figures 1 and 2). This novel paradigm of exercise training integrates the four major fitness components into the training regimen of all athletes, regardless of sport, while still allowing for an athlete to emphasize sport-specific training.

Perhaps equally, if not more, important for athletic performance is proper nourishment, including the type, timing, and amount of specific food and dietary supplement sources. Currently, there is disconnect between sports nutrition guidelines and the progressive multicomponent exercise training regimen (PRISE) that many athletes follow. As an example, most endurance athletes (marathoners, triathletes, etc.) are encouraged to follow a consistent diet of relatively high carbohydrate intake (60-70\% of total kcals). However, most endurance athletes adhere to a PRISE training schedule, including resistance (R), interval (I), and stretching (S) training, and therefore need to adapt their nourishment to match this integrative training paradigm in order to achieve success and the same applies to the sprint-type athlete.

It is clear that our current exercise training and nutrition practices need to be readjusted to meet the needs of the evolving athlete. Thus, the major objective of the current sports nutrition review is to establish a clear rationale and link between a scientifically proven integrative model of exercise training (PRISE) performed four days per week and a matching sports performance enhancing diet (PED), to maximize athletic performance. We advocate following the PRISE protocol and linking the prescribed PED to each component for that day to maximize the physiological, biochemical, and hormonal responses. The advantage of incorporating these nutritional strategies on a temporal basis allows the body to avoid repeated long-term exposure and thus potential for adverse side effects, downregulation (i.e., decreased cellular sensitivity), and tolerance to occur. In addition, athletes should follow a balanced, protein-rich diet that incorporates $20-30$ grams of high-quality protein evenly spaced throughout the day ( every 3 hours), including nonexercising days.

\section{Timed-Daily Protein-Pacing (P) Intake}

Protein is arguably the most crucial nutrient for general health and athletic performance because of its role in protein synthesis, energy metabolism, body composition (optimal lean muscle mass and fat mass), immune support, and satiation. Further, research supports timed-daily protein feedings throughout the day to maximize protein synthesis and thus lean muscle mass accretion [5-7]. Dietary guidelines have consistently encouraged a higher carbohydrate $(\mathrm{CHO})$ intake (up to $65 \%$ of total kcals), moderate fat (20-35\% of total kcals), and $10-35 \%$ of intake as protein (PRO) for proper weight control [8]. However, recent data suggests that consuming protein at the higher acceptable range ( $25-35 \%)$ enhances energy expenditure [9-11] and body composition $[4,7,12-14]$ and may do so independent of inducing weight loss [15]. This is important because it will have important implications for athletes attempting to improve health and performance outcomes without undergoing caloric restriction and weight reduction. Recent data also shows that the combined effects of increased dietary PRO and reduced glycemic index (GI) diets enhances weight loss maintenance [16] and improves body composition [17, 18].

Meal frequency (number of meals eaten) is another important factor for optimization of body composition and athletic performance. Several studies have suggested meal frequency is inversely related to body weight $[19,20]$.

Mechanisms. It is well established that energy expenditure and metabolism differ greatly in response to macronutrient intake of isoenergetic meals. For example, protein intake elicits the greatest thermogenic response compared to carbohydrate and fat [21-23] and this may be related to increased satiation [21]. In addition, compelling evidence favors dietary proteins containing a full complement of essential amino acids with a high leucine content to maximally stimulate muscle protein 
TABLE 2: Resistance exercise (R).

\begin{tabular}{lll}
\hline & \multicolumn{1}{c}{ Circle the exercises performed from each category } & Reps/time \\
\hline \multicolumn{1}{c}{ Perform prior to each workout (5-10 minutes): } \\
\hline \\
Dynamic & (1) Pendulum swings (side-to-side) & (8) Hip opening/closing \\
warm-up & (2) Pendulum swings (front-to-back) & (9) High knees \\
& (3) High knee (chest) & (10) Butt kicks \\
& (4) High knee (external rotation) & (11) Lunge with twist \\
(5) Side shuffle & (12) Arm windmills \\
\hline
\end{tabular}

Perform using agility ladder (10 minutes):

$\begin{array}{lll} & \text { (1) Forward, double-step } & \text { (1) Side shuffle } \\ \text { (2) Sideways double-step } & \text { (2) Figure 8's } \\ \text { Footwork and } & \text { (3) Side-step, double in/out } & \text { (3) Kangaroo hops 2/1 foot } \\ \text { agility } & \text { (4) Side shuffle, two-in/out } & \text { (4) Kangaroo hops, sideways } \\ \text { (5) Two leg hops } & \text { (5) T-drill } \\ & \text { (6) One leg hops } & \text { (6) Jump rope } \\ \text { (7) Two leg hops, in/out } & \\ \text { (8) One leg hops, in/out } & \\ \text { (9) One leg hops, sideways } & \end{array}$

Perform each below (10 minutes):

(1) Side-steps toes in/out, ankles/knees

-Side-steps with bands and med ball

(2) Forward/backward walk with bands

(3) Squats

(4) Lunges with tubing (with med ball)

Resistance and power exercises

(5) Lateral lunges (with med ball)

Choose 2 below:
(6) Front step-ups
(7) Squat thrusts, med ball throws
(8) Jump squats
(9) Mountain climbers
(10) Squat-plank-jump squats
(11) Lateral step-ups

Perform each below (10 minutes):

(1) Back rows/flys

(2) Pull-ups

(3) Chest press/fly

(4) Pushups (choose one):

(i) Side walking

(ii) Knees/toes w/physioball

(iii) Down dog

(iv) Side to side (ball)

(v) Heart-to-heart

(vi) $\mathrm{Hi} / \mathrm{low}$

(5) Front/lateral raises

(6) Biceps curls

(7) Shoulder press

(8) Hyperextensions Perform 4 below (5 minutes):

Perform 4 below (10 minutes)

(1) Knees to chest

(2) Hyperextension on ball

(3) Reverse planks

(4) Ab hollow

(5) Walking sit-ups

(6) Crunch bent knee

(7) Tug-of-war

(8) Side touch/scissors/toe

(8) Supermans/womans

(9) Crunches on ball

(10) Plank with ball on knees/toes

Resistance exercises utilize medicine balls, physioballs, rubber tubes and bands which are incorporated into a dynamic warm-up, footwork and agility drills, resistance and power movements, and core exercises, bodyweight exercises (e.g., lunges, squats, and jumping rope). A 5 minute cool down follows the R routine with gentle stretching. Total $\mathrm{R}$ exercise time is 60 minutes. 


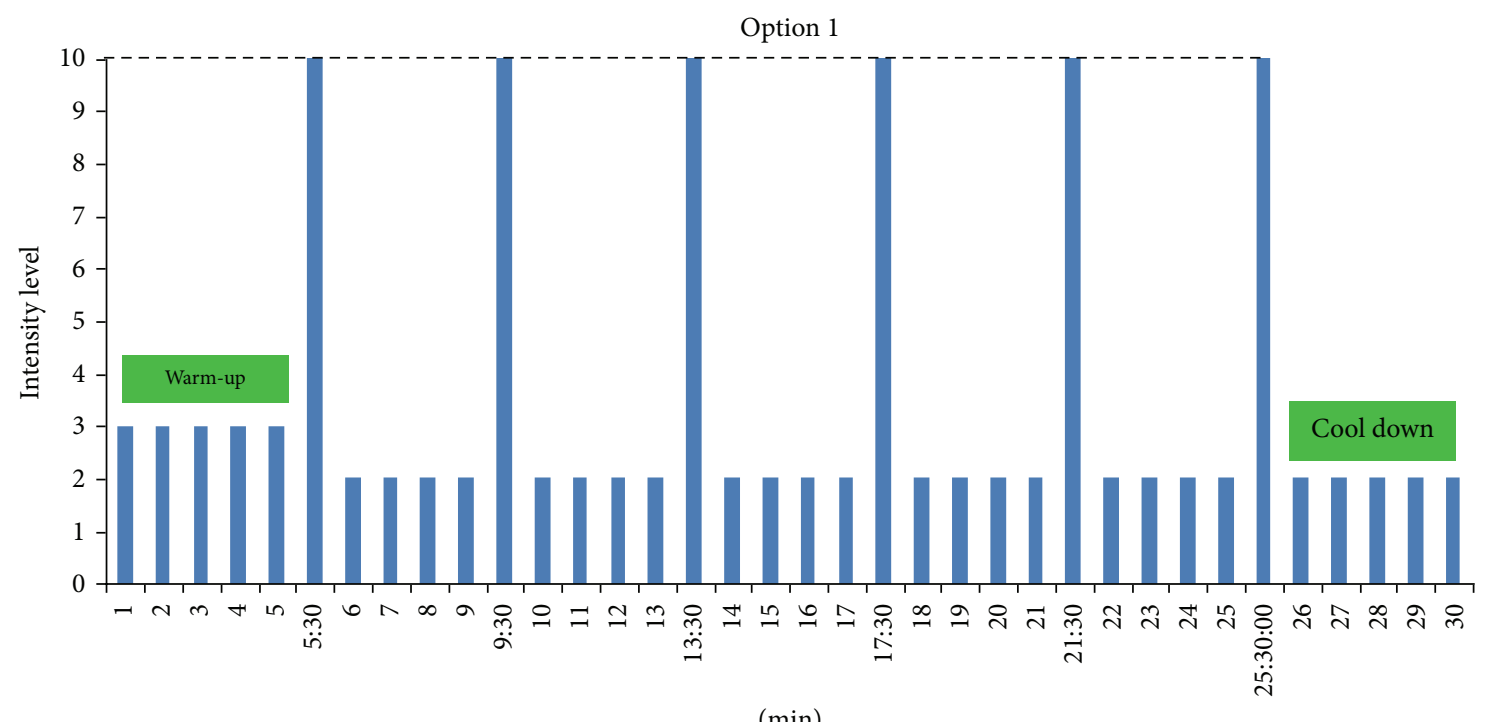

$(\min )$

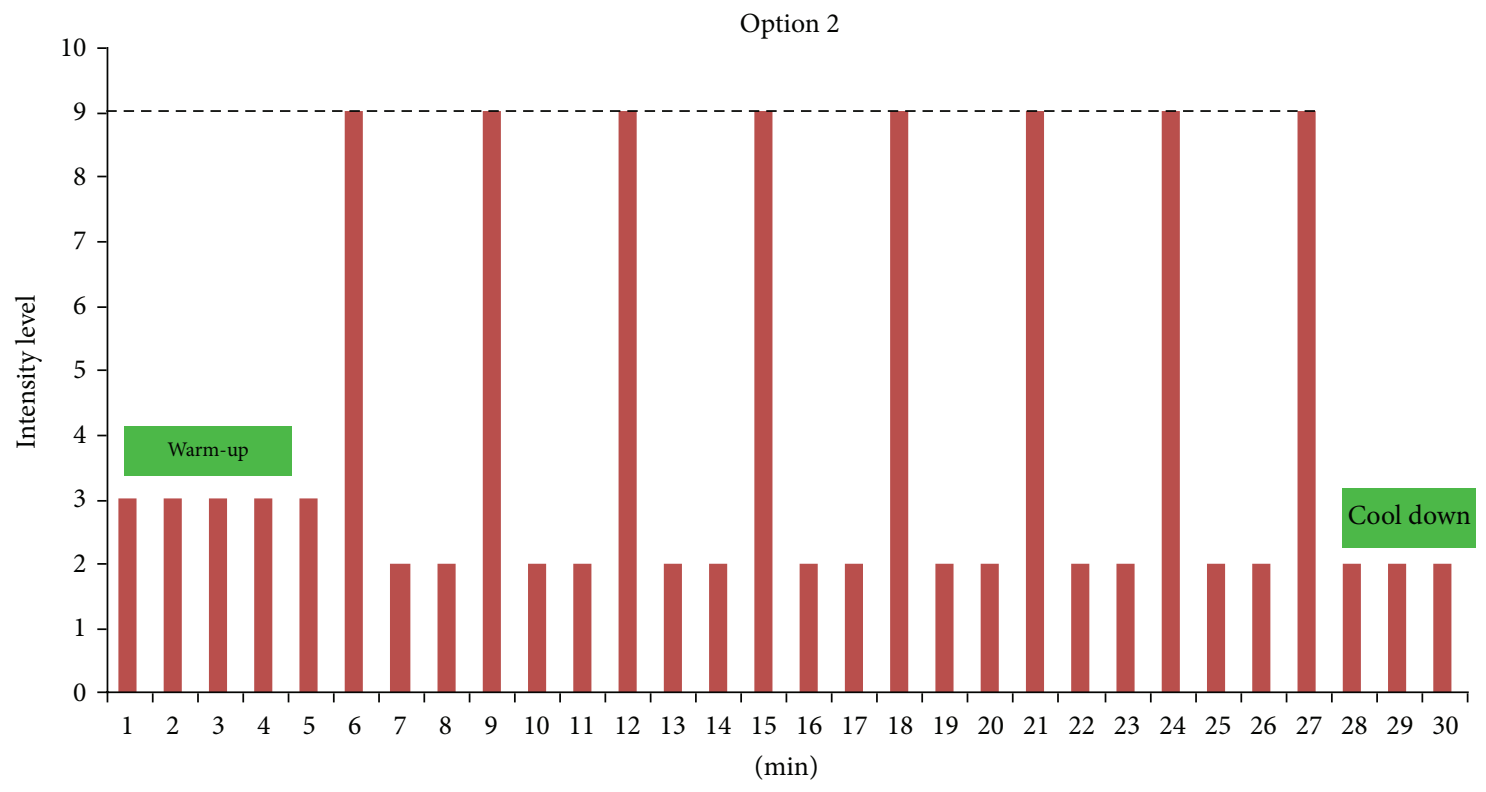

Figure 1: Interval exercise (I). Choose an exercise (walking, jogging, running, cycling, swimming, elliptical, snowshoeing, cross-country skiing, jumping rope, rollerblading, rowing, etc.) and one of two options. Option 1: perform 5-7 "all-out" sprint Intervals for 30-seconds at intensity level 10 followed by a 4 minute recovery at intensity Level 2; or Option 2: perform 8-12 sprint "almost all-out" intervals for 60 seconds at intensity level 9 followed by a 2 -minute recovery at intensity Level 2 . At the beginning and end of each interval session perform a 5-minute dynamic warm-up and gentle stretching cool down, respectively, so that each session is completed within 30-40 minutes.

synthesis [24-26]. In this case, whey protein is considered the ideal protein source. Thus, the precise mechanism responsible for enhanced energy expenditure following macronutrient intake is partly due to an increase in muscle protein synthesis (MPS) that is triggered by protein ingestion. In addition, there is speculation that a frequent macronutrient intake, especially protein-containing meals, favors an anabolic state resulting in an increase in protein synthesis and accretion $[5,26]$. Specifically, increased meal frequency (timed-ingestion every 3 hours) of 20 gram servings of whey protein maximizes MPS as well as signaling proteins and transcriptional activity of muscle cells [5]. Indeed, not only does this have beneficial implications for increased energy expenditure but also for enhanced functional capacity of muscles and an increase in lean body mass, all of which lead to improved body weight control and athletic performance.

Evidence. Our laboratory previously demonstrated that higher PRO $(25 \%, 40 \%)$ intakes, including whey protein, more favorably affect body composition compared with a traditional diet $(\mathrm{PRO}<20 \%)$ consumed over 6 meals per day $[12,13]$. In both studies, subjects consuming the higher PRO 6 meals/day lost more body weight, fat mass, and abdominal fat mass and maintained lean body mass. In follow-up to these 
TABLE 3: Stretching exercise (S).

\begin{tabular}{|c|c|c|}
\hline & Circle the exercises performed from each category & Breaths/time \\
\hline \multirow{8}{*}{ Sun salutations } & (1) Mountain pose (Tadasana) & \\
\hline & (2) Standing forward bend (Uttanasana) & \\
\hline & (3) Plank pose (Phalakasana) & \\
\hline & (4) Four-limbed staff pose (Chaturanga Dandasana) & \\
\hline & (5) Cobra pose (Bhujangasana) & \\
\hline & (6) Upward facing dog pose (Urdhva Mukha Svanasana) & \\
\hline & (7) Downward facing dog pose (Adho Mukha Svanasana) & \\
\hline & (8) Child's pose/rest pose (Balasana) & \\
\hline \multirow{12}{*}{ Standing poses } & (1) Neck stretching & \\
\hline & (2) Side bending & \\
\hline & (3) Lunge pose (Anjaneyasana) & \\
\hline & (4) Warrior I pose (Virabhadrasana I) & \\
\hline & (5) Warrior II pose (Virabhadrasana II) & \\
\hline & (6) Triangle pose (Utthita Trikonasana) & \\
\hline & (7) Extended side angle pose (Utthita Parsvakonasana) & \\
\hline & (8) Goddess pose (Utkata Konasana) & \\
\hline & (9) Chair pose (Utkatasana) & \\
\hline & (10) Revolved chair pose (Parivrtta Utkatasana) & \\
\hline & (11) Squat pose (Malasana) & \\
\hline & (12) Standing wide-legged forward bend pose (Prasarita Padottanasana) & \\
\hline \multirow{11}{*}{ Balance in motion poses } & (1) Tree pose (Vrksasana) & \\
\hline & (2) Warrior III (Virabhadrasana III) & \\
\hline & (3) Lord of the dance pose (Natarajasana) & \\
\hline & (4) Standing one-legged balance & \\
\hline & (5) Eagle pose (Garudasana) & \\
\hline & (6) Boat pose (Navasana) & \\
\hline & (7) Bicycle pose & \\
\hline & (8) Bow pose (Dhanurasana) & \\
\hline & (9) Candlestick pose & \\
\hline & (10) Camel pose (Ustrasana) & \\
\hline & (11) Pigeon pose (Eka Pada Rajakapotasana) & \\
\hline \multirow{15}{*}{ Floor poses } & (1) Seated cross-legged pose (Sukhasana) & \\
\hline & (2) Staff pose (Dandasana) & \\
\hline & (3) Seated forward bend (Paschimottanasana) & \\
\hline & (4) Head to knee pose (Janu Sirsasana) & \\
\hline & (5) Wide seated forward bend pose (Upavistha Konasana) & \\
\hline & (6) Table top pose and cat/cow & \\
\hline & (7) Bridge pose (Setu Bandhasana) & \\
\hline & (9) Butterfly pose (Baddha Konasana) & \\
\hline & (10) Happy baby pose (Ananda Balasana) & \\
\hline & (11) Half twist pose (Ardha Matsyendrasana) & \\
\hline & (12) Head to knee pose (Janu Sirsasana) & \\
\hline & (13) Front split pose (Hanumanasana) & \\
\hline & (14) Frog pose (Mandukasana) & \\
\hline & (15) Spinal twist pose (Supta Matsyendrasana) & \\
\hline & (16) Corpse pose (Savasana) & \\
\hline
\end{tabular}

S is based primarily on traditional yoga "asanas," or poses, with modern elements of Pilates for a total body stretching, flexibility, and strengthening workout. All (S) routines include basic sun salutations, standing poses, balance in motion, a floor core strengthening portion, and a final resting relaxation phase. As participants progress they are instructed to increase the intensity in which they perform the poses so the level of intensity ranges from 7 to 9 on the intensity scale.

investigations, our laboratory recently compared a higher PRO ( 35\% of kcals) diet (containing $~ 50 \%$ whey protein), moderate in $\mathrm{CHO}(\sim 40 \%$ of kcals) consumed at either 3 or 6 meals/day versus a lower PRO ( $15 \%$ of kcals $)$ diet, higher in $\mathrm{CHO}(\sim 60 \%$ of kcals) consumed at 3 meals/day, both of which contained complex, low-GI (GI values of $<50)$ CHO's consumed throughout 28 days of energy balance (weight maintenance), and deficit (weight loss), respectively (56 days total) [7]. Our results demonstrated that following the 28-day period of energy balance (weight maintenance) 


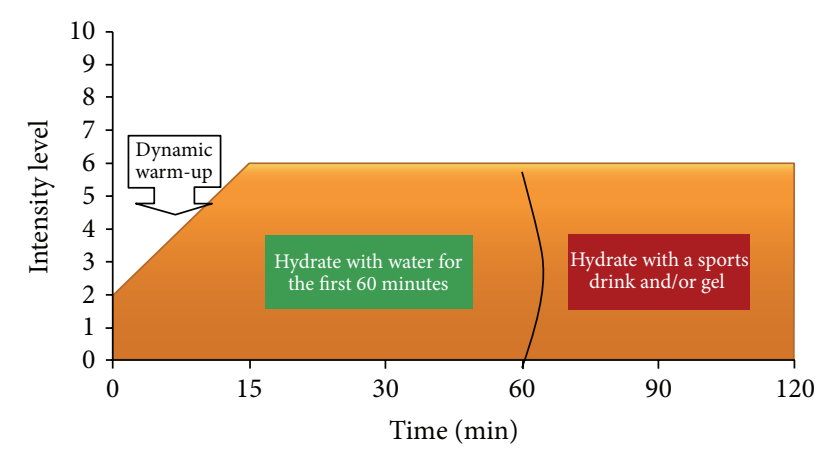

Figure 2: Endurance exercise (E). Perform endurance (E) exercise at an intensity level of 6 for 60 minutes or longer using any form of exercise (walking, jogging, running, cycling, swimming, hiking, cross-country skiing, snowshoeing, rollerblading, rowing, etc.). Ideally, perform E outside in nature and in the morning. At the beginning and end of each $\mathrm{E}$ session perform a 5-minute dynamic warm-up and a cool-down gentle stretch, respectively.

total and abdominal body fat decreased and lean body mass (LBM) increased in the higher PRO six meals/day (HP6) group versus the 3 meals/day higher PRO and $\mathrm{CHO}$ groups. During the 28-day weight loss period, total and abdominal fat continued to decrease and LBM remained elevated only in HP6.

Perhaps most interesting was the finding that postprandial thermogenesis during both weight maintenance and loss was significantly elevated (67-100\%) in HP6 compared to the 3 meals per day groups [7]. The increased thermic response in HP6 may partly explain the enhanced total and abdominal fat loss in this group. These findings indicate that macronutrient composition (increased dietary protein), nutrient quality (low glycemic index and unprocessed carbohydrates), and frequency of eating (6x per day) are more important than total energy intake to enhance body composition (reduce abdominal obesity and maintain lean body mass) and enhance postprandial thermogenesis during both weight maintenance and weight loss.

Practical Use. Consuming increased amounts of dietary protein (20-30 grams/serving or 25-35\% of total kcal intake), mostly from whey protein sources, more often (4-6 meals meals/day) throughout the day (every 3 hours) decreases abdominal fat and increases postprandial thermogenesis and lean body mass compared to traditional protein and meal frequency intakes. These body composition changes may directly lead to enhanced athletic performance. Importantly, these beneficial improvements are achieved even though total kcals consumed are identical to a traditional feeding pattern. The data from our laboratory indicate, for the first time, that macronutrient composition (increased dietary protein), nutrient quality (low glycemic index and unprocessed carbohydrates), and frequency of eating (4-6x per day) are more important than total energy intake to improve body composition and postprandial thermogenesis and thus athletic performance [7].

\section{Resistance (R) and Muscular Performance Training and PEDs}

Resistance training $(R)$ is a vital component of every athlete's training regimen given its role in athletic performance. Thus, identifying nutritional strategies that enhance muscle strength, power, and function are essential (Table 4).

3.1. Creatine. Creatine, a component of phosphocreatine, is critical for rapid production of adenosine triphosphate (ATP) [27]. Along with creatine being the most well-researched sports supplement, it has been shown to enhance lean muscle mass, strength, and anaerobic performance and may also improve aerobic endurance [28]. Thus, there is strong evidence it is a potent performance enhancing nutrient.

Mechanisms. Creatine supplementation clearly increases intramuscular creatine and phosphocreatine concentrations [29-33]. Based on the role of phosphocreatine in energy production, this has commonly been proposed as an explanation for creatine's ergogenic effects [31,34-36]. While one study found creatine to enhance phosphocreatine resynthesis [37], others have not, but have shown the higher phosphocreatine levels to persist throughout contraction and recovery $[31,38$, 39]. As such, initial levels of phosphocreatine appear to be more important than its rate of resynthesis.

Protons are consumed when ATP is resynthesized from phosphocreatine [27], which implies that creatine may enhance performance by buffering against intracellular acidosis during exercise $[35,40]$. Creatine may also act as a buffer by reducing reliance on glycolysis and the adenylate kinase reaction [35].

Creatine is known to increase intracellular fluid volume [41], which may increase glycogen [42] and protein [43] synthesis, and has been proposed as a mechanism of performance enhancement $[41,44]$. However, investigation of creatine's influence on protein synthesis has led to conflicting results in both animals $[45,46]$ and humans [47-50]. Alternatively, creatine may indirectly increase protein synthesis by facilitating greater training volume [44].

Other possible mechanisms include increased energy efficiency of muscle contraction resulting from a faster relaxation response [51] and enhanced forced production from increased antioxidant capacity [52].

Evidence. In a large meta-analysis, creatine supplementation was found to increase either body weight or lean body mass in 43 of 67 trials [53]. Furthermore, our laboratory has shown creatine supplementation to be effective for increasing lean body mass, particularly when combined with resistance training [34].

Although the influence of creatine supplementation on lean body mass has not received much recent attention, several studies have further supported its benefit. In male professional soccer players, 5 days of creatine loading at $20 \mathrm{~g} \cdot \mathrm{d}^{-1}$ during typical training and competition led to increases in body mass and jumping power that did not occur with the placebo [54]. Two other recent trials, which did not control for creatine intake, provide some practical 


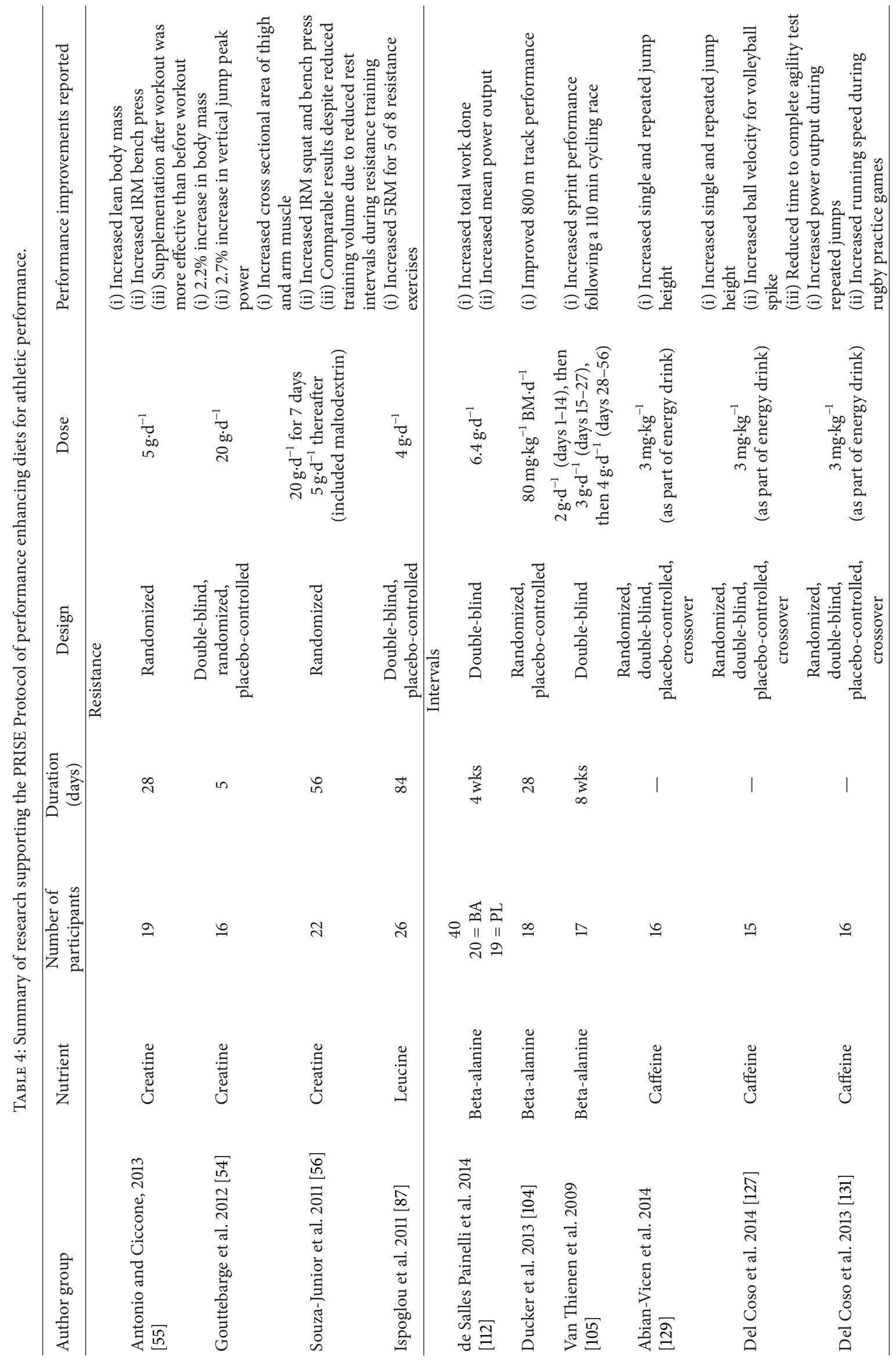




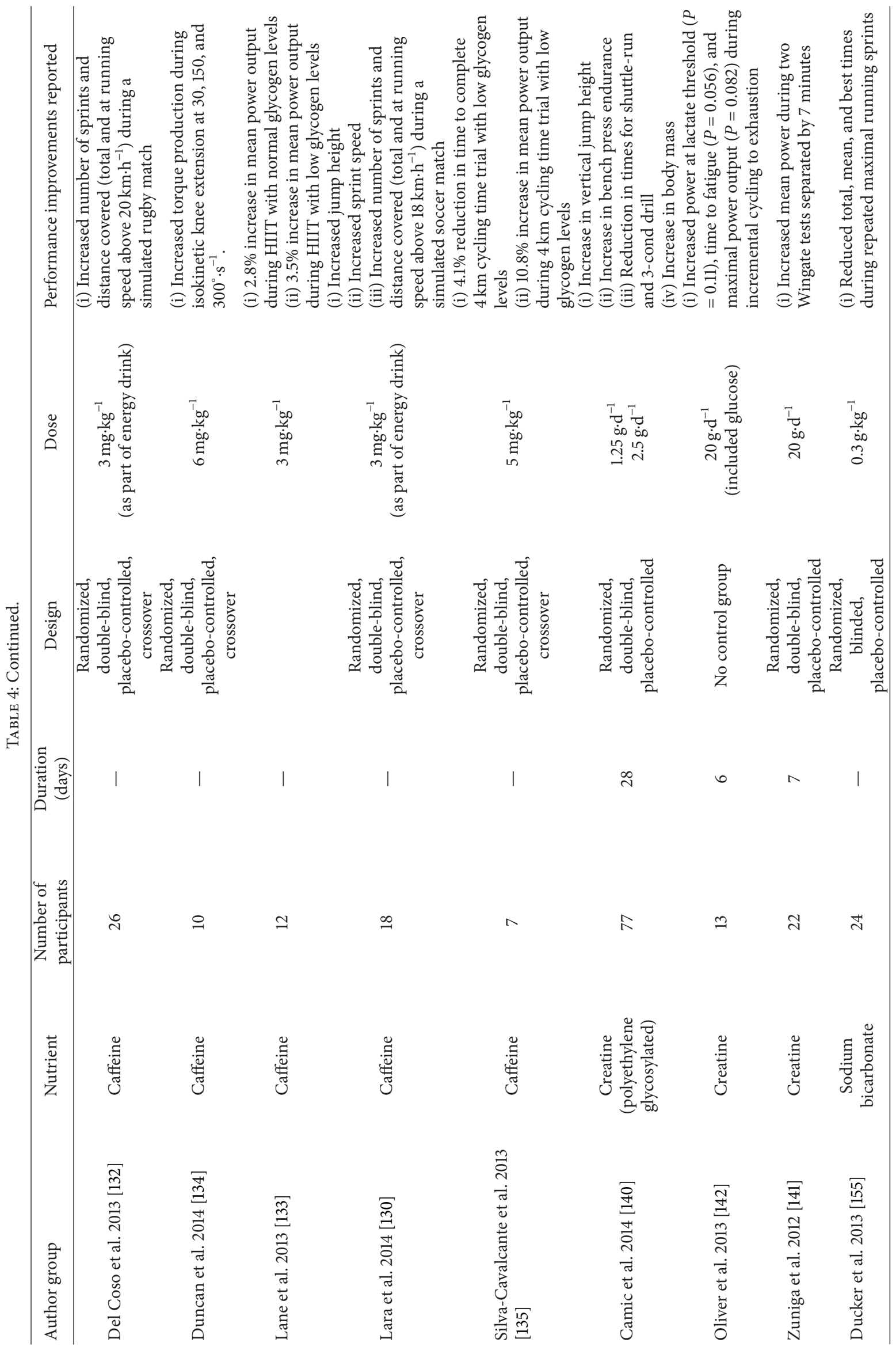




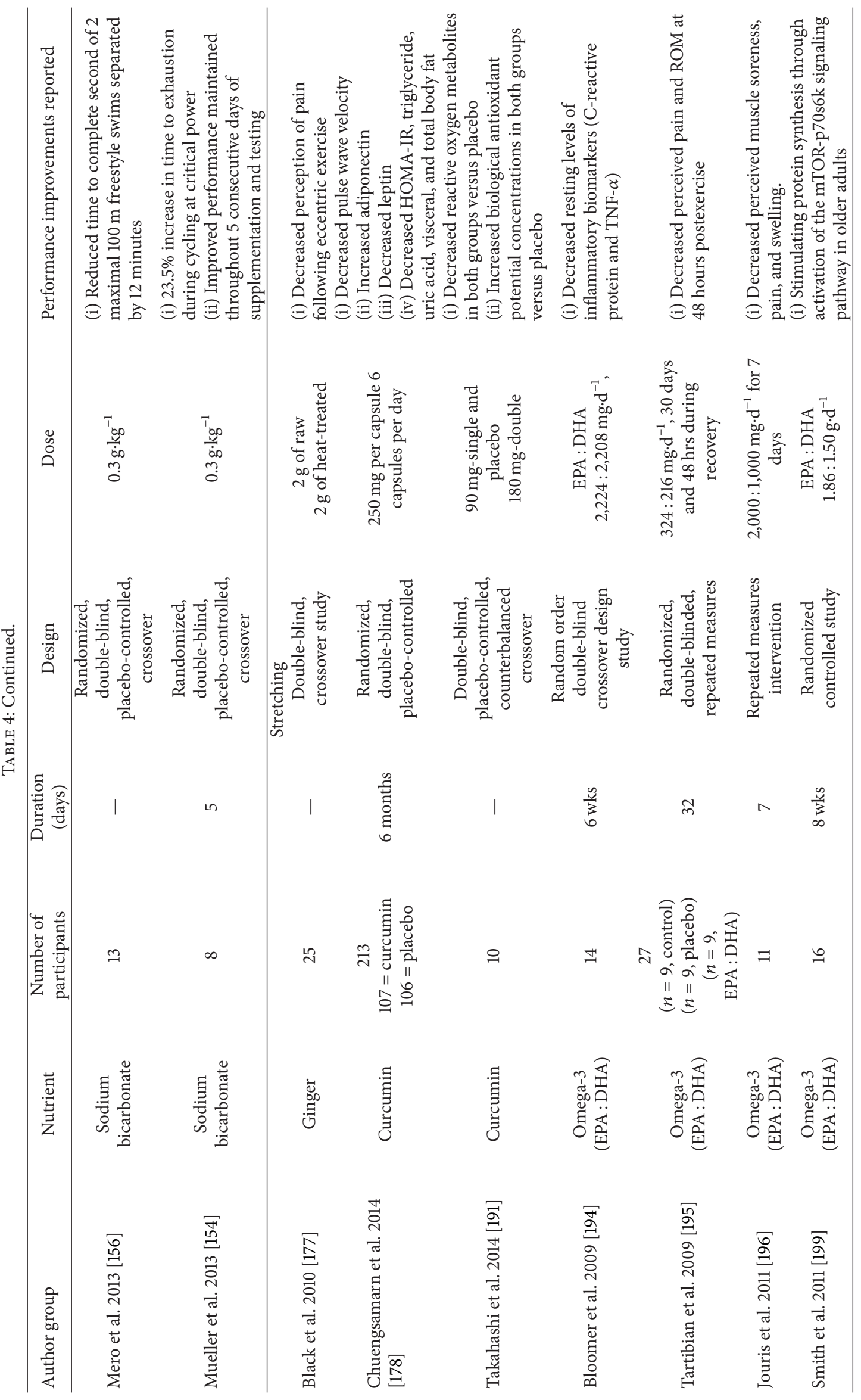




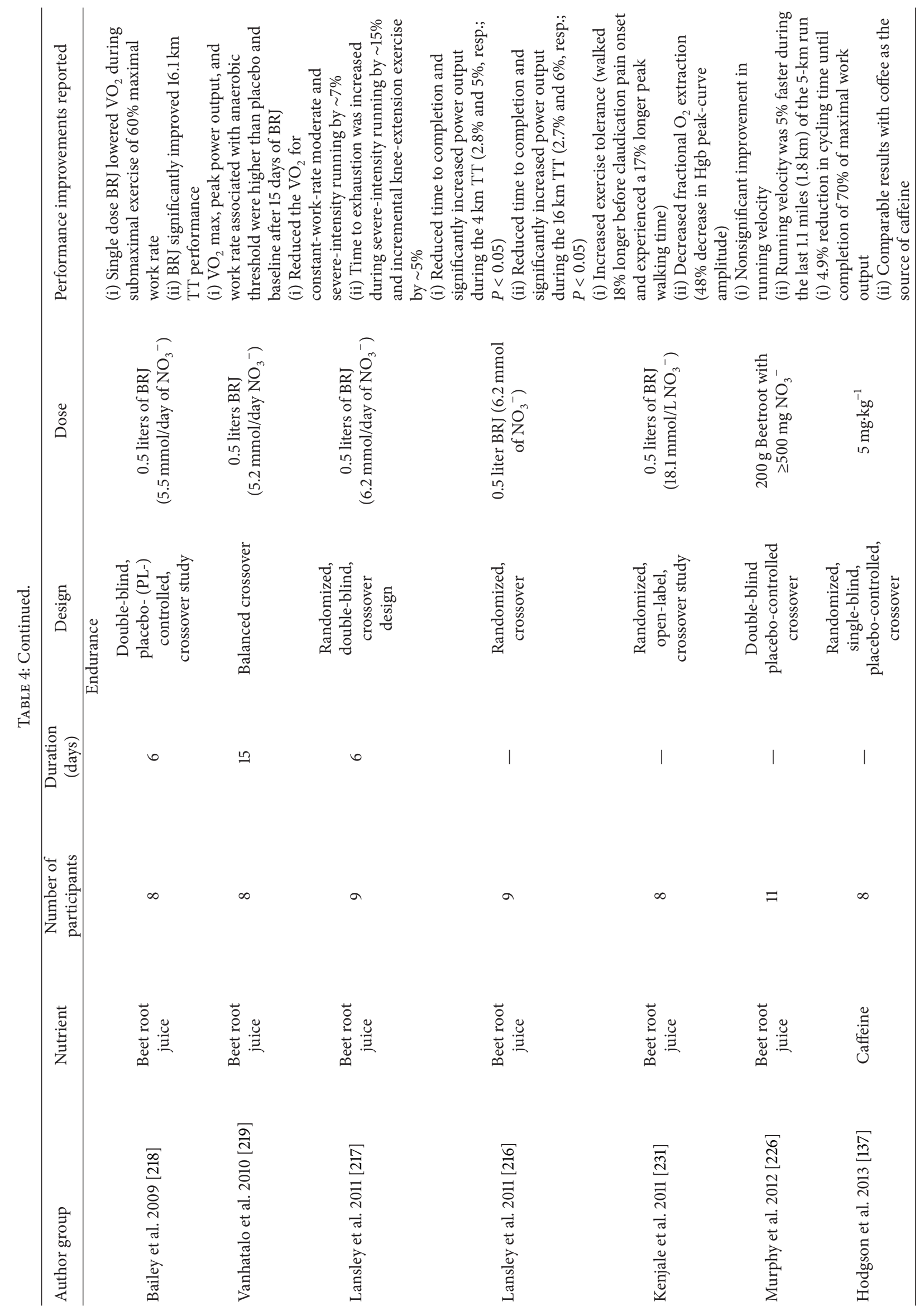




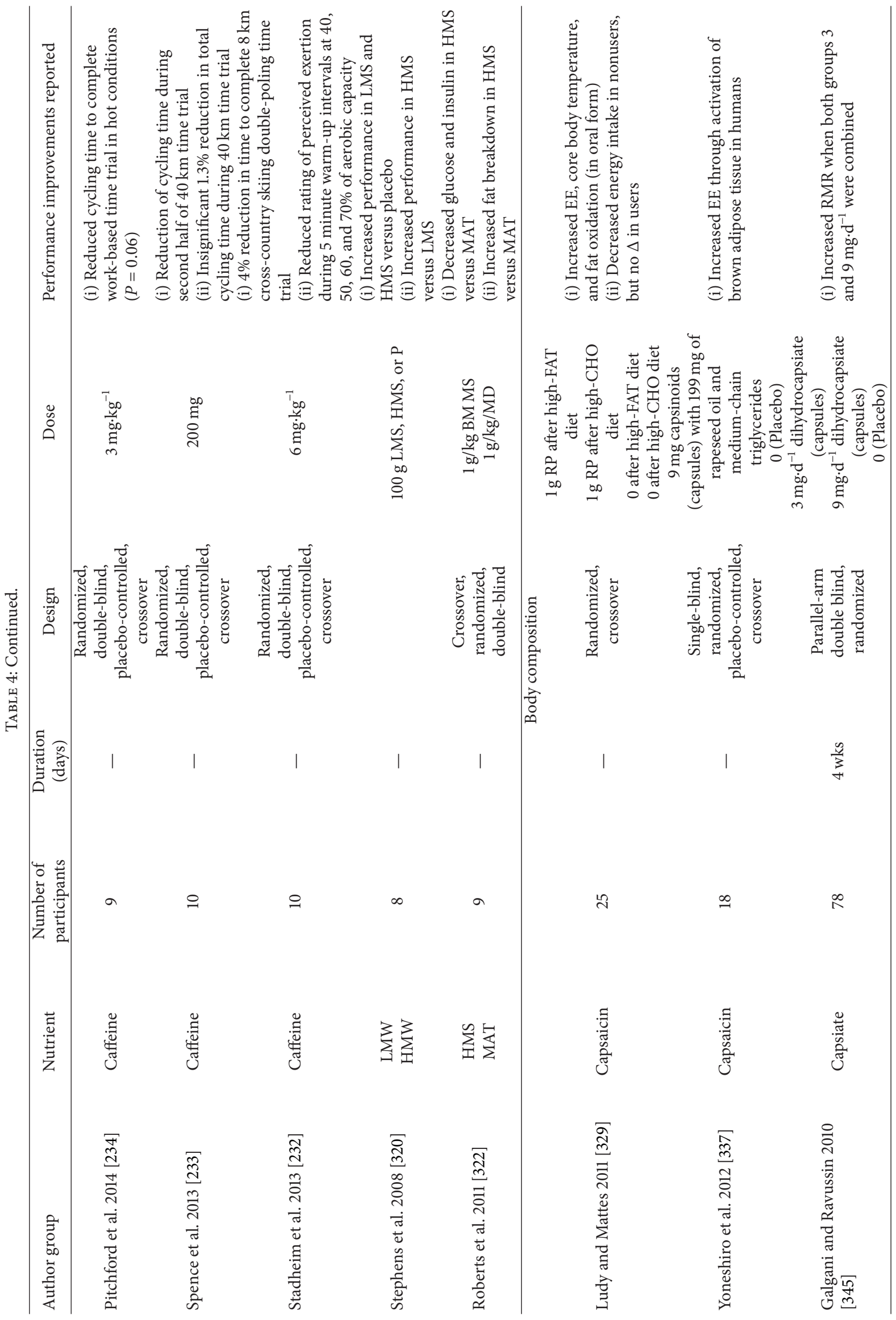




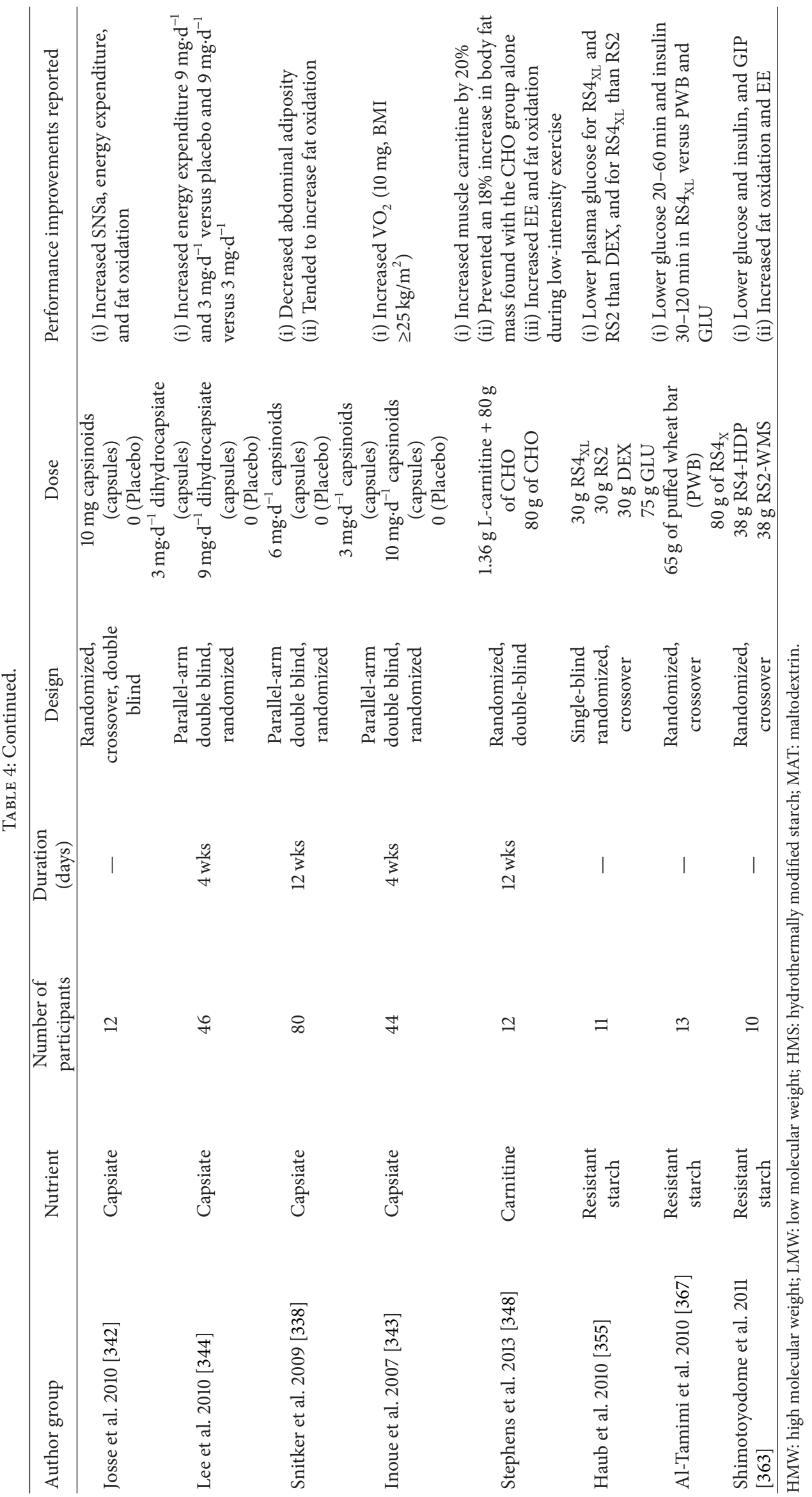


insights for using creatine to increase lean body mass. In male recreational bodybuilders, 4 weeks of creatine supplementation at $5 \mathrm{~g} \cdot \mathrm{d}^{-1}$, combined with resistance training, led to increases in lean body mass and 1 repetition maximum (RM) bench press with indication of greater benefit from postexercise versus preexercise supplementation [55]. The second trial also focused on recreationally trained men but included a creatine loading phase and lasted for 8 weeks [56]. Furthermore, for one of the groups, the rest interval between resistance exercises was progressively decreased by 15 seconds each week, which resulted in a lower training volume [56]. Despite the reduced training volume, increases in muscle cross sectional area for the upper arm and thigh, as well as $1 \mathrm{RM}$ for the squat and bench press, were not different between groups, suggesting that creatine supplementation can be used to increase training efficiency [56]. Other recent trials have shown creatine to reduce postexercise levels of inflammation [57] and muscle damage [58], suggesting it may facilitate recovery.

Practical Use. A common dosage regimen for creatine is $20 \mathrm{~g} \cdot \mathrm{d}^{-1}$ during the first $4-7$ days, followed by $5 \mathrm{~g} \cdot \mathrm{d}^{-1}$ thereafter [59]. As little as $2 \mathrm{~g} \cdot \mathrm{d}^{-1}$ has fully [30] or partially [32] maintained the intramuscular creatine levels achieved with loading, and $3 \mathrm{~g} \cdot \mathrm{d}^{-1}$ for 28 days has produced comparable levels without loading [30]. However, as a part of the PRISE protocol, an acute dosage of 2-5 g 1 hour prior to an R exercise bout may enhance muscular and physical performance. It is unclear if creatine intake from food will provide the same benefits as supplementation. However, herring, salmon, pork, beef, and cod are prominent sources containing $3-10 \mathrm{~g} \cdot \mathrm{kg}^{-1}$ $[60,61]$. Chicken and rabbit are also within this range [62]. Therefore, it is possible to achieve a maintenance dose with whole foods [61], but a loading dose would be much less practical. For example, beef contains approximately $4.5 \mathrm{~g} \cdot \mathrm{kg}^{-1}$ of creatine [60], which translates to $0.8 \mathrm{~g}$ in a single $6 \mathrm{oz}$. serving.

3.2. Branched-Chain Amino Acids. The branched-chain amino acids (BCAAs), which include leucine, isoleucine, and valine, are essential nutrients involved in muscle protein synthesis and energy metabolism [63]. Leucine is particularly important for stimulating muscle protein synthesis [25], but BCAAs can be used collectively to enhance endurance, reduce muscle breakdown, and stimulate recovery after exercise.

Mechanisms. During exercise, BCAAs are catabolized into succinyl-CoA and acetyl-CoA, both of which can enter the citric acid cycle to support ATP resynthesis [63, 64]. This pathway has a critical role in exercise tolerance [65] and is likely fed by muscle protein breakdown, which can be reduced with BCAA supplementation [66]. Therefore, BCAAs can preserve muscle protein by acting as an energy substrate. Furthermore, BCAAs may enhance exercise performance by reducing central fatigue $[67,68]$ and enhancing fat oxidation [69-72].
Protein synthesis is the most well-known and arguably the most important mechanism through which BCAAs enhance performance. Although all three of the BCAAs contribute to protein synthesis, leucine is particularly important. This is because leucine activates translation initiation factors and the mammalian target of rapamycin (mTOR), which are influential in the regulation of protein synthesis [73-76].

Evidence. Some trials have shown BCAAs to enhance exercise capacity [72, 77-79] while others have not [80-85]. In a recent trial including 19 untrained males and 8 weeks of resistance training, $9 \mathrm{~g} \cdot \mathrm{d}^{-1}$ of BCAAs failed to change body composition or improve strength or muscular endurance to a greater extent than the placebo [86]. However, in a similar trial including 26 untrained men and 12 weeks of resistance training, $4 \mathrm{~g} \cdot \mathrm{d}^{-1}$ of leucine led to greater strength gains [87]. These contrasting results suggest that either leucine alone is more effective, or that 8 weeks is too short of a training period.

Further supporting the importance of leucine, a recent crossover trial including 9 military personnel found that increasing the leucine content of a $10 \mathrm{~g}$ essential amino acid (EAA) dose from 1.87 to $3.5 \mathrm{~g}$ led to greater muscle protein synthesis and less total-body protein breakdown following 60 minutes of cycle ergometry [88]. Similarly, another recent trial assessed myofibrillar protein synthesis following a bout of resistance exercise and found that increasing the leucine content of $6.25 \mathrm{~g}$ of whey protein from 3 to $5 \mathrm{~g}$ resulted in the same rate of protein synthesis as $25 \mathrm{~g}$ of whey [24]. However, the inclusion of additional BCAAs prevented this outcome, possibly due to increased competition for absorption [24].

Practical Use. As little as $77 \mathrm{mg} \cdot \mathrm{kg}^{-1}$ of BCAAs has been shown to reduce muscle protein breakdown during exercise [66]. For EAAs, although $6 \mathrm{~g}$ has been shown to enhance protein synthesis [89], $10 \mathrm{~g}$ appears to be the optimal dose $[26,90]$.

While it is generally ideal to consume protein from whole-food sources, EAA supplementation has been suggested as an efficient method of promoting muscle growth while limiting caloric intake [91]. This is particularly relevant to athletes who need to lose or maintain weight. Furthermore, because exercising with a full stomach is generally not desirable [92], supplementation may be more appropriate for preexercise consumption.

A single acute serving of high-quality protein containing the optimal $10 \mathrm{~g}$ dose of EAAs contains approximately $1.8 \mathrm{~g}$ of leucine [93]. Relative to common protein sources, the leucine content of a $100 \mathrm{~g}(3.5 \mathrm{oz}$.) serving of beef, pork, chicken, turkey, salmon, cod, or tuna ranges from approximately 1.3 to $2.3 \mathrm{~g}$ [94]. Two eggs or a $100 \mathrm{~g}$ serving of haddock, shrimp, or scallops contains slightly less leucine, but still more than $\lg$ [94].

Finally, liquid sources of protein are known to elevate BCAA, EAA, and leucine concentrations more rapidly [95, 96], which can result in greater protein synthesis [97-99]. Whey [98] and milk [100], if well tolerated, are particularly effective. 


\section{PEDs for Interval (I) Sprint Training}

A growing body of research has documented the benefits of interval sprint training (I) for improved anaerobic and aerobic athletic performance (Table 4). Certain nutritional strategies have proven effective to counter the increased acidic environment induced by I training and thus prolong training time and adaptations, all of which may directly enhance athletic performance.

4.1. Beta-Alanine. Beta-alanine is the rate-limiting precursor in the synthesis of carnosine, a cytoplasmic dipeptide that buffers intracellular $\mathrm{H}^{+}$[101]. As such, it may reduce the acidic environment inside the muscle allowing for continued highintensity anaerobic work performance and therefore may be suitable prior to and during an I exercise session.

Mechanism. Carnosine's role as an $\mathrm{H}^{+}$buffer in the muscle is the first line of defense against local changes in $\mathrm{pH}$. The absence of carnosine in isolated muscles leads to acidification and fatigue [101]. Therefore, the use of $\beta$-alanine supplementation to buffer $\mathrm{H}^{+}$during high intensity exercise that causes muscle acidosis may extend the onset to fatigue by elevating intracellular carnosine concentrations [101] leading to increased work performance.

Evidence. Research has shown improved performance following $\beta$-alanine supplementation among different exercise modalities, such as swimming [102], cycling [103], running [104], and sprint performance following long endurance cycling [105]. However, these results are conflicting in nature with others reporting little or no change in performance [106109] despite elevated carnosine concentrations [107, 110] or resistance to fatigue $[107,108]$. Derave et al. [107] reported that four weeks of $\beta$-alanine supplementation $\left(4.8 \mathrm{~g} \cdot \mathrm{d}^{-1}\right)$ versus placebo in trained male athletes showed significant improvements in both dynamic knee extension torque (during the fourth and fifth bouts) and carnosine content in the soleus (47\%) and gastrocnemius (37\%). However, there were no differences in isometric strength or $400 \mathrm{~m}$ race time between groups. These findings contradict Ducker et al. [104] who found that male recreational runners improved $800 \mathrm{~m}$ race time following 4 weeks of $\beta$-alanine supplementation $\left(6.4 \mathrm{~g} \cdot \mathrm{d}^{-1}\right)$ versus placebo. Such contrasting results suggest that differences in training status may limit the effectiveness of $\beta$-alanine on improved performance more so than the dosage of $\beta$-alanine supplementation.

It is speculated that the effectiveness of $\beta$-alanine supplementation may be blunted in trained athletes due to the already elevated muscle buffering capacity from intense exercise training [111]. To compare the effects of $\beta$-alanine supplementation and training status, de Salles Painelli et al. [112] tested the effects of $\beta$-alanine supplementation in trained and nontrained cyclists. Forty males were separated in two groups based on training status $(N=20$ endurance trained (T); $N=20$ nontrained (NT) cyclists). Participants performed four $30 \mathrm{~s}$ lower-body Wingate bouts separated by $3 \mathrm{~min}$, both before and after 4 weeks of either placebo or $\beta$-alanine supplementation $\left(6.4 \mathrm{~g} \cdot \mathrm{day}^{-1}\right)$. The sum of the four bouts represented the total work done (TWD) and the mean power (MPO) and peak power (PPO) output were obtained from each of the four bouts individually. $\beta$-Alanine supplementation was shown to significantly increase TWD in both $\mathrm{T}$ and NT groups with no significant difference in the T cyclist placebo group. Furthermore, it was found that MPO significantly improved in the T group during bouts 1 , 2 , and 4 but also improved in bout 4 for the NT group. It was concluded by de Salles Painelli et al. [112] that, despite training status, $\beta$-alanine improved both TWD and MPO during high-intensity exercise.

Practical Use. Research has found that $\beta$-alanine supplementation of $3-6 \mathrm{~g} \cdot \mathrm{d}^{-1}\left(\sim 40-80 \mathrm{mg} \cdot \mathrm{kg}^{-1} \cdot \mathrm{BW} \cdot \mathrm{d}^{-1}\right)$ for at least 4 weeks or longer will increase intramuscular concentrations (30-80\%) possibly improving muscle buffering capacity [107, $113,114]$. However, a higher intake $\left(\sim 6 \mathrm{~g} \cdot \mathrm{d}^{-1}\right)$ for four weeks has been shown to elicit greater carnosine concentrations and improvements in performance $[103,104,112]$. A single acute dosage prior to an I exercise session may elicit similar favorable buffering capacity.

4.2. Caffeine. Caffeine is the most widely consumed drug in the world and one of the most extensively studied ergogenic aids. It is well known for enhancing endurance [61, 115118] but has also been shown to improve strength, power, and other aspects of high-intensity exercise $[115,117,118]$. Its effects are acute and peak with 30-60 minutes.

Mechanisms. The performance benefits of caffeine are related to enhanced fat oxidation and glycogen sparing. Caffeine is known to increase energy expenditure and fat oxidation, mostly through sympathetic nervous system activity (SNSa) [119], and other related mechanisms [61, 118, 120]. Inhibition of adenosine receptor activity, resulting from the molecular similarity between caffeine and adenosine, is the primary mechanism $[116,118,121]$. By binding to its receptors, adenosine can promote an increase in perceived pain and a reduction in arousal [116]. Exercise can accentuate this effect through the catabolism of ATP, adenosine diphosphate (ADP), and adenosine monophosphate (AMP) [116]. Therefore, caffeine-induced impairment of adenosine receptor activity may enhance performance by reducing the perception of discomfort and maintaining or enhancing motor unit firing rates [116]. Further supporting the role of pain perception, caffeine has been observed to increase concentrations of $\beta$-endorphins during exercise [122].

Peripheral mechanisms are also believed to contribute to caffeine's ergogenic effects $[116,117,121]$. The most notable is enhanced excitation-contraction coupling, resulting from increased potassium transport in muscle by $\mathrm{Na}^{+} / \mathrm{K}^{+}$ATPase and increased release of calcium from the sarcoplasmic reticulum $[116,121]$.

Evidence. In a meta-analysis including 40 trials, caffeine had mild benefit for high-intensity exercise of short duration and stronger benefit for endurance exercise, but no benefit for graded exercise to exhaustion [123]. In a systematic review of 21 studies involving time trials of at least 5 minutes, caffeine enhanced performance by $2.3-4.3 \%$ [124]. For activities 
lasting 5 minutes or less, another systematic review found caffeine to improve intermittent exercise performance in 11 of 17 trials and strength-related measures in 6 of 11 trials [125]. Finally, in a meta-analysis including 27 trials for strength and 23 trials for muscular endurance, caffeine produced small but significant benefits for each attribute [126].

Trials published since 2013 have shown caffeine to improve agility $[127,128]$, jump height $[127,129,130]$ and power [131], sprint performance [131], and sport-specific performance $[127,130-132]$ in athletes involved in a variety of sports, including basketball [129], rugby [131, 132], soccer [130], volleyball [127], and several racket sports [128]. Other recent trials have found improvements in cycling power output [133] and isokinetic knee extension torque during resistance exercise [134].

Two recent trials evaluated the influence of caffeine on exercise performed in a glycogen depleted state. In the first, which was a crossover with 12 competitive cyclists, $3 \mathrm{mg} \cdot \mathrm{kg}^{-1} \cdot \mathrm{BW}$ of caffeine resulted in similar power output during high-intensity interval training (HIIT) compared to the placebo with normal glycogen levels, indicating that caffeine attenuates the performance decline caused by glycogen depletion [133]. In the second crossover trial, which included 7 amateur cyclists, $5 \mathrm{mg} \cdot \mathrm{kg}^{-1} \cdot \mathrm{BW}$ of caffeine led to better $4 \mathrm{~km}$ time trial performance compared to the placebo with normal glycogen levels [135]. However, the difference was not significant.

Practical Use. The dosage of caffeine most commonly shown to enhance performance with minimal side effects is 3$6 \mathrm{mg} \cdot \mathrm{kg}^{-1}[61,118,124]$. It is possible to consume such a dosage from coffee [61], but the evidence comparing the efficacy of coffee and caffeine is conflicting [136, 137]. This discrepancy may be a result of variability in other coffee constituents [137], suggesting that caffeine is likely to be more reliable.

Athletes who regularly consume caffeine may have a higher tolerance and experience less benefit [138]. Furthermore, cessation of caffeine usage can result in withdrawal symptoms including headaches and impaired performance [138]. Therefore, to maximize benefit, usage should be discontinued at least 7 days prior to an event with a gradual reduction spread over 3-4 days [138]. Finally, because caffeine has been shown to negate the performance benefits of creatine [139], there appears to be little value in using them together.

4.3. Creatine. The mechanisms and practical applications of creatine were previously discussed in relation to resistance (R) training for muscular development. In regard to highintensity exercise performance, creatine is most commonly recognized for its effect on strength but has also shown potential for enhancing anaerobic endurance.

In a meta-analysis of 7 trials, including a total of 70 subjects, creatine supplementation with concomitant resistance training led to a $6.85 \mathrm{~kg}$ greater increase in 1-3 RM bench press [59]. Similarly, among 37 subjects from 4 trials, there was a $9.6 \mathrm{~kg}$ greater increase in $1 \mathrm{RM}$ squat [59]. Despite this evidence of enhanced strength, a meta-analysis of 10 trials, including a total of 92 participants, found no improvement in cycling power output [59]. However, in a larger metaanalysis, performance improvements were reported in 45 of 61 trials for activities lasting 30 seconds or less, in 17 of 25 trials for activities lasting between 30 and 150 seconds, and in 9 of 18 trials for activities lasting longer than 150 seconds [53]. Effect sizes were significant, although modest, for all measures, and were indicative of diminishing performance benefit with increased exercise duration [53].

Recent evidence indicates that creatine supplementation can enhance performance independently of training. In a trial including 77 men, creatine improved vertical jump, 20-yard shuttle run, 3-cone drill, and bench press endurance despite the lack of a training intervention [140]. Similarly, in two other trials lacking a training intervention, 7 days of creatine supplementation improved mean power during two bouts of the Wingate protocol [141], and 6 days of supplementation showed a tendency for increased lactate threshold, power output, and time to fatigue during incremental cycling [142].

4.4. Sodium Bicarbonate. Bicarbonate is a prominent buffer in human physiology. Supplementation with sodium bicarbonate increases blood $\mathrm{pH}$ and bicarbonate concentration, is particularly effective for enhancing anaerobic capacity, and may also improve strength and endurance $[143,144]$.

Mechanisms. Although the mechanisms are not fully understood, intramuscular acidosis has reduced muscle contractile capacity in multiple studies [145]. When exercise creates a demand for ATP that exceeds mitochondrial capacity, accumulation of protons released from glycolysis and ATP hydrolysis promote acidosis [146]. Although intramuscular acidosis has been argued to have a minimal effect on performance [147], sodium bicarbonate is known to increase $\mathrm{pH}$ and bicarbonate concentration $[148,149]$, which has persisted as the most likely mechanism of performance enhancement [148]. During exercise, sodium bicarbonate has been shown to result in higher lactate levels during exercise despite a similar intramuscular $\mathrm{pH}$ [150] and promotes greater glycogen and phosphocreatine utilization [151], suggesting increased capacity for anaerobic energy production. Furthermore, exercise-induced acidosis can inhibit oxidative phosphorylation [152], which implies that the buffering effect of sodium bicarbonate may enhance aerobic energy production as well.

Sodium bicarbonate supplementation has led to greater muscle contraction velocity following 50 minutes of highintensity cycling [153], suggesting it may reduce neuromuscular fatigue in addition to enhancing energy production.

Evidence. In a meta-analysis including 29 trials, sodium bicarbonate was found to increase anaerobic exercise capacity, with the largest improvements observed for time to exhaustion [149]. The greatest benefit was observed in conjunction with larger drops in $\mathrm{pH}$ during exercise [149], suggesting that the benefits are most applicable to glycolytic activities. A more recent meta-analysis, including 38 studies, 
standardized all results as a measure of mean power production during time trial performance and found a clear but modest performance benefit [148]. Improvement increased slightly as exercise duration increased beyond 1 minute, but durations beyond 10 minutes slightly reduced benefit [148].

In a recent trial including 11 well-trained endurance athletes, $0.3 \mathrm{~g} \cdot \mathrm{kg}^{-1} \cdot \mathrm{BW}$ of sodium bicarbonate was consumed prior to exercise for 5 consecutive days [154]. A similar improvement in time to exhaustion was maintained each day [154], suggesting that supplementation is appropriate for multiday events. Two other recent trials evaluated sodium bicarbonate in combination with beta-alanine. A single $0.3 \mathrm{~g} \cdot \mathrm{kg}^{-1} \cdot \mathrm{BW}$ dose of sodium bicarbonate improved repeated sprint performance in team-sport athletes [155] and improved sprint swimming performance in competitive male swimmers [156]. In both trials, however, the addition of betaalanine failed to further enhance performance.

In another recent trial including well-trained rowers, preexercise consumption of $0.3 \mathrm{~g} \cdot \mathrm{kg}^{-1} \cdot \mathrm{BW}$ of sodium bicarbonate throughout 4 weeks of HIIT failed to improve time trial performance compared to the placebo [157], suggesting that supplementation may not be effective for enhancing training adaptations. However, this is in contrast to a previous trial that observed greater improvements in lactate threshold and time to exhaustion [158].

Practical Use. The dose of sodium bicarbonate most frequently associated with performance enhancement is $0.3 \mathrm{~g} \cdot \mathrm{kg}^{-1}[148,149]$. However, benefits have been observed with as little as $0.15 \mathrm{~g} \cdot \mathrm{kg}^{-1} \cdot \mathrm{BW}$ [159]. Common gastrointestinal symptoms can be avoided during competition by consuming the dose 3 hours prior to initiating I exercise [160]. Consuming the dose with food may also help [161] but increases the importance of distancing intake from the start of competition [92]. Alternatively, smaller doses can be consumed over several days preceding an I event [162].

Although the buffering effect of alkalizing food $[163,164]$ is unlikely to produce the 0.05 increase in $\mathrm{pH}$ or $6 \mathrm{mmol} \cdot \mathrm{L}^{-1}$ increase in bicarbonate that appear necessary for performance improvement [161], potential for benefit may still exist. The alkalizing potential of food is primarily attributed to potassium salts, which increase bicarbonate availability when metabolized [165-167]. Vegetables and fruit are most abundant in potassium salts [165] and have the highest alkalizing potential [168]. Therefore, in conjunction with the numerous health benefits of vegetables and fruit [169], as well as potassium [170], high intakes may facilitate performance enhancement. Furthermore, the alkalizing potential of vegetables and fruit can help to offset the acidifying effect of protein $[165,167,168]$, which athletes require in greater amounts [92]. In support of this, a high vegetable intake has recently been shown to increase capillary $\mathrm{pH}$ in adults during rest and submaximal exercise [171]. Bicarbonate can be more directly incorporated into the diet with mineral water $[163,172]$ or baking soda.

\section{PEDs for Stretching (S) and Restorative Training}

It is well known that intense exercise training induces muscle damage, including an imbalanced ratio of protein breakdown to protein synthesis and increased muscle soreness (i.e., perception of pain) and inflammation [173]. A growing number athletes turn to common nonsteroidal antiinflammatory drugs (NSAIDs) (i.e., ibuprofen) to alleviate or reduce the perception of pain and to attenuate the inflammatory response [174]. Furthermore, many athletes will perform certain modes of $S$ exercise (i.e., yoga, stretching, and massage) as a form of restorative training to actively alleviate pain from previous strenuous exercise [175]. More recently, the combination of both active recovery exercises and nutraceuticals in the form of BCAA [176], ginger [177], turmeric [178], omega-3 (PUFAs) [179], and tart cherry [180, 181] have been suggested as natural alternatives for reducing exercise-induced inflammation (Table 4).

5.1. Ginger. Ginger (Zingiber officinale) is one of the ten most commonly used natural complementary and alternative medical treatments in the United States [182] and has been suggested as a possible alternative to pharmaceuticals for reducing pain and/or inflammation [177].

Mechanism. In animal models, ginger and its chemical constituents gingerols, shogaols, paradols, and zingerone are agonists to the transient receptor potential vanilloid subfamily, member 1 (TRPV1) that function in central and peripheral nociceptive signaling by inhibiting the release of prostaglandins and leukotrienes [183-185]. Ginger has been proposed as an effective analgesic based on its evidence as a natural medicinal in reducing pain and inflammation. Moreover, there are inconsistent findings from NSAIDs such as ibuprofen, naproxen, aspirin, and diclofenac as effective analgesics following eccentric exercise [186]. Thus, ginger consumption may be more efficacious for reducing exercise induced pain and inflammation through activation of TRPV1. Evidence. It has been found that the use of ginger as pain treatment, with smaller dosages ( 30 to $510 \mathrm{mg} \cdot \mathrm{d}^{-1}$ ) and longer durations (4 to 36 weeks), resulted in reductions in knee or hip pain in individuals with osteoarthritis. Black et al. [177] reported that following eccentric exercise (18 eccentric elbow flexor contractions at $120 \%$ of 1 RM) $2 \mathrm{~g}$ of both raw and heat-treated ginger for 11 days significantly decreased the perception of pain following exercise. Evidence supports the use of ginger to aid recovery from muscle-damaging exercise and for longer durations of intake ( $>2$ days), as a singleacute dose had no effect on pain perception following lowmoderate $\left(60 \% \mathrm{VO}_{2 \text { peak }}\right)$ intensity cycling [187]. Thus, effectiveness of ginger on pain perception may prove beneficial as treatment for alleviating intense, muscle-damaging (i.e., eccentric) exercise induced pain, more so as an alternative to pharmaceuticals.

Practical Uses. A higher dosage of $6 \mathrm{~g}$ of ginger may lead to possible stomach irritation and therefore a lower dose of 2$3 \mathrm{~g}$ of ginger is suggested as it has been shown to be effective 
in reducing both pain following exercise and blood sugar concentrations [177]. This dosing regimen also allows for daily consumption of ginger beyond just on $S$ days and is welltolerated.

5.2. Curcumin. Curcumin, a polyphenol responsible for the yellow color of turmeric (curry powder), is known to reduce inflammation and influence metabolic function [188]. As such, curcumin has the potential to support recovery and performance on $S$ training days by promoting metabolic health.

Mechanism. Curcumin is known to regulate inflammation and directly interact with adipocytes, pancreatic cells, and muscle cells [188]. Curcumin has been well documented to regulate biochemical and molecular pathways by modulating molecular targets such as transcription factors, cytokines, enzymes, and the genes responsible for both cell proliferation and apoptosis [189].

Evidence. Curcumin has recently been shown to reduce pain associated with delayed onset muscle soreness (DOMS) following downhill running [190]. Chuengsamarn et al. [178] tested the effects of $250 \mathrm{mg}$ of curcumin compared to placebo (corn starch) ingested twice a day for 6 months on atherogenic risks in individuals with type II diabetes mellitus (T2DM). After 6 months of supplementation it was found that curcumin significantly decreased pulse wave velocity, increased adiponectin and decreased leptin, and also decreased homeostasis model assessment-estimated insulin resistance (HOMA-IR), triglycerides, uric acid, and abdominal obesity (visceral fat and total body fat). These findings indicate that daily incorporation of curcumin will significantly alter the proinflammatory cytokine leptin and the anti-inflammatory cytokine adiponectin, as well as reduce abdominal obesity, all of which helps to ameliorate the atherogenic risks of T2DM individuals [178].

Though a plethora of information on the positive effects of curcumin on diseased individuals has been well documented [189], only one study known to date has specifically reviewed the effects of curcumin on oxidative stress following exercise in humans. Takahashi et al. [191] tested the effects of curcumin on oxidative stress and antioxidant capacity following exercise ( $60 \mathrm{~min}$ at $75 \%$ of $\mathrm{VO}_{2 \max }$ ) in ten healthy men. The participants completed three trials in a random order of ingesting either placebo, $90 \mathrm{mg}$ of curcumin-single (before exercise only, $2 \mathrm{hr}$ ), or $90 \mathrm{mg}$ of curcumin-double (before and immediately after exercise). It was found that immediately following exercise, both the curcumin-single and double groups had significantly lower derivatives of reactive oxygen metabolites and plasma thioredoxin-1 and significantly elevated biological antioxidant potential and reduced glutathione concentrations compared to the placebo group. These results suggest that exercise-induced oxidative stress may be attenuated by increasing blood antioxidant capacity from curcumin supplementation [191].

Practical Use. Though the consumption of curcumin has shown to be safe and has been consumed by ancient people for thousands of years the scientific analysis and understanding of curcumins effects are still being researched. It has been noted that when working with certain diseased populations or those unaccustomed to curcumin lower dosages $(<250 \mathrm{mg}$ ) have been shown to reduce abdominal fullness or pain. Dosages of 90-250 mg daily, particularly on S training days, may be an effective adjuvant therapy to aid recovery and healing from strenuous exercise. A possible limitation is the relatively low bioavailability of curcumin consumed orally. However, there have been recent modifications in producing a bioavailable and higher orally absorptive curcumin known as Theracurmin [192].

5.3. Omega-3 Poly-Unsaturated Fatty Acids (PUFAs). The main components of omega-3 polyunsaturated fatty acids (PUFAs) found in fish oil are eicosapentaenoic acid (EPA) and docosahexaenoic acid (DHA) and are produced from the omega-3 fatty acid alpha-linolenic acid (ALA).

Mechanism. Because EPA and DHA are not naturally synthesized in the body and the breakdown of ALA to produce EPA and DHA is enzymatically inefficient, the consumption of fish oil through diet or supplementation is important for providing adequate EPA and DHA concentrations. Both EPA and DHA are eicosanoids that have anti-inflammatory, antithrombotic, antiarrhythmic, and vasodilatory properties. The derivative of the longer chain fatty acid linoleic acid (LA) is arachidonic acid, the precursor to the proinflammatory and prothrombotic eicosanoids. Because ALA and LA compete for the same enzymes in the production of the longer chain fatty acids EPA and arachidonic acid, the consumption of fish or fish oil avoids the enzymatic competition to convert ALA to EPA by providing EPA and DHA directly [193].

Evidence. More commonly known for their cardiovascular benefits, EPA and DHA have been documented to reduce inflammation, as well as delayed onset muscle soreness (DOMS) or the perception of pain from exercise $[179,194-$ 196]. When supplementing with EPA and DHA either prior to or during exercise, or the combination of both, research has found decreased resting levels of inflammatory biomarkers $\left(2,224: 2,208 \mathrm{mg} \cdot \mathrm{d}^{-1}, 6 \mathrm{wks}\right)$ [194], decreased acute-phase proteins after exercise $\left(1.75: 1.05 \mathrm{~g} \cdot \mathrm{d}^{-1}, 3 \mathrm{wks}\right)$ [179], and improved perceived muscle soreness, pain, and range of motion $48 \mathrm{hrs}$ post exercise $\left(324: 216 \mathrm{mg} \cdot \mathrm{d}^{-1}, 30\right.$ days and $48 \mathrm{hrs}$ during recovery) [195]. More recently, Jouris et al. [196] reported the attenuation of DOMS when consuming EPA and DHA at a $2: 1$ ratio $\left(2,000: 1,000 \mathrm{mg} \cdot \mathrm{d}^{-1}\right)$ for 7 days following an eccentric arm-curl exercise protocol. Yet, despite these beneficial findings, there have been reports of little or no change in inflammation or DOMS following exercise $[197,198]$. Recently, in addition to ameliorating pain and inflammation, supplementation with omega-3 PUFA for 8 weeks $\left(1.86: 1.50 \mathrm{~g} \cdot \mathrm{d}^{-1} \mathrm{EPA}: \mathrm{DHA}\right)$ was shown to augment the activation of the mTOR-p70s6k signaling pathway stimulating protein synthesis in older adults [199]. Thus, omega-3 supplementation may also prove beneficial for the prevention 
or management of sarcopenia or the atrophy of skeletal muscle [199].

Practical Use. It should be noted that fish oil consumption at higher levels ( $>4 \mathrm{~g}$ per day) may increase the risk of bleeding from decreased adherence of blood platelets and lower blood pressure. Hence, individuals with already low blood pressure or increased risk of hemorrhage should consume moderate to lower intakes of omega-3 PUFA. Athletes that wish to mitigate the effects of exercise-induced inflammation and DOMS are suggested to incorporate omega-3 FA in their diet, especially during $S$ days, and are suggested to do so with 1$2 \mathrm{~g} \cdot \mathrm{d}^{-1}$ of an EPA : DHA ratio of $2: 1$ [200], or $2-4 \mathrm{~g} \cdot \mathrm{d}^{-1}$ for those with higher blood lipid profiles or rheumatoid arthritis [193]. A designated safe and general consumption dose of omega-3 PUFA (EPA + DHA) for athletes to consume is $\leq 3,000 \mathrm{mg} \cdot \mathrm{d}^{-1}(3 \mathrm{~g})$, as recommended by the US Food and Drug Administration [201]. For many individuals omega-3 capsule supplementation is convenient for ensuring adequate consumption of PUFA, and an alternative for vegetarians, but for those who are able to incorporate whole food sources, flax seeds, walnuts, sardines, and salmon are considered excellent sources of rich omega-3 (e.g., EPA, DHA, and ALA). Because of the concern of high levels of mercury the following fishes have been given as examples of $1 \mathrm{~g}$ servings of EPA : DHA because of their low mercury content: $4.0 \mathrm{oz}$. Tuna (Canned, Light), 2.0-3.5 oz. of salmon (Atlantic, wild), $15 \mathrm{oz}$. of catfish, and $11 \mathrm{oz}$. of shrimp (mixed species). For more recommendations of grams of EPA and DHA for various types of fishes and servings see the review by Covington [193].

5.4. Tart Cherry. Cherries are known to be a rich source of bioactive compounds with antioxidant and anti-inflammatory effects [202, 203]. Both the antioxidant and antiinflammatory effects of cherries are believed to contribute to their potential to reduce pain and enhance exercise recovery [202].

Mechanisms. Although the precise mechanisms of how cherry consumption influences exercise recovery are not fully understood, the mechanical muscle damage induced by eccentric contraction is unlikely to be affected [202]. Instead, improvements in recovery are most likely related to the attenuation of secondary oxidative stress and inflammation [202]. The anthocyanins from both sweet and tart cherries are known to inhibit cyclooxygenase-I and cyclooxygenase-II [204], which provides at least a partial explanation for their anti-inflammatory effects. Tart cherries have a more potent effect.

Evidence. Although the influence of tart cherry on exercise recovery has only been investigated to a limited extent, the available evidence is very promising. Connolly et al. [180] assessed the effect of tart cherry juice (TCJ) on recovery from maximal elbow flexion contractions. The trial included 14 men who consumed $12 \mathrm{oz}$. of tart cherry juice twice per day for 8 days. Eccentric contractions were performed on the 4 th day and recovery was assessed during the subsequent 4 days. The TCJ significantly reduced loss of strength and pain during recovery [180]. However, no differences were observed in tenderness or loss of range of motion [180]. A similar trial was conducted to determine if the response to tart cherry juice differed for well-trained athletes. In this trial, TCJ was administered as TCJ concentrate of $30 \mathrm{~mL}$ (1 oz.) twice per day for 7 days before and 2 days after knee extension exercise performed at $80 \%$ of maximum voluntary contraction (MVC) [205]. Consistent with the previous trial, TCJ significantly reduced loss of strength during the two days of recovery, but without any differences in muscle tenderness [205]. The TCJ also reduced protein carbonyl levels during recovery, suggesting a reduction in oxidative stress [205]. These data support TCJ as an effective PED aid following intense, muscle damaging $\mathrm{R}$ exercise as a result of mitigating the subsequent oxidative damage [205].

Several trials have also focused on recovery from endurance (E) exercise. Howatson et al. [206] evaluated the effect of two $8 \mathrm{oz}$. servings per day of TCJ supplementation for 5 days prior, the day of, and 2 days following a marathon run. The tart cherry juice resulted in significantly faster recovery of isometric strength, reduced inflammation and oxidative stress, and increased antioxidant capacity during the subsequent 2 day recovery [206]. In another running trial, consumption of tart cherry juice for 7 days prior to and during a $26.3 \mathrm{~km}$ relay race significantly reduced perceived pain following the race [207].

Practical Use. Consumption of approximately 45 sweet Bing cherries per day has been shown to reduce markers of inflammation [208, 209]; however, it is not clear whether the antioxidant and anti-inflammatory potentials of sweet cherries are comparable to tart cherries. Furthermore, most of the available evidence indicating a benefit from tart cherries is based on consumption of juice containing the equivalent of 90-120 cherries per day or 12-16 oz [180, 205207]. As such, practicality and the limited scope of available evidence favor the use of tart cherry juice. The TCJ used in the aforementioned studies was derived directly from fresh cherries in concentrate or juice form making it feasible for most people to consume.

Emerging evidence indicates that oxidative stress is an important signaling mechanism for muscle remodeling [210] and may therefore be necessary for beneficial adaptations to exercise [211]. This concern is supported by evidence of antioxidant supplementation inhibiting adaptation to exercise [211]. Furthermore, anti-inflammatory substances such as nonsteroidal anti-inflammatory drugs present a similar concern. Similar to antioxidant containing foods, such as TCJ, NSAIDs reduce inflammation by inhibiting cyclooxygenase activity. There is indication of this mechanism inhibiting regeneration of muscle [212] and connective tissue [213], which could impair adaptations to exercise [212] and increase injury risk [213]. As such, the long-term use of antioxidants and NSAIDs may be contraindicated for athletes pursuing enhanced muscle mass development. Based on these findings, acute supplementation with TCJ may be most effective endurance sessions or competitions, rather than for continual use. 


\section{PEDs for Endurance (E) and Aerobic Training}

More athletes are choosing nutritional supplements, from both natural and organic sources, to gain a competitive advantage in endurance-based sports. The increased energy demands of endurance activities require fluid, electrolyte, and energy consumption during training and competition (Table 4). Facilitating the delivery of these key nutrients to working muscles is paramount to athletic performance.

6.1. Beet Root Juice (BRJ). Beetroot juice (BRJ) is among the most popular nutritional supplements to improve endurance performance [214]. Much of this is due to an increased consumption of organic and natural foods [215]. Thus, the trend for organic and natural food products is particularly relevant for athletes at all levels of competition. BRJ is particularly popular among endurance (E) athletes, because of its high concentration of nitrate that has been hypothesized to enhance endurance. For example, there is both anecdotal and scientific support for BRJ to improve time-trial endurance [216] and time to exhaustion [217], reduce steadystate oxygen consumption [218], and increase peak power and work rate at the gas exchange threshold [219].

Mechanisms. Several mechanisms have been postulated for the endurance exercise improvement effects of BRJ. A reduction in phosphocreatine ( $\mathrm{PCr}$ ) degradation and the reduction of build-up of ADP and inorganic phosphate (Pi) at the same relative exercise intensity following BRJ consumption [216, 219] are likely mechanisms responsible for the decrease in $\mathrm{O}_{2}$ cost (oxidative phosphorylation) of exercise and increased time to exercise failure (reduced muscle fatigue). Beetroot has a high nitrate $\left(\mathrm{NO}_{3}{ }^{-}\right)$content $(>250 \mathrm{mg} / 100 \mathrm{~g}$ of fresh weight), among the highest assessed, and contains more than other foods high in $\mathrm{NO}_{3}{ }^{-}$including spinach, celery, arugula, and carrot juice [220]. Nitrate is reduced to nitrite via bacteria in the oral cavity and by specific enzymes (e.g., xanthine oxidase) within tissues. There are several pathways to metabolize nitrite to nitric oxide (NO) and other biologically active nitrogen oxides [221]. Nitric oxide is a signaling molecule formed in the endothelium by the enzyme endothelium nitric oxide synthase (eNOS) which triggers the vasculature to relax (vasodilatation) by interacting with vascular smooth muscle leading to increased blood flow [222] at rest [223] and during exercise [224].

Given these properties, NO has gained a lot of attention for possible E exercise improvements including increased $\mathrm{O}_{2}$, glucose, and other nutrient uptake to better fuel working muscles. Currently there is no means to provide NO supplementation through the diet (as it is a gas), thus BRJ and its high nitrate concentration are used as a means to generate NO endogenously. Indeed, there is an impressive and growing body of scientific data in support of whole food sources of inorganic nitrate, such as that found in BRJ, showing improved athletic performance.

Evidence. While there is very limited scientific data demonstrating BRJ's effect on resistance (R) exercise [225], the vast majority of data strongly supports its beneficial effect on improving E performance. Lansley et al. [217] recruited 9 healthy, physically active men who consumed either 0.5 liters of BRJ $\left(6.2 \mathrm{mmol} \cdot \mathrm{d}^{-1}\right.$ of $\left.\mathrm{NO}_{3}{ }^{-}\right)$or 0.5 liters of $\mathrm{NO}_{3}{ }^{-}$depleted BRJ placebo $\left(0.0034 \mathrm{mmol} \cdot \mathrm{d}^{-1}\right.$ of $\left.\mathrm{NO}_{3}{ }^{-}\right)$for 6 days followed by acute bouts of submaximal and high-intensity (to exhaustion) running and incremental knee-extension exercises. BRJ consumption increased plasma nitrite by $105 \%$ and reduced the $\mathrm{O}_{2}$ cost for constant-work-rate moderate and severe-intensity running by $\sim 7 \%$ compared to placebo. In addition, time to exhaustion was increased during severeintensity running by $\sim 15 \%$ and incremental knee-extension exercise by $\sim 5 \%$ with BRJ compared to placebo. These findings suggest that performance benefits (oxygen sparing and enhanced exercise tolerance) of consuming BRJ are attributed to its high $\mathrm{NO}_{3}^{-}$content. More recently, Murphy et al. [226], using a double-blind placebo-controlled crossover trial, had 11 recreationally fit men and women consume either baked beetroot ( $200 \mathrm{~g}$ with $\geq 500 \mathrm{mg} \mathrm{NO}_{3}{ }^{-}$) or an isocaloric placebo (cranberry relish) 75 minutes prior to performing a $5 \mathrm{~km}$ time trial treadmill run to determine whether whole beetroot consumption would improve running performance. They observed a nonsignificant, 41-second faster finishing time $\left(12.3 \pm 2.7\right.$ versus $11.9 \pm 2.6 \mathrm{~km} \cdot \mathrm{h}^{-1}$, resp.; $\left.P=0.06\right)$ following beetroot consumption compared to placebo. Most impressive, during the last 1.1 miles $(1.8 \mathrm{~km})$ of the $5 \mathrm{~km}$ run, running velocity was $5 \%$ faster $(12.7 \pm 3.0$ versus $12.1 \pm 2.8 \mathrm{~km} \cdot \mathrm{h}^{-1}$, resp.; $\left.P=0.02\right)$ and rating of perceived exertion was lower $(13.0 \pm 2.1$ versus $13.7 \pm 1.9$, resp.; $P=$ 0.04 ) during the beetroot trial compared to the placebo. Thus, it appears that the ingestion of whole-foods containing inorganic $\mathrm{NO}_{3}{ }^{-}$(such as beetroot or BRJ) increase plasma nitrite and ultimately NO levels which favorably affect the cellular and vasculature pathways which likely result in the observed improvements in endurance athletic performance.

Given the favorable impact of BRJ on E performance, it would seem likely that BRJ would also favorably impact other markers of athletic performance. As such, Lansley et al. [216] examined the effects of BRJ ingestion on power output, oxygen consumption $\left(\mathrm{VO}_{2}\right)$, and performance cycling time trials (TT) using nine competitive male cyclists who consumed either 0.5 liters BRJ $\left(6.2 \mathrm{mmol}\right.$ of $\left.\mathrm{NO}_{3}{ }^{-}\right)$or placebo containing nitrate-depleted BRJ $\left(0.0047 \mathrm{mmol}\right.$ of $\left.\mathrm{NO}_{3}{ }^{-}\right)$ before each TT of 4 or $16 \mathrm{~km}$. BRJ consumption increased plasma nitrite by $138 \%$ and resulted in significantly reduced time to completion and increased power output during both the $4 \mathrm{~km}(2.8 \%$ and $5 \%$, resp.; $P<0.05)$ and $16 \mathrm{~km} \mathrm{TT}(2.7 \%$ and $6 \%$, resp.; $P<0.05)$ compared to the placebo treatment.

Similarly, Bailey et al. [218] supplemented eight healthy, recreationally active men with 0.5 liters of BRJ $\left(5.5 \mathrm{mmol} \cdot \mathrm{d}^{-1}\right.$ of $\mathrm{NO}_{3}{ }^{-}$) or a low-calorie black currant juice cordial (negligible $\mathrm{NO}_{3}{ }^{-}$content) for 6 days while performing moderate (80\% gas exchange threshold) and intense cycling ( $70 \%$ of the difference between the power output at the gas exchange threshold and $\mathrm{VO}_{2 \text { peak }}$ ) protocols during the last 3 days. BRJ ingestion increased the average plasma nitrite by $96 \%$ and increased the time to task failure by $\sim 16 \%$ during fixed high intensity exercise. The authors concluded that increased 
dietary inorganic $\mathrm{NO}_{3}{ }^{-}$consumption from BRJ has the potential to improve high-intensity exercise tolerance.

These data confirm that BRJ improves endurance exercise performance; however, the minimal time needed to use BRJ for a performance benefit remains to be elucidated. One attempt to answer this question was reported by Vanhatalo et al. [219] in which they examined the effects of acute (1 and 5 days) and chronic (15 days) BRJ consumption on a moderateintensity exercise bout ( $90 \%$ gas exchange threshold) and an incremental cycle ergometer ramp test (increasing work rate by $1 \mathrm{~W}$ every $2 \mathrm{sec}(30 \mathrm{~W} / \mathrm{min}))$ to exhaustion.

Eight healthy subjects (5 males, 3 females) consumed either 0.5 liters BRJ $\left(5.2 \mathrm{mmol} \cdot \mathrm{d}^{-1} \mathrm{NO}_{3}{ }^{-}\right)$or a placebo (blackcurrant juice cordial with negligible $\mathrm{NO}_{3}{ }^{-}$content) for 15 days and were exercise tested on days 1, 5, and 15. Plasma nitrite was significantly increased on all test days following BRJ compared to placebo. The $\mathrm{O}_{2}$ cost of moderate-intensity exercise (increase in $\mathrm{VO}_{2}$ relative to the increase in external work rate) was lower during BRJ and was maintained throughout the 15 days $(P=0.002) . \mathrm{VO}_{2 \max }$, peak power output, and the work rate associated with the anaerobic threshold were all higher following 15 days of BRJ consumption compared to placebo and baseline conditions. In addition, BRJ systolic blood pressure was significantly lower at 2.5 hours after ingestion as well as 2, 12, and 15 days after ingestion compared to PL $(-3 \% ; P<0.05)$. Diastolic blood pressure decreased with BRJ compared to PL ( $-5 \%$; $P<0.01)$.

The authors concluded that acute (1-5 days) dietary $\mathrm{NO}_{3}{ }^{-}$ supplementation significantly decreased blood pressure and the $\mathrm{O}_{2}$ cost of submaximal exercise and increased $\mathrm{VO}_{2 \max }$ and peak power output and these outcomes were maintained for at least 15 days with continued BRJ supplementation [219]. While most studies agree with these findings [227229], others note that highly trained athletes (average $\mathrm{VO}_{2} \max$ of $72 \pm 4 \mathrm{~mL} \cdot \mathrm{kg}^{-1} \cdot \mathrm{min}^{-1}$ ) may not have the same response to BRJ [230], suggesting that the impact of BRJ may be influenced by the training status of the individual.

In nonathletic populations, the impact of BRJ also has a significant positive impact on endurance performance. Kenjale et al. [231] provided 8 patients with peripheral arterial disease either 0.5 liters of BRJ $\left(18.1 \mathrm{mmol} \cdot \mathrm{L}^{-1} \mathrm{NO}_{3}{ }^{-}\right)$ or an isocaloric placebo on two separate occasions while performing an incremental, graded treadmill running test and demonstrated an increased exercise tolerance (walked $18 \%$ longer before claudication pain onset and experienced a $17 \%$ longer peak walking time), and decreased fractional $\mathrm{O}_{2}$ extraction. These findings support BRJ to enhance peripheral tissue oxygenation in hypoxic areas and increase exercise tolerance in individuals with peripheral arterial disease. Thus, strong scientific evidence supports BRJ supplementation as an effective ergogenic aid for both athletes and nonathletes alike in order to improve endurance/aerobic exercise performance.

Practical Use. It is important to note that the acute dose of BRJ used in most research studies is approximately 0.5 liters or $\sim 16 \mathrm{fl}$ oz. There are several ways to incorporate BRJ into an athlete's diet. One strategy is to prepare the BRJ from the whole beets using the following technique: remove the stalks and thoroughly wash the beets, cut into cubes, submerge in water, bring to a boil and then simmer for 45 minutes until beets are tender, allow to cool, pour off the fluid, and place in refrigerator (lasts up to 5 days) or freeze (up to 3 months). Consume $16 \mathrm{fl}$. oz. alone or mixed with another antioxidantrich juice (tart cherry, grape, cranberry, and pomegranate) on endurance exercise days. Another technique is to thoroughly blend 2-3 whole beets (stalks removed) in a food processor, blender, or juice compressor.

6.2. Caffeine. The mechanisms through which caffeine enhances performance, as well as the practical considerations for caffeine use, were previously discussed in relation to anaerobic performance. In addition to the potential for caffeine to enhance anaerobic performance, meta-analysis has indicated it is more effective for enhancing aerobic performance [123].

Several recent studies have demonstrated the beneficial influence of caffeine on endurance performance. In 10 welltrained cross-country skiers, $6 \mathrm{mg} \cdot \mathrm{kg}^{-1} \cdot \mathrm{BW}$ of caffeine consumed 45 minutes prior to exercise led to better performance and reduced rating of perceived exertion (RPE) during an $8 \mathrm{~km}$ double-poling time trial [232]. Similarly, in trained cyclists, $200 \mathrm{mg}$ of caffeine consumed 60 minutes before exercise improved $40 \mathrm{~km}$ time trial performance [233], and $5 \mathrm{mg} \cdot \mathrm{kg}^{-1} \cdot \mathrm{BW}$ of caffeine consumed 60 minutes before exercise, either in supplement form or from coffee, improved performance during an approximately 45 minute time trial with a target of $70 \%$ of maximal work output [137]. In addition, $3 \mathrm{mg} \cdot \mathrm{kg}^{-1} \cdot \mathrm{BW}$ of caffeine consumed 90 minutes prior to exercise has been shown to improve performance during an approximately 60 minute work-based time trial during hot conditions [234].

6.3. Carbohydrate and Fat Intake. Although protein contributes to energy production during E exercise, it is a small contribution relative to fat and carbohydrate [235]. As such, optimal macronutrient intake for supporting the energy demands of $\mathrm{E}$ athletic performance is primarily related to fat and carbohydrate.

Storage capacity for glycogen is greatly limited compared to fat and is therefore more tightly regulated [236]. Furthermore, reduced glycogen availability is commonly associated with fatigue [237-239], which implies that it may be advantageous to adjust macronutrient intake in a manner that either spares glycogen or reduces dependency on it. Two contrasting strategies for reducing dependency on glycogen are increasing carbohydrate intake to maintain high glucose and glycogen availability or restricting carbohydrate intake to promote adaptations that increase reliance on fat oxidation.

Mechanisms. Despite the well-established associations between glycogen depletion and fatigue, the mechanisms are not well understood [237-239]. However, it is clear that shifts in macronutrient intake alter the balance between fat and carbohydrate oxidation. In contrast to carbohydrate oxidation, which is largely influenced by carbohydrate intake, 
fat oxidation is influenced more so by carbohydrate intake than fat intake $[236,240]$. More specifically, fat oxidation increases as carbohydrate intake decreases [236, 240].

Carbohydrate metabolism inhibits fat oxidation, and one mechanism for this has been eloquently isolated to the carnitine palmitoyltransferase (CPT) system, which transports long-chain fatty acids through the inner mitochondrial membrane. Infusion of glucose and insulin has been shown to inhibit oxidation of long-chain fatty acids, but not mediumchain fatty acids, implicating the CPT system as a location of inhibition [241]. Similar results have been observed in conjunction with elevated levels of malonyl CoA [242], which is known to inhibit the CPT system [243]. Furthermore, insulin activates acetyl CoA carboxylase (ACC), which catalyzes the production of malonyl CoA [244]. As such, carbohydrate intake is likely to inhibit fat oxidation by promoting insulin release, which then increases production of malonyl CoA by ACC and, in turn, inhibits the CPT system from transporting long-chain fatty acids into mitochondria [243, 245].

In addition to acute shifts in substrate selection, consistent changes in macronutrient intake can promote adaptations that may further enhance energy metabolism. For example, 5 days of reduced carbohydrate and increased fat intake in actively training cyclists increased genetic expression in skeletal muscle for fatty acid translocase (FAT), fatty acid binding protein, and $\beta$-hydroxyacyl CoA dehydrogenase $(\beta-\mathrm{HAD})$, all of which are related to fat oxidation [246]. Similarly, 2 days of reduced carbohydrate and increased fat intake following glycogen depleting exercise led to increased expression for FAT and uncoupling protein 3 (UCP3), while a higher carbohydrate diet led to increased expression for glucose transporter type 4 and glycogenin [247]. In contrast, even without a change in regular diet, the consumption of glucose during moderate exercise has been shown to inhibit expression of FAT, UCP3, and CPT1 compared to the same exercise performed in a fasted state [248].

In addition to enzymatic changes, reduced carbohydrate and increased fat intake have been shown to increase intramuscular fat storage in conjunction with a lower respiratory quotient during exercise in both trained [249-251] and untrained [252] subjects. Although reduction of carbohydrate intake typically results in lower glycogen levels compared to a high-carbohydrate intake [251,252], similar glycogen levels were maintained in one trial in conjunction with increased intramuscular fat and decreased respiratory quotient during exercise [250].

Evidence. It is well established that carbohydrate consumption prior to or during prolonged exercise enhances performance [238, 253-255]. In contrast, a number of trials have shown a high-fat and reduced-carbohydrate diet to increase fat oxidation or reduce reliance on glycogen during exercise, but with mixed effects on performance, ranging from deleterious to advantageous [250, 252, 256-267]. A meta-analysis of 38 trials found high-carbohydrate intake to be more beneficial, but the results were concluded to be unreliable due to heterogeneity [268]. Furthermore, benefit was minimal for trained subjects [268], and the results were skewed by intervention durations of less than 7 days, which may have not been enough time for adaptation to reduced carbohydrate intake [262, 268].

Given that carbohydrate restriction reduces glycogen $[251,259,262,263,269,270]$, limited capacity for highintensity exercise is expected. However, the evidence is mixed [250, 257-259, 265, 266, 270-272], with indication that it is possible to maintain high-intensity exercise capacity even when carbohydrate is restricted to less than $10 \%$ of energy intake [259, 270-272]. Furthermore, normal glycogen levels and thus performance can be maintained with moderate carbohydrate restriction $[250,252]$, as well as with supplementation of carbohydrate during the exercise bout, if needed.

Practical Use. It is commonly recommended that athletes follow a high-carbohydrate diet to replenish glycogen and maintain blood glucose $[92,273]$. However, a high-fat and reduced-carbohydrate diet may be an effective alternative $[237,274,275]$. The equivocal evidence indicates that a wide range in the ratio of fat and carbohydrate intakes can support high-level performance, although the enhancements in fat utilization observed with carbohydrate restriction are unlikely to have ergogenic value beyond that of a highcarbohydrate diet [276-278]. Despite this, fat adaptation can still be compatible with optimal performance and may have beneficial implications for weight management, training adaptation, and metabolic health. A meta-analysis of 87 trials [15] and a number of more recent trials [271, 279, 280] have shown carbohydrate restriction to have a more favorable influence on body composition during weight loss, particularly when combined with resistance training [281283]. Furthermore, carbohydrate restriction has clearly been shown to have a highly favorable effect on cardiovascular and metabolic risk factors [284-289]. It has been suggested that only a quarter of the population can tolerate the current recommendations for carbohydrate intake without developing signs of metabolic dysfunction [275]. Although athletes are less susceptible [275], the presence of metabolic risk factors in athletes is not rare, especially in sports that favor a heavier body weight [290, 291]. As such, a high-fat and carbohydraterestricted diet can be a valuable alternative for athletes who need to manage body weight or have signs of metabolic impairment. In addition, the lower glycogen levels that result from carbohydrate restriction may enhance adaptations to endurance training [273, 292, 293].

Overall, a high-carbohydrate intake is not the only way to support optimal endurance performance. However, carbohydrate intake is likely to be more important for highintensity performance $[278,294]$. Furthermore, there may be considerable variation in the optimal macronutrient ratio for each athlete $[256,262]$. Given the equivocal evidence, athletes should determine their optimal ratio of fat and carbohydrate intakes based on a combination of factors including the demands of their sport, their individual response to different macronutrient ratios, and any concerns related to health or body composition. Considerations related to health and individuality are especially applicable to nonelite athletes, who have less reason to prioritize performance over wellbeing. One strategy to determine an ideal and individualized 
macronutrient ratio, which would be best implemented during the off-season, is to restrict carbohydrate for several weeks and then gradually increase carbohydrate intake until the minimal effective dose needed to sustain performance can be identified. This may include carbohydrate supplementation during exercise, if needed. However, it is important to understand that sufficient adaptation to carbohydrate restriction may take 2-4 weeks [262] and that further adaptation may continue beyond the 4th week [295]. Another approach is to restrict carbohydrate intake long enough to promote fat adaptation and then increase carbohydrate intake prior to or during a competition in order to restore glycogen levels. Enhanced fat oxidation has been shown to persist with such a strategy, although to a lesser extent, and with mixed effects on performance [296].

6.4. Fluid Hydration: Glycerol and Electrolytes. Fluid intake and adequate hydration are critical during E training sessions and competition events. Fluid intake helps to maintain hydration, body temperature (thermoregulations), and plasma volume. For events lasting longer than one hour, athletes need fluids containing carbohydrates and electrolytes rather than water alone. Reduction in body water, availability of carbohydrates, and an inadequate electrolyte balance during prolonged exercise events will hamper performance and may lead to serious medical disorders such as heat exhaustion, heat stroke, or hyponatremia. A $1 \%$ reduction in body weight due to water loss may evoke undue stress on the cardiovascular system accompanied by increases in heart rate and inadequate heat transfer to the skin and the environment, an increase in plasma osmolality, and a decrease in plasma volume and affect the intracellular and extracellular electrolyte balance [297].

Water loss occurs through respiration, sweat, feces, and urine; however, during prolonged endurance most water is lost in sweat, especially during high environmental temperatures. About $580 \mathrm{kcals}$ are lost for every liter of sweat that is evaporated [298]. Loss of body fluid during endurance exercise can be determined by changes in body weight; each $\mathrm{kg}$ of body weight loss accounts for about 1 liter of fluid loss. Sports drinks with adequate concentrations of electrolytes and carbohydrates promotes maintenance of homeostasis, prevents injuries, and maintains optimal performance [299].

Mechanisms. Regulation of fluid balance is a remarkably complex process. Water is lost from the body through the skin, feces, lungs, and kidneys. Water retention by the kidneys is directly controlled by vasopressin produced in the hypothalamus. Production of vasopressin is affected by hypothalamic receptors sensitive to plasma osmolarity and stretch receptors in the atria of the heart, carotid arteries, and aorta.

The kidneys actively reabsorb sodium to regulate extracellular fluid osmolarity and this is largely controlled by aldosterone produced by the adrenal cortex. As serum osmolarity decreases, the adrenal cortex release of aldosterone is triggered resulting in more sodium reabsorbed and an increase in osmolarity. The kidneys also regulate aldosterone production through the rennin-angiotensin mechanism. Receptors in the juxtaglomerular complex of the kidney tubules respond to low volume (pressure) by releasing rennin, which leads to a hormonal cascade effect resulting in production of angiotensin II, a potent vasoconstrictor, which stimulates the release of aldosterone.

Prolonged E exercise significantly taxes the body's ability to regulate hydration status, body temperature, and electrolytes, thus maintaining hydration during exercise is critical to optimal performance. It is recommended that athletes ingest $\sim 500 \mathrm{~mL}$ of fluid 1-2 hours prior to performance and continue to consume cool drinks in the amount of 4-6 ounces every 20 minutes during exercise to replace sweat losses $[297,300,301]$. The rate of water ingestion should not exceed the rate of water loss, as it might result in water retention, weight gain, and exercise-associated hyponatremia [301, 302].

Evidence. Consumption of sports beverage drinks during exercise is recommended to meet carbohydrate energy needs and to replace sweat, water, and electrolyte losses [297]. The majority of the literature supports fluid, carbohydrate, and electrolyte replacement during prolonged ( $\geq 60$ minutes) endurance exercise. Replacement of $\mathrm{Na}^{+}$and $\mathrm{K}^{+}$are essential to maintain plasma volume and hydration [303]. Different exercise tasks (metabolic requirements, duration, clothing, and equipment), weather conditions, and other factors such as genetic predisposition, heat acclimatization, and training status influence sweating rate and electrolyte concentrations and determine fluid needs [297].

Carbohydrate and electrolyte content, palatability, color, odor, taste, temperature, and texture of a sports drink can increase fluid consumption before, during, and after exercise [297, 304] and therefore improve performance. Athletes should ingest 4 to 8 ounces of a $6 \%-8 \%$ carbohydrateelectrolyte sports drink every 10 to 20 minutes during exercise and avoid carbohydrate concentrations over $8 \%$ as this will delay gastric-emptying and should be avoided. Increasing plasma volume can positively affect performance and sodium in sports drinks may help achieve this by improving glucose and water absorption in the small intestine. Sodium is important in rehydration, especially during exercise in the heat [305].

Galloway and Maughan [306] studied six healthy males who cycled to exhaustion while ingesting either no drink, a $15 \%$ carbohydrate-electrolyte drink, or a $2 \%$ carbohydrateelectrolyte drink. Consumption of the $2 \%$ carbohydrateelectrolyte drink leads to a lower serum osmolality and reduced plasma volume deficits. Potassium is important in rehydration after exercise due to the increased retention of fluid in the intracellular space [305]. Numerous recent studies [305, 307-310] have confirmed that during E events, consumption of glucose-electrolyte solutions improved performance greater than water alone.

Several factors including fluid, fuel substrate, and electrolyte depletion have been implicated in the reduction of endurance performance. Recent investigations have suggested that consumption of lactate and fructose in energyelectrolyte hydration beverages improves performance and 
delays fatigue compared to glucose-electrolyte beverages via increased substrate oxidation and enhanced buffering capacity [311].

Hyperhydration may be induced by the oral consumption of glycerol which induces an osmotic gradient that favors greater renal water absorption. Studies examining the effect of hyperhydration by glycerol consumption on performance are equivocal. Several studies have shown performance enhancements $[298,312,313]$ while others have shown no difference when comparing hyperhydration by glycerol consumption to hyperhydration by water or flavored-water consumption [314-316]. Recently, investigations have examined the effect of glycerol ingestion and fluids of varying tonicities $(0.9 \%$ versus $0.45 \% \mathrm{NaCl}$ ) during the rehydration period following exercise-induced dehydration ( $\sim 4 \%$ of body weight) and prior to exercise in the heat $[307,317]$. Rehydration with either a $0.45 \%$ or $0.9 \% \mathrm{NaCl}$ solution resulted in similar fluid restoration, similar cardiovascular, thermoregulatory, and exercise performance responses and were superior to no fluid ingestion [317]. Glycerol ingestion during the rehydration period was found to significantly prolong subsequent exercise time to exhaustion in the heat but was not associated with specific thermoregulatory or cardiovascular advantages compared to rehydration with water alone [307].

Practical Use. The most recent data suggest that multipletransportable-carbohydrates containing a combination of glucose/maltodextrin + fructose in combination with electrolytes are the most favorable beverages to ingest during endurance exercise to enhance performance. Specifically, a 6$8 \%$ carbohydrate mixture of glucose and fructose (GF) plus an electrolyte solution containing $\mathrm{NaCl}$ and $\mathrm{K}$ will further aid endurance performance [318]. Coconut water is also gaining in popularity due to its high $\mathrm{K}$ concentration. Mixing the coconut water with a GF plus $\mathrm{NaCL}$ solution may serve as another electrolyte beverage to enhance hydration and performance.

6.5. Modified and Resistant Starches. As previously mentioned (see carbohydrate intake), endurance athletes must maintain blood glucose and replenish glycogen stores during and following longer bouts, respectively $[92,273]$. Indeed, the type of $\mathrm{CHO}$ (glycemic index and gastric-emptying rate) in relation to the timing of exercise (pre- and during exercise) is critical in the maintenance of blood glucose and insulin, sparing hepatic glycogen stores, and manipulating substrate utilization for endurance exercise. The blood glucose and insulin responses vary depending on $\mathrm{CHO}$ digestion and gastric-emptying rate and need to be considered prior to competition. In efforts to minimize and control the spike in blood glucose and insulin from $\mathrm{CHO}$ intake prior to exercise, research has turned to the use of modified and resistance starches as $\mathrm{CHO}$ alternatives.

Mechanism. Modified starches have gained popularity because of the benefits to digestion and gastric-emptying rate mostly due to the amylose:amylopectin ratio. In general, the higher the ratio of amylose:amylopectin, the greater the resistance to digestion [319], blunting the initial response of blood glucose and insulin. This spares glycogen stores and enhances fat oxidation. However, it should be noted that despite the amylose:amylopectin ratio the gastric emptying and absorption rates may also be manipulated by modifying the different starches consumed (i.e., hydrothermal modification) [253].

Evidence. Stephens et al. [320] measured the effects of a high molecular weight (HMW) rapidly digested modified starch commercially known as Vitargo, a low molecular weight glucose polymer (LMW) (similar to commercial sports drinks), and sugar-free water (SFW) on blood glucose and insulin for two hours after a glycogen depleting exercise (GDE) (60 min at $75 \%$ of $\mathrm{VO}_{2 \max }$ ). Following the two-hour postprandial period each individual performed a 15 min "allout" bout of cycling. Both the HMW and LMW starch elevated blood glucose and insulin during the two-hour recovery versus the SFW, with the initial response $(<60 \mathrm{~min})$ of HMW being significantly greater than the LMW. A greater work output (10\%) during the 15 min cycle performance was found when consuming HMW compared to LMW and SFW suggesting that the rise in blood glucose and insulin allowed replenishment of glycogen stores from the HMW between exercise sessions [320].

Jozsi et al. [321] tested blood glucose and insulin response to amylose and amylopectin versus glucose and maltodextrin. Amylose in the form of a resistance starch (see Section 7) acts similar to a dietary fiber allowing increased fat oxidation by blunting glucose and insulin prior to exercise, whereas amylopectin (as waxy maize starch) responds similar to a normal CHO (i.e., glucose). In their study [321] male cyclists $(n=8)$ completed a GDE (60 $\min$ at $75 \%$ of $\mathrm{VO}_{2 \max }$ ) where they consumed either resistance starch (100\% amylose), waxy maize (100\% amylopectin), glucose, or maltodextrin as $65 \%$ ( $1950 \mathrm{kcals})$ of a 3,000 kcal diet for twenty-four hours after GDE. Following the GDE and $\mathrm{CHO}$ consumption the individuals performed a thirty-minute cycling time trial. Twentyfour hours after the GDE, immediately before exercise the resistance starch (100\% amylose) resulted in significantly lower muscle glycogen concentrations compared to waxy maize (100\% amylopectin), glucose, and maltodextrin. However, no differences were found between the four types of $\mathrm{CHO}$ during the thirty-minute cycling time trial [321]. Therefore, a high amylopectin starch (100\%) [321] and a HMW rapidly digesting starch both [320] increase blood glucose and insulin following a glycogen depleting exercise, while high amylose resistant starch (100\%) results in a lower blood glucose and insulin response, thereby inhibiting glycogen resynthesis [321].

However, modification of these starches (i.e., hydrothermal modification) may decrease the digestion time altering the response of blood glucose and insulin regardless of the amylose : amylopectin ratio [253]. Roberts et al. [322] measured a hydrothermally modified and slow digesting starch (HMS) consisting primarily of amylopectin (95\%), commercially known as UCAN versus maltodextrin $\left(1 \mathrm{~g} \cdot \mathrm{kg}^{-1} \cdot \mathrm{BW}\right)$ during both steady state (150 min submaximal cycling bout at $\left.70 \% \mathrm{VO}_{2 \text { peak }}\right)$ and exhaustive $\left(100 \% \mathrm{VO}_{2 \text { peak }}\right)$ exercise, as well as during 75 minutes of recovery. There was no 
significant difference in performance between either HMS or maltodextrin. However, both the initial and recovery periods of glucose and insulin were blunted with HMS compared to maltodextrin, allowing an increase in fat oxidation [322]. Thus, despite the HMS consisting of amylopectin (95\%) known to increase postprandial glucose and insulin [321], modification of the HMS resulted in a lower postprandial glucose and insulin, similar to that of a high amylose starch [321]. This finding suggests that chemical modification of amylopectin as HMS may augment fat oxidation and spare muscle glycogen.

Practical Use. Although performance benefits from modified and resistant starches appear to be minimal, the glucose and insulin responses during exercise and recovery are optimal for both fat oxidation and glycogen resynthesis. Therefore, in efforts to minimize glucose and insulin secretions and promote a greater reliance on fat oxidation it may be recommended to consume $\left(1 \mathrm{~g} \cdot \mathrm{kg}^{-1} \cdot \mathrm{BW}\right)$ either a modified-HMW (UCAN) or $100 \%$ amylose starch prior to and during exercise. Athletes who will be competing in multiple events or are dependent on the replenishment of glycogen stores between exercises are recommended a high molecular weight rapidly digesting starch, such as Vitargo. Other whole food sources of resistant starches include cooked and cooled potatoes, whole grains (rice, pasta, etc.), and legumes and, thus, should be consumed prior to and between extended bouts of exercise.

\section{PEDs for Energy Metabolism and Body Composition}

Optimal body composition plays a critical factor in athletic performance and it varies among different types of athletes and sports. It is well known that energy metabolism and body composition are directly related to each other and nutritional factors are the primary determinants of each (Table 4).

7.1. Caffeine. The practical use of caffeine, as well as mechanisms through which it may enhance performance and energy metabolism, was previously discussed in relation to I and $\mathrm{E}$ athletic performance. In regard to energy metabolism, a meta-analysis including 6 trials found caffeine consumption to increase daily energy expenditure by approximately $100 \mathrm{kcal}$ [323]. However, fat oxidation was found to only increase when caffeine was combined with catechins [323], indicating that tea may be a favorable source of caffeine for the purpose of weight management. In this meta-analysis, caffeine intake ranged from 150 to $1604 \mathrm{mg} \cdot \mathrm{d}^{-1}$ [323]. Consistent with the above results, our laboratory found a $5 \mathrm{mg} \cdot \mathrm{kg}^{-1} \cdot \mathrm{FFM}$ dose of caffeine to increase energy expenditure in men [324] and women [325]. Although fat oxidation was not measured in the women, it did not change in the men [324]. In addition, the increase in energy expenditure was reduced for older versus younger women [325], but this was not the case with the men $[319,324]$ suggesting a gender difference in the influence of age on the metabolic response to caffeine.

In contrast to previous results, two recent trials found $5 \mathrm{mg} \cdot \mathrm{kg}^{-1} \cdot \mathrm{d}^{-1} \cdot \mathrm{BW}$ of caffeine, consumed for 4 days, to have no influence on resting, active, or total energy expenditure in young men [326, 327]. However, in both trials, the caffeine was divided into two doses, one of which was consumed with breakfast and the other with lunch. Furthermore, although participation was restricted to individuals who habitually consumed less than $100 \mathrm{mg} \cdot \mathrm{d}^{-1}$ of caffeine, actual caffeine consumption prior to the trials was not reported. As such, the previously described evidence, indicating that caffeine does increase energy expenditure, appears to be more reliable.

7.2. Capsinoids. Capsaicin, the known pungent flavor of hot red chili peppers, has become a popularly marketed natural spice for enhancing thermogenesis (i.e., catecholamines, fat oxidation) and improving satiety [328].

Mechanism. Capsaicin will bind to the TRVP1 passively absorbing through the stomach and upper portion of the small intestine. After being released into circulation, capsaicin will be transported to the adrenal gland to release catecholamines, thereby increasing SNSa and energy expenditure [328, 329].

Evidence. Research has shown capsaicin to increase SNSa [330-334], energy expenditure [329, 335-337], and substrate oxidation [329, 330, 335, 336, 338], although these findings are not universal $[339,340]$. The effectiveness of capsaicin to increase thermogenesis and satiety may differ due to varying dosages and with individuals who frequently consume capsaicin compared to nonusers. More recently, Ludy and Mattes [329] tested the effects of capsaicin (1 $\mathrm{g}$ red pepper) on energy expenditure, fat oxidation, and satiety in individuals who regularly consume red peppers versus nonusers in both oral and capsule forms. The postprandial energy expenditure increased in both groups following both oral and capsule form. Interestingly, fat oxidation increased only with the oral form with satiety and energy intake decreasing in only the nonusers. Because capsaicin binds to the TRPV1 in the oral cavity activating heat and pain sensitive sensory neurons it is suggested that when consumed orally rather than in capsule form capsaicin's influence on substrate oxidation may be greatest [329].

Because the pungent sensory burn and pain elicited from capsaicin may cause difficulty in palatability, the capsaicinlike compound capsiate, in the form of nonpungent red pepper "CH-19 Sweet," is an alternative for those unaccustomed or opposed to eating spices. Despite the difference of activation sites, both capsaicin and capsiate bind with high affinity to TRPV1 located in the gut, increasing SNSa [338, 341] without the elevated systolic blood pressure and heart rate response reported with capsaicin [334]. As documented with capsaicin, similar supporting research has found capsiate to increase SNSa [334, 342], energy expenditure [342-344] and substrate oxidation [338, 342-344] in higher dosages. Josse et al. [342] found increases in SNSa, energy expenditure, and fat oxidation with $10 \mathrm{mg}$. Likewise, Galgani and Ravussin [345] found a $54 \mathrm{kcal} \cdot \mathrm{d}^{-1}$ increase in RMR when individuals consumed 3 and $9 \mathrm{mg}$ compared to placebo, and Lee et al. [344] reported increases in postprandial energy expenditure and fat oxidation with 3 and $9 \mathrm{mg}$. Thus, when consumed 
in higher concentrations (3-10 mg) in capsule form, capsiate appears to elicit the greatest thermogenic response.

Practical Use. Individuals not accustomed or willing to consume spices, capsaicin, and capsiate may serve as effective PED supplements to augment and optimize postprandial thermogenesis and substrate oxidation. Common sources of capsaicin in market stores are chili powder, chili peppers, cayenne pepper, jalapenos, and habaneros. A lower dosage of $2 \mathrm{mg}$ to a higher dosage of $10 \mathrm{mg}$ is recommended for individuals with varying thresholds and tolerance, with capsiate as an alternative to those unwilling or unable to consume the pungent capsaicin. However, those unaccustomed to eating capsaicin should consider timing because consumption of the spice prior to exercise has been reported to cause stomach discomfort, nausea, intestinal cramping, flatulence, and burning bowel movements in male athletes [346].

7.3. Carnitine. Carnitine is naturally synthesized in the body from the essential amino acids lysine and methionine [347]. Based on its role in fatty acid transport, carnitine has the potential to support weight management by facilitating fat oxidation.

Mechanism. Carnitine makes up the substrate to CPT1, a ratelimiting step in fatty acid oxidation within skeletal muscle [348]. It is logical to assume that consuming exogenous carnitine via diet or supplementation would be beneficial by inhibiting carbohydrate utilization and augmenting fatty acid oxidation through enhanced translocation of long-chain acyl groups across the inner mitochondrial membrane [348, 349].

Evidence. Recently, Stephens et al. [348] tested the effects of 12 weeks of L-carnitine (CAR) in combination with a $\mathrm{CHO}$ consumed twice daily on muscle expression of genes associated with metabolism, body composition (DEXA), and energy expenditure during low intensity exercise $(50 \%$ of $\mathrm{VO}_{2 \max }$ for $30 \mathrm{~min}$ ) in twelve males. Participants ingested either the CAR + CHO, $n=6(1.36 \mathrm{~g}+80 \mathrm{~g}$ l-CAR + $\mathrm{CHO})$, or $\mathrm{CHO}, n=6(80 \mathrm{~g})$ first thing in the morning and again 4 hours later. Those who consumed CAR + CHO had a $20 \%$ and $200 \%$ increase in total carnitine and long-chain acyl-CoA, respectively $(P<0.05)$, and elevated expression of genes involved in fatty acid metabolism. There were no changes in body composition in the CAR + $\mathrm{CHO}$ group; however over 12 weeks there was a 1.9 and $1.8 \mathrm{~kg}$ increase in body mass and whole-body fat mass, respectively, in the $\mathrm{CHO}$ group. Furthermore, there were no changes in wholebody energy expenditure in the $\mathrm{CHO}$ group, but there was a significant increase of $6 \%$ in the CAR $+\mathrm{CHO}$ group during the $30 \mathrm{~min}$ low-intensity exercise. These findings from Stephens et al. [348] suggest that the consumption of CAR + $\mathrm{CHO}$ for twelve weeks prevented increased body fat mass and in turn was associated with a greater energy expenditure and fat oxidation during low-intensity exercise, as supported in previous research [350].

Practical Use. Carnitine is found in abundance throughout the skeletal muscle cells of the body [351] and may be ingested through diet containing red meat, fish, poultry, and dairy products (for amount of carnitine per each nutrient, see Rebouche [352]) or can be biosynthesized within the liver and kidneys primarily from the essential amino acids lysine and methionine [351, 352]. Those who consume a vegetarian diet are estimated to receive $\sim 90 \%$ of their total available carnitine from endogenous synthesis due to the lack of available carnitine in plant foods, while omnivores receive one-eighth to one-half of total carnitine through diet [352]. Therefore athletes consuming a predominately plant based diet may consider commercially produced carnitine supplements which have been shown to be safe in humans [353].

7.4. Dietary Fiber and Resistant Starches. Resistance starches (RS) are touted as weight loss wonder foods because they have digestive properties and satiating effects similar to those of dietary fibers [354]. In addition, RS may further facilitate weight management by increasing fat oxidation and total energy expenditure and improving glycemic regulation [354].

Mechanism. In comparison to normal dietary starches (DS), RS lowers the glycemic response by passing digestion in the small intestine and moving directly into the large intestine, where it is fermented into short-chain fatty acids [354, 355]. Of the five types of RS1, RS2, RS3, and RS4 are most commonly measured in humans for their effects on postprandial glycemia/insulinemia responses and gut satiety peptides that influence weight loss or weight maintenance (i.e., energy expenditure). RS1 is physically inaccessible to digestive enzymes from the presence of seed coats (e.g., whole grains), RS2 is a high amylose maize starch comprised primarily of $\alpha-1,4$ glycosidic links, RS3 is retrograded starch (e.g., pasta or rice that has been cooked then cooled), and RS4 is chemically modified to be resistant to digestion $[354,356]$.

Evidence. Following consumption of RS2, the postprandial glycemia/insulinemia responses in healthy men and women have been shown to significantly decrease compared to DS $[357,358]$. Interestingly though, when RS2 was adjusted as $0 \%, 2.7 \%, 5.4 \%$, and $10.7 \%$ (percentage of total carbohydrate) at $30 \%$ of an individuals' daily energy needs there were no differences in postprandial glycemia/insulinemia, suggesting dosages up to $10 \%$ have little impact on glycemia and that a combination of additional ingredients might affect RS2 function [359]. Among the other types of RS, RS3 has been shown to decrease postprandial glycemia [360], and RS4 has resulted in decreases in both postprandial glycemia and insulinemia [361-363].

In addition to improved postprandial glycemic/insulinemic responses, RS2 and 3 have shown to positively alter gut satiating peptides (glucose-dependent insulinotropic peptide (GIP)) [358], suppress energy intake [357], improve satiation/appetite [358,364], and significantly increase fat oxidation [359], although these findings are not universal $[357,359,365,366]$. Yet, despite the conflicting results of RS2 and RS3, RS4 has consistently reported favorable postprandial glycemia/insulinemia responses [355, 363, 367] 
and beneficial increases in energy expenditure in healthy individuals [363].

To determine differences in postprandial glycemia/insulinemia responses between RS (RS2 and RS4 cross-linked, XL) and a normal carbohydrate (dextrose), Haub et al. [355] tested eleven healthy males $(n=4)$ and females $(n=$ 7) for two hours after consuming $30 \mathrm{~g}$ of $\mathrm{RS} 4_{\mathrm{XL}}, \mathrm{RS} 2$, or dextrose combined with water. Postprandial glucose and insulin responses were significantly lower in the $\mathrm{RS} 4_{\mathrm{XL}}$ and RS2 compared to dextrose, with RS4 ${ }_{\mathrm{XL}}$ being significantly lower than that of the RS2 [355]. Because RS is more commonly consumed in combination with foods rather than water alone, Al-Tamimi et al. [367] examined the effects $\mathrm{RS}_{\mathrm{XL}}$ in combination with additional ingredients in the form of a nutrition bar and found that RS4 $4_{\mathrm{XL}}$ compared to wheat starch resulted in significantly lower $2 \mathrm{hr}$ postprandial glycemia/insulinemia response.

Shimotoyodome et al. [363] tested RS4 (hydroxypropyldistarch, HDP) versus waxy maize starch (WMS) using a pancake meal on the $3 \mathrm{hr}$ postprandial glycemic/insulinemic, GIP, and energy expenditure response in healthy lean males. HDP resulted in significantly lower postprandial glycemia/insulinemia and GIP, as well as increased fat oxidation and energy expenditure compared to WMS. Research supports suppressed postprandial glycemia/insulinemia by both RS2 and RS4; interestingly, only RS4 has elicited significant increases in energy expenditure [363].

Practical Use. Current research suggests the effects of RS4 $\left(\mathrm{RS} 4_{\mathrm{XL}}\right.$ and HDP) on postprandial glycemia/insulinemia, gut satiety peptides GIP, and augmented energy expenditure and fat oxidation $[355,363,367]$ are greater than those of RS2. A suggested dosage of $20-40 \mathrm{~g}$ of RS4 consumed at breakfast or a late evening snack may facilitate greater appetite suppression, postprandial glycemia and insulinemia, and increase energy expenditure.

7.5. Medium-Chain Triglycerides. Medium-chain triglycerides (MCTs) consist of fatty acids ranging in length from 6 to 12 carbons [368]. Although MCTs appear to have little influence on performance, benefits related to energy balance and weight loss are better supported [369].

Mechanisms. The benefits of MCT consumption may be explained by the unique ways their constituent fatty acids are absorbed and metabolized. Prior to reaching systemic circulation, long-chain fatty acids are reincorporated into triglycerides, assembled into chylomicrons, and released into lymphatic circulation [370]. In contrast, medium-chain fatty acids enter portal circulation directly through the enterocyte [370]. As such, medium-chain fatty acids enter circulation more rapidly and are primarily absorbed by the liver [368]. Once absorbed, medium-chain fatty acids pass through the inner mitochondrial membrane independently of the CPT transport system and can therefore be rapidly oxidized [368]. This, along with the poor binding potential between mediumchain fatty acids and fatty-acid-binding protein, limits the lipogenic potential of MCTs [368]. As such, MCTs are more likely to be utilized for energy and less likely to be stored as body fat.

MCTs also have the potential to increase energy expenditure [371]. Urinary noradrenaline excretion has been found to increase in conjunction with increased energy expenditure following MCT consumption [372]. Furthermore, in rats fed MCTs, an increase in energy expenditure was prevented with administration of propranolol [373]. Therefore, increased SNSa may be the underlying mechanism.

Evidence. In a recent systematic review [371], 6 of 8 trials found MCT consumption to improve body composition, and 4 of 6 trials identified an increase in energy expenditure [371]. However, an increase in satiety was only observed in 1 of 7 trials [371]. Some trials have shown MCT consumption to increase average daily energy expenditure by more than $100 \mathrm{kcal}$ in overweight [374] and normal-weight [372] men, which could amount to more than $30 \mathrm{lbs}$ of weight loss over a year [375]. However, such an increase is not consistently supported [371] and may be less notable in women [376]. Furthermore, the increase in energy expenditure induced by MCT consumption has been shown to diminish over time [369]. Despite this, superior weight loss has been observed in trials lasting as long as 16 weeks [369]. However, because the increases in energy expenditure and fat oxidation associated with MCT consumption have been inversely correlated with initial body weight, MCT consumption may be more effective for preventing weight gain than promoting weight loss [377].

In a recent trial including 7 normal-weight subjects, a breakfast meal containing $20 \mathrm{~g}$ of MCTs was found to increase diet-induced thermogenesis and fat oxidation compared to the same meal with a calorically matched content of sunflower oil [378]. Similarly, in another recent trial, the inclusion of MCTs in a meal replacement shake led to greater diet-induced thermogenesis compared to shakes with lesser amounts of MCTs or no MCTs at all [379]. As such, replacing a portion of dietary fat with MCTs may be an effective strategy for weight maintenance.

Practical Use. Increases in energy expenditure have been observed with MCT intakes ranging from 8 to $35 \mathrm{~g} \cdot \mathrm{d}^{-1}$ [371]. While MCT oil is readily available, coconut oil and palm kernel oil are two alternatives that more closely resemble whole foods. They contain approximately 63 and 58\% MCT, respectively [380]. These oils can easily be incorporated into the diet through cooking or by melting them for use as a sauce or salad dressing. The meat of a coconut, although less practical, is truly a whole food and contains approximately $19 \%$ MCT [94].

\section{Summary}

Advances in athletic performance training and nutrition have prompted a reevaluation of our current practices in order for both (training and nutrition) to work synergistically with each other instead of in isolation to one another. The current review, albeit novel, bridges the gap between athletic 
performance training and sports nutrition by linking the scientifically validated multicomponent training model (timedprotein feedings; resistance training; interval sprint training; stretching/recovery training; and endurance training; PRISE) employed by most, if not all, athletes with specific performance enhancing diets (PEDs) to foster optimal athletic performance. The goal of this innovative review is to provide a new paradigm of sports nutrition that allows performance training (PRISE) and sports nutrition (PEDs) to complement each other instead of working apart from one another.

\section{Conflict of Interests}

Paul J. Arciero is president and founder of Nourishing Science LLC, a company providing nutrition, fitness, and wellness consultative services utilizing certain content contained in this paper. The authors declare no other conflict of interests.

\section{Acknowledgments}

The authors are grateful to the following individuals for their assistance with the research conducted on the PRISE protocol: (i) nurses, Patricia Bosen NP and Michelle Lapo, (ii) student researchers, Christopher Darin, Qian Zheng, Kanokwan Bunsawat, JunZhu Zhang, Nicholas Steward, Jake Mendell, Caitlin Ketcham, Steven Brink, Steve Vasquez, Gabriel Zeiff, and Elise Britt, (iii) Scott Connelly MD for financial support, (iv) the hundreds of research study participants for their dedication, cooperation, and strong spirits.

\section{References}

[1] L. Dwyer-Lindgren, G. Freedman, R. E. Engell et al., "Prevalence of physical activity and obesity in US counties, 2001-2011: a road map for action," Population Health Metrics, vol. 11, no. 1, article 7, 2013.

[2] US Department of Health and Human Services, 2008 Physical Activity Guidelines for Americans, US Department of Health and Human Services, Washington, DC, USA, 2008.

[3] National Physical Activity Plan Alliance, 2014 United States Report Card on Physical Activity for Children and Youth, National Physical Activity Plan Alliance, Columbia, SC, USA, 2014.

[4] P. J. Arciero, D. Baur, S. Connelly, and M. J. Ormsbee, “Timeddaily ingestion of whey protein and exercise training reduces visceral adipose tissue mass and improves insulin resistance: the PRISE study," Journal of Applied Physiology, vol. 117, no. 1, pp. 110, 2014.

[5] J. L. Areta, L. M. Burke, M. L. Ross et al., "Timing and distribution of protein ingestion during prolonged recovery from resistance exercise alters myofibrillar protein synthesis," Journal of Physiology, vol. 591, no. 9, pp. 2319-2331, 2013.

[6] S. M. Phillips, D. R. Moore, and J. E. Tang, "A critical examination of dietary protein requirements, benefits, and excesses in athletes," International Journal of Sport Nutrition and Exercise Metabolism, vol. 17, supplement, pp. S58-S76, 2007.

[7] P. J. Arciero, M. J. Ormsbee, C. L. Gentile, B. C. Nindl, J. R. Brestoff, and M. Ruby, "Increased protein intake and meal frequency reduces abdominal fat during energy balance and energy deficit," Obesity, vol. 21, no. 7, pp. 1357-1366, 2013.
[8] U. S. Department of Agriculture, Report of the Dietary Guidelines Advisory Committee on the Dietary Guidelines for Americans, 2010.

[9] G. A. Bray, S. R. Smith, L. de Jonge et al., "Effect of dietary protein content on weight gain, energy expenditure, and body composition during overeating: a randomized controlled trial," The Journal of the American Medical Association, vol. 307, no. 1, pp. 47-55, 2012.

[10] C. B. Ebbeling, J. F. Swain, H. A. Feldman et al., "Effects of dietary composition on energy expenditure during weight-loss maintenance," Journal of the American Medical Association, vol. 307, no. 24, pp. 2627-2634, 2012.

[11] T. P. Wycherley, L. J. Moran, P. M. Clifton, M. Noakes, and G. D. Brinkworth, "Effects of energy-restricted high-protein, low-fat compared with standard-protein, low-fat diets: a meta-analysis of randomized controlled trials," American Journal of Clinical Nutrition, vol. 96, no. 6, pp. 1281-1298, 2012.

[12] P. J. Arciero, C. L. Gentile, R. Martin-Pressman et al., "Increased dietary protein and combined high intensity aerobic and resistance exercise improves body fat distribution and cardiovascular risk factors," International Journal of Sport Nutrition and Exercise Metabolism, vol. 16, no. 4, pp. 373-392, 2006.

[13] P. J. Arciero, C. L. Gentile, R. Pressman et al., "Moderate protein intake improves total and regional body composition and insulin sensitivity in overweight adults," Metabolism: Clinical and Experimental, vol. 57, no. 6, pp. 757-765, 2008.

[14] M. S. Westerterp-Plantenga, S. G. Lemmens, and K. R. Westerterp, "Dietary protein-its role in satiety, energetics, weight loss and health," British Journal of Nutrition, vol. 108, supplement 2, pp. S105-S112, 2012.

[15] J. W. Krieger, H. S. Sitren, M. J. Daniels, and B. LangkampHenken, "Effects of variation in protein and carbohydrate intake on body mass and composition during energy restriction: a meta-regression," The American Journal of Clinical Nutrition, vol. 83, no. 2, pp. 260-274, 2006.

[16] T. M. Larsen, S.-M. Dalskov, M. Van Baak et al., "Diets with high or low protein content and glycemic index for weight-loss maintenance," The New England Journal of Medicine, vol. 363, no. 22, pp. 2102-2113, 2010.

[17] F. Isken, S. Klaus, K. J. Petzke, C. Loddenkemper, A. F. H. Pfeiffer, and M. O. Weickert, "Impairment of fat oxidation under high- vs. low-glycemic index diet occurs before the development of an obese phenotype," The American Journal of Physiology-Endocrinology and Metabolism, vol. 298, no. 2, pp. E287-E295, 2010.

[18] S. Soenen, E. A. P. Martens, A. Hochstenbach-waelen, S. G. T. Lemmens, and M. S. Westerterp-plantenga, "Normal protein intake is required for body weight loss and weight maintenance, and elevated protein intake for additional preservation of resting energy expenditure and fat free mass," The Journal of Nutrition, vol. 143, no. 5, pp. 591-596, 2013.

[19] S. E. Drummond, N. E. Crombie, M. C. Cursiter, and T. R. Kirk, "Evidence that eating frequency is inversely related to body weight status in male, but not female, non-obese adults reporting valid dietary intakes," International Journal of Obesity, vol. 22, no. 2, pp. 105-112, 1998.

[20] P. Fábry, Z. Hejl, J. Fodor, T. Braun, and K. Zvolánková, “The frequency of meals. Its relation to overweight, hypercholesterolaemia, and decreased glucose tolerance," The Lancet, vol. 284, no. 7360 , pp. $614-615,1964$. 
[21] R. Crovetti, M. Porrini, A. Santangelo, and G. Testolin, “The influence of thermic effect of food on satiety," European Journal of Clinical Nutrition, vol. 52, no. 7, pp. 482-488, 1998.

[22] J. O. Hill, S. B. Heymsfield, C. McMannus III, and M. DiGirolamo, "Meal size and thermic response to food in male subjects as a function of maximum aerobic capacity," Metabolism, vol. 33, no. 8, pp. 743-749, 1984.

[23] K. S. Nair, D. Halliday, and J. S. Garrow, “Thermic response to isoenergetic protein, carbohydrate or fat meals in lean and obese subjects," Clinical Science, vol. 65, no. 3, pp. 307-312, 1983.

[24] T. A. Churchward-Venne, L. Breen, D. M. di Donato et al., "Leucine supplementation of a low-protein mixed macronutrient beverage enhances myofibrillar protein synthesis in young men: a double-blind, randomized trial," The American Journal of Clinical Nutrition, vol. 99, no. 2, pp. 276-286, 2014.

[25] S. M. Phillips, "A brief review of critical processes in exerciseinduced muscular hypertrophy," Sports Medicine, vol. 44, supplement 1, pp. S71-S77, 2014.

[26] D. R. Moore, M. J. Robinson, J. L. Fry et al., "Ingested protein dose response of muscle and albumin protein synthesis after resistance exercise in young men," The American Journal of Clinical Nutrition, vol. 89, no. 1, pp. 161-168, 2009.

[27] L. Guimarães-Ferreira, "Role of the phosphocreatine system on energetic homeostasis in skeletal and cardiac muscles," Einstein (São Paulo), vol. 12, no. 1, pp. 126-131, 2014.

[28] R. Cooper, F. Naclerio, J. Allgrove, and A. Jimenez, "Creatine supplementation with specific view to exercise/sports performance: an update," Journal of the International Society of Sports Nutrition, vol. 9, no. 1, article 33, 2012.

[29] R. C. Harris, K. Soderlund, and E. Hultman, "Elevation of creatine in resting and exercised muscle of normal subjects by creatine supplementation," Clinical Science, vol. 83, no. 3, pp. 367-374, 1992.

[30] E. Hultman, K. Söderlund, J. A. Timmons, G. Cederblad, and P. L. Greenhaff, "Muscle creatine loading in men," Journal of Applied Physiology, vol. 81, no. 1, pp. 232-237, 1996.

[31] R. Kreis, M. Kamber, M. Koster et al., "Creatine supplementation-part II: in vivo magnetic resonance spectroscopy," Medicine and Science in Sports and Exercise, vol. 31, no. 12, pp. 1770-1777, 1999.

[32] L. J. C. van Loon, A. M. Oosterlaar, F. Hartgens, M. K. C. Hesselink, R. J. Snow, and A. J. M. Wagenmakers, "Effects of creatine loading and prolonged creatine supplementation on body composition, fuel selection, sprint and endurance performance in humans," Clinical Science (Lond), vol. 104, no. 2, pp. 153-162, 2003.

[33] J. S. Volek, N. D. Duncan, S. A. Mazzetti et al., "Performance and muscle fiber adaptations to creatine supplementation and heavy resistance training," Medicine \& Science in Sports \& Exercise, vol. 31, no. 8, pp. 1147-1156, 1999.

[34] P. J. Arciero, N. S. Hannibal III, B. C. Nindl, C. L. Gentile, J. Hamed, and M. D. Vukovich, "Comparison of creatine ingestion and resistance training on energy expenditure and limb blood flow," Metabolism: Clinical and Experimental, vol. 50, no. 12, pp. 1429-1434, 2001.

[35] J. L. M. Mesa, J. R. Ruiz, M. M. González-Gross, Á. Gutiérrez Sáinz, and M. J. Castillo Garzón, "Oral creatine supplementation and skeletal muscle metabolism in physical exercise," Sports Medicine, vol. 32, no. 14, pp. 903-944, 2002.

[36] R. L. Terjung, P. Clarkson, E. R. Eichner et al., “The American College of Sports Medicine Roundtable on the physiological and health effects of oral creatine supplementation," Medicine and Science in Sports and Exercise, vol. 32, no. 3, pp. 706-717, 2000.

[37] P. L. Greenhaff, K. Bodin, K. Soderlund, and E. Hultman, "Effect of oral creatine supplementation on skeletal muscle phosphocreatine resynthesis," The American Journal of Physiology, vol. 266, no. 5, pp. E725-E730, 1994.

[38] A. M. Jones, D. P. Wilkerson, and J. Fulford, "Influence of dietary creatine supplementation on muscle phosphocreatine kinetics during knee-extensor exercise in humans," American Journal of Physiology: Regulatory Integrative and Comparative Physiology, vol. 296, no. 4, pp. R1078-R1087, 2009.

[39] K. Vandenberghe, P. van Hecke, M. van Leemputte, F. Vanstapel, and P. Hespel, "Phosphocreatine resynthesis is not affected by creatine loading," Medicine \& Science in Sports \& Exercise, vol. 31, no. 2, pp. 236-242, 1999.

[40] T. W. Demant and E. C. Rhodes, "Effects of creatine supplementation on exercise performance," Sports Medicine, vol. 28, no. 1, pp. 49-60, 1999.

[41] T. N. Ziegenfuss, L. M. Lowery, and P. W. R. Lemon, "Acute fluid volume changes in men during three days of creatine supplementation," Journal of Exercise Physiology, vol. 1, no. 3, 1998.

[42] S. Y. Low, M. J. Rennie, and P. M. Taylor, "Modulation of glycogen synthesis in rat skeletal muscle by changes in cell volume," Journal of Physiology, vol. 495, part 2, pp. 299-303, 1996.

[43] B. Stoll, W. Gerok, F. Lang, and D. Haussinger, "Liver cell volume and protein synthesis," Biochemical Journal, vol. 287, no. 1, pp. 217-222, 1992.

[44] J. S. Volek and E. S. Rawson, "Scientific basis and practical aspects of creatine supplementation for athletes," Nutrition, vol. 20, no. 7-8, pp. 609-614, 2004.

[45] D. M. Fry and M. F. Morales, "A reexamination of the effects of creatine on muscle protein synthesis in tissue culture," Journal of Cell Biology, vol. 84, no. 2, pp. 294-297, 1980.

[46] J. S. Ingwall, C. D. Weiner, M. F. Morales, E. Davis, and F. E. Stockdale, "Specificity of creatine in the control of muscle protein synthesis," Journal of Cell Biology, vol. 62, no. 1, pp. 145151, 1974.

[47] M. Louis, J. R. Poortmans, M. Francaux et al., "No effect of creatine supplementation on human myofibrillar and sarcoplasmic protein synthesis after resistance exercise," The American Journal of Physiology_Endocrinology and Metabolism, vol. 285, no. 5, pp. E1089-E1094, 2003.

[48] M. Louis, J. R. Poortmans, M. Francaux et al., "Creatine supplementation has no effect on human muscle protein turnover at rest in the postabsorptive or fed states," The American Journal of Physiology-Endocrinology and Metabolism, vol. 284, no. 4, pp. E764-E770, 2003.

[49] G. Pakise, S. Mihic, D. MacLennan, K. E. Yakasheski, and M. A. Tarnopolsky, "Effects of acute creatine monohydrate supplementation on leucine kinetics and mixed-muscle protein synthesis," Journal of Applied Physiology, vol. 91, no. 3, pp. 10411047, 2001.

[50] D. S. Willoughby and J. Rosene, "Effects of oral creatine and resistance training on myosin heavy chain expression," Medicine and Science in Sports and Exercise, vol. 33, no. 10, pp. 1674-1681, 2001.

[51] M. van Leemputte, K. Vandenberghe, and P. Hespel, "Shortening of muscle relaxation time after creatine loading," Journal of Applied Physiology, vol. 86, no. 3, pp. 840-844, 1999. 
[52] J. M. Lawler, W. S. Barnes, G. Wu, W. Song, and S. Demaree, "Direct antioxidant properties of creatine," Biochemical and Biophysical Research Communications, vol. 290, no. 1, pp. 47-52, 2002.

[53] J. D. Branch, "Effect of creatine supplementation on body composition and performance: a meta-analysis," International Journal of Sport Nutrition and Exercise Metabolism, vol. 13, no. 2, pp. 198-226, 2003.

[54] V. Gouttebarge, H. Inklaar, and C. A. Hautier, "Short-term oral creatine supplementation in professional football players: a randomized placebo-controlled trial," European Journal of Sports \& Exercise Science, vol. 1, no. 2, p. 7, 2012.

[55] J. Antonio and V. Ciccone, "The effects of pre versus post workout supplementation of creatine monohydrate on body composition and strength," Journal of the International Society of Sports Nutrition, vol. 10, article 36, 2013.

[56] T. P. Souza-Junior, J. M. Willardson, R. Bloomer et al., "Strength and hypertrophy responses to constant and decreasing rest intervals in trained men using creatine supplementation," Journal of the International Society of Sports Nutrition, vol. 8, no. 1, article 17, 2011.

[57] R. Deminice, F. T. Rosa, G. S. Franco, A. A. Jordao, and E. C. de Freitas, "Effects of creatine supplementation on oxidative stress and inflammatory markers after repeated-sprint exercise in humans," Nutrition, vol. 29, no. 9, pp. 1127-1132, 2013.

[58] K. F. T. Veggi, M. Machado, A. J. Koch, S. C. Santana, S. S. Oliveira, and M. J. Stec, "Oral creatine supplementation augments the repeated bout effect," International Journal of Sport Nutrition and Exercise Metabolism, vol. 23, no. 4, pp. 378387, 2013.

[59] R. L. Dempsey, M. F. Mazzone, and L. N. Meurer, "Does oral creatine supplementation improve strength? A meta-analysis," Journal of Family Practice, vol. 51, no. 11, pp. 945-951, 2002.

[60] P. D. Balsom, K. Soderlund, and B. Ekblom, "Creatine in humans with special reference to creatine supplementation," Sports Medicine, vol. 18, no. 4, pp. 268-280, 1994.

[61] M. A. Tarnopolsky, "Caffeine and creatine use in sport," Annals of Nutrition and Metabolism, vol. 57, supplement 2, pp. 1-8, 2011.

[62] R. C. Harris, J. A. Lowe, K. Warnes, and C. E. Orme, "The concentration of creatine in meat, offal and commercial dog food," Research in Veterinary Science, vol. 62, no. 1, pp. 58-62, 1997.

[63] Y. Shimomura, Y. Yamamoto, G. Bajotto et al., "Nutraceutical effects of branched-chain amino acids on skeletal muscle," The Journal of Nutrition, vol. 136, no. 2, pp. 529S-532S, 2006.

[64] L. L. Tatpati, B. A. Irving, A. Tom et al., "The effect of branched chain amino acids on skeletal muscle mitochondrial function in young and elderly adults," Journal of Clinical Endocrinology and Metabolism, vol. 95, no. 2, pp. 894-902, 2010.

[65] P. She, Y. Zhou, Z. Zhang, K. Griffin, K. Gowda, and C. J. Lynch, "Disruption of BCAA metabolism in mice impairs exercise metabolism and endurance," Journal of Applied Physiology, vol. 108, no. 4, pp. 941-949, 2010.

[66] D. A. MacLean, T. E. Graham, and B. Saltin, "Branched-chain amino acids augment ammonia metabolism while attenuating protein breakdown during exercise," The American Journal of Physiology, vol. 267, no. 6, pp. E1010-E1022, 1994.

[67] E. Blomstrand, "A role for branched-chain amino acids in reducing central fatigue," Journal of Nutrition, vol. 136, no. 2, pp. 544S-547S, 2006.
[68] E. A. Newsholme and E. Blomstrand, "Branched-chain amino acids and central fatigue," Journal of Nutrition, vol. 136, no. 1, supplement, pp. 274S-276S, 2006.

[69] B. K. Greer, J. P. White, E. M. Arguello, and E. M. Haymes, "Branched-chain amino acid supplementation lowers perceived exertion but does not affect performance in untrained males," Journal of Strength and Conditioning Research, vol. 25, no. 2, pp. 539-544, 2011.

[70] A. B. Gualano, T. Bozza, P. de Lopes Campos et al., "Branchedchain amino acids supplementation enhances exercise capacity and lipid oxidation during endurance exercise after muscle glycogen depletion," The Journal of Sports Medicine and Physical Fitness, vol. 51, no. 1, pp. 82-88, 2011.

[71] H. Kainulainen, J. J. Hulmi, and U. M. Kujala, "Potential role of branched-chain amino acid catabolism in regulating fat oxidation," Exercise and Sport Sciences Reviews, vol. 41, no. 4, pp. 194-200, 2013.

[72] K. Matsumoto, T. Koba, K. Hamada, H. Tsujimoto, and R. Mitsuzono, "Branched-chain amino acid supplementation increases the lactate threshold during an incremental exercise test in trained individuals," Journal of Nutritional Science and Vitaminology, vol. 55, no. 1, pp. 52-58, 2009.

[73] E. Blomstrand, J. Eliasson, H. K. R. Karlssonr, and R. Köhnke, "Branched-chain amino acids activate key enzymes in protein synthesis after physical exercise," Journal of Nutrition, vol. 136, no. 1, supplement, pp. 269S-273S, 2006.

[74] S. R. Kimball and L. S. Jefferson, "Signaling pathways and molecular mechanisms through which branched-chain amino acids mediate translational control of protein synthesis," Journal of Nutrition, vol. 136, no. 1, supplement, pp. 227S-231S, 2006.

[75] L. E. Norton and D. K. Layman, "Leucine regulates translation initiation of protein synthesis in skeletal muscle after exercise," Journal of Nutrition, vol. 136, no. 2, pp. 533S-537S, 2006.

[76] S. M. Pasiakos and J. P. Mcclung, "Supplemental dietary leucine and the skeletal muscle anabolic response to essential amino acids," Nutrition Reviews, vol. 69, no. 9, pp. 550-557, 2011.

[77] E. Blomstrand, P. Hassmen, B. Ekblom, and E. A. Newsholme, "Administration of branched-chain amino acids during sustained exercise-effects on performance and on plasma concentration of some amino acids," European Journal of Applied Physiology and Occupational Physiology, vol. 63, no. 2, pp. 8388, 1991.

[78] M. J. Crowe, J. N. Weatherson, and B. F. Bowden, "Effects of dietary leucine supplementation on exercise performance," European Journal of Applied Physiology, vol. 97, no. 6, pp. 664$672,2006$.

[79] K. D. Mittleman, M. R. Ricci, and S. P. Bailey, "Branched-chain amino acids prolong exercise during heat stress in men and women," Medicine and Science in Sports and Exercise, vol. 30, no. 1, pp. 83-91, 1998.

[80] J. M. Davis, R. S. Welsh, K. L. de Volve, and N. A. Alderson, "Effects of branched-chain amino acids and carbohydrate on fatigue during intermittent, high-intensity running," International Journal of Sports Medicine, vol. 20, no. 5, pp. 309-314, 1999.

[81] K. Madsen, D. A. Maclean, B. Kiens, and D. Christensen, "Effects of glucose, glucose plus branched-chain amino acids, or placebo on bike performance over $100 \mathrm{~km}$," Journal of Applied Physiology, vol. 81, no. 6, pp. 2644-2650, 1996.

[82] H. T. Pitkänen, S. S. Oja, H. Rusko et al., "Leucine supplementation does not enhance acute strength or running performance 
but affects serum amino acid concentration," Amino Acids, vol. 25, no. 1, pp. 85-94, 2003.

[83] H. K. Strüder, W. Hollmann, P. Platen, M. Donike, A. Gotzmann, and K. Weber, "Influence of paroxetine, branched-chain amino acids and tyrosine on neuroendocrine system responses and fatigue in humans," Hormone and Metabolic Research, vol. 30, no. 4, pp. 188-194, 1998.

[84] G. Van Hall, J. S. H. Raaymakers, W. H. M. Saris, and A. J. M. Wagenmakers, "Ingestion of branched-chain amino acids and tryptophan during sustained exercise in man: failure to affect performance," Journal of Physiology, vol. 486, no. 3, pp. 789-794, 1995.

[85] P. Watson, S. M. Shirreffs, and R. J. Maughan, "The effect of acute branched-chain amino acid supplementation on prolonged exercise capacity in a warm environment," European Journal of Applied Physiology, vol. 93, no. 3, pp. 306-314, 2004.

[86] M. Spillane, C. Emerson, and D. S. Willoughby, "The effects of 8 weeks of heavy resistance training and branched-chain amino acid supplementation on body composition and muscle performance," Nutrition and Health, vol. 21, no. 4, pp. 263-273, 2012.

[87] T. Ispoglou, R. F. G. J. King, R. C. J. Polman, and C. Zanker, "Daily L-leucine supplementation in novice trainees during a 12-week weight training program," International Journal of Sports Physiology and Performance, vol. 6, no. 1, pp. 38-50, 2011.

[88] S. M. Pasiakos, H. L. McClung, J. P. McClung et al., "Leucineenriched essential amino acid supplementation during moderate steady state exercise enhances postexercise muscle protein synthesis," The American Journal of Clinical Nutrition, vol. 94, no. 3, pp. 809-818, 2011.

[89] E. Børsheim, K. D. Tipton, S. E. Wolf, and R. R. Wolfe, "Essential amino acids and muscle protein recovery from resistance exercise," The American Journal of Physiology-Endocrinology and Metabolism, vol. 283, no. 4, pp. E648-E657, 2002.

[90] D. J. Cuthbertson, J. Babraj, K. Smith et al., "Anabolic signaling and protein synthesis in human skeletal muscle after dynamic shortening or lengthening exercise," The American Journal of Physiology -Endocrinology and Metabolism, vol. 290, no. 4, pp. E731-E738, 2006.

[91] E. Volpi, H. Kobayashi, M. Sheffield-Moore, B. Mittendorfer, and R. R. Wolfe, "Essential amino acids are primarily responsible for the amino acid stimulation of muscle protein anabolism in healthy elderly adults," The American Journal of Clinical Nutrition, vol. 78, no. 2, pp. 250-258, 2003.

[92] N. R. Rodriguez, N. M. DiMarco, and S. Langley, "Position of the American Dietetic Association, Dietitians of Canada, and the American College of Sports Medicine: nutrition and athletic performance," Journal of the American Dietetic Association, vol. 109, no. 3, pp. 509-527, 2009.

[93] E. L. Glynn, C. S. Fry, M. J. Drummond et al., "Excess leucine intake enhances muscle anabolic signaling but not net protein anabolism in young men and women," Journal of Nutrition, vol. 140, no. 11, pp. 1970-1976, 2010.

[94] U. S. Department of Agriculture, USDA National Nutrient Database for Standard Reference, Release 26, U. S. Department of Agriculture, 2013.

[95] L. M. Burke, J. A. Winter, D. Cameron-Smith, M. Enslen, M. Farnfield, and J. Decombaz, "Effect of intake of different dietary protein sources on plasma amino acid profiles at rest and after exercise," International Journal of Sport Nutrition and Exercise Metabolism, vol. 22, no. 6, pp. 452-462, 2012.
[96] T. B. Conley, J. W. Apolzan, H. J. Leidy, K. A. Greaves, E. Lim, and W. W. Campbell, "Effect of food form on postprandial plasma amino acid concentrations in older adults," British Journal of Nutrition, vol. 106, no. 2, pp. 203-207, 2011.

[97] R. Koopman, N. Crombach, A. P. Gijsen et al., "Ingestion of a protein hydrolysate is accompanied by an accelerated in vivo digestion and absorption rate when compared with its intact protein," The American Journal of Clinical Nutrition, vol. 90, no. 1, pp. 106-115, 2009.

[98] J. E. Tang, D. R. Moore, G. W. Kujbida, M. A. Tarnopolsky, and S. M. Phillips, "Ingestion of whey hydrolysate, casein, or soy protein isolate: effects on mixed muscle protein synthesis at rest and following resistance exercise in young men," Journal of Applied Physiology, vol. 107, no. 3, pp. 987-992, 2009.

[99] D. W. D. West, N. A. Burd, V. G. Coffey et al., "Rapid aminoacidemia enhances myofibrillar protein synthesis and anabolic intramuscular signaling responses after resistance exercise," The American Journal of Clinical Nutrition, vol. 94, no. 3, pp. 795803, 2011.

[100] S. B. Wilkinson, M. A. Tarnopolsky, M. J. MacDonald, J. R. MacDonald, D. Armstrong, and S. M. Phillips, "Consumption of fluid skim milk promotes greater muscle protein accretion after resistance exercise than does consumption of an isonitrogenous and isoenergetic soy-protein beverage," American Journal of Clinical Nutrition, vol. 85, no. 4, pp. 1031-1040, 2007.

[101] R. M. Hobson, B. Saunders, G. Ball, R. C. Harris, and C. Sale, "Effects of beta-alanine supplementation on exercise performance: a meta-analysis," Amino Acids, vol. 43, no. 1, pp. 25-37, 2012.

[102] V. de Salles Painelli, H. Roschel, F. de Jesus et al., "The ergogenic effect of beta-alanine combined with sodium bicarbonate on high-intensity swimming performance," Applied Physiology, Nutrition and Metabolism, vol. 38, no. 5, pp. 525-532, 2013.

[103] C. Sale, B. Saunders, S. Hudson, J. A. Wise, R. C. Harris, and C. D. Sunderland, "Effect of $\beta$-alanine plus sodium bicarbonate on high-intensity cycling capacity," Medicine and Science in Sports and Exercise, vol. 43, no. 10, pp. 1972-1978, 2011.

[104] K. J. Ducker, B. Dawson, and K. E. Wallman, "Effect of beta-alanine supplementation on 800-m running performance," International Journal of Sport Nutrition and Exercise Metabolism, vol. 23, no. 6, pp. 554-561, 2013.

[105] R. van Thienen, K. van Proeyen, B. V. Eynde, J. Puype, T. Lefere, and P. Hespel, " $\beta$-alanine improves sprint performance in endurance cycling," Medicine \& Science in Sports \& Exercise, vol. 41, no. 4, pp. 898-903, 2009.

[106] B. Saunders, C. Sale, R. C. Harris, and C. Sunderland, "Effect of beta-alanine supplementation on repeated sprint performance during the Loughborough Intermittent Shuttle Test," Amino Acids, vol. 43, no. 1, pp. 39-47, 2012.

[107] W. Derave, M. S. Özdemir, R. C. Harris et al., "beta-Alanine supplementation augments muscle carnosine content and attenuates fatigue during repeated isokinetic contraction bouts in trained sprinters," Journal of Applied Physiology, vol. 103, no. 5, pp. 1736-1743, 2007.

[108] S. T. Howe, P. M. Bellinger, M. W. Driller, C. M. Shing, and J. W. Fell, "The effect of beta-alanine supplementation on isokinetic force and cycling performance in highly trained cyclists," International Journal of Sport Nutrition and Exercise Metabolism, vol. 23, no. 6, pp. 562-570, 2013.

[109] K. M. Sweeney, G. A. Wright, A. Glenn Brice, and S. T. Doberstein, "The effect of beta-alanine supplementation on power performance during repeated sprint activity," Journal of 
Strength and Conditioning Research, vol. 24, no. 1, pp. 79-87, 2010.

[110] W. Chung, A. Baguet, T. Bex, D. J. Bishop, and W. Derave, "Doubling of muscle carnosine concentration does not improve laboratory 1-hr cycling time-trial performance," International Journal of Sport Nutrition and Exercise Metabolism, vol. 24, no. 3, pp. 315-324, 2014.

[111] P. M. Bellinger, " $\beta$-Alanine supplementation for athletic performance: an update," The Journal of Strength \& Conditioning Research, vol. 28, no. 6, pp. 1751-1770, 2014.

[112] V. de Salles Painelli, B. Saunders, C. Sale et al., "Influence of training status on high-intensity intermittent performance in response to $\beta$-Alanine supplementation," Amino Acids, vol. 46, no. 5, pp. 1207-1215, 2014.

[113] A. Baguet, H. Reyngoudt, A. Pottier et al., "Carnosine loading and washout in human skeletal muscles," Journal of Applied Physiology, vol. 106, no. 3, pp. 837-842, 2009.

[114] R. C. Harris, M. J. Tallon, M. Dunnett et al., "The absorption of orally supplied beta-alanine and its effect on muscle carnosine synthesis in human vastus lateralis," Amino Acids, vol. 30, no. 3, pp. 279-289, 2006.

[115] L. M. Burke, "Caffeine and sports performance," Applied Physiology, Nutrition, and Metabolism, vol. 33, no. 6, pp. 1319-1334, 2008.

[116] J. K. Davis and J. M. Green, "Caffeine and anaerobic performance: ergogenic value and mechanisms of action," Sports Medicine, vol. 39, no. 10, pp. 813-832, 2009.

[117] E. R. Goldstein, T. Ziegenfuss, D. Kalman et al., "International society of sports nutrition position stand: caffeine and performance," Journal of the International Society of Sports Nutrition, vol. 7, article 5, 2010.

[118] T. E. Graham, "Caffeine and exercise metabolism, endurance and performance," Sports Medicine, vol. 31, no. 11, pp. 785-807, 2001.

[119] K. J. Acheson, G. Gremaud, I. Meirim et al., "Metabolic effects of caffeine in humans: lipid oxidation or futile cycling?" The American Journal of Clinical Nutrition, vol. 79, no. 1, pp. 40-46, 2004.

[120] T. E. Graham, "Caffeine, coffee and ephedrine: Impact on exercise performance and metabolism," Canadian Journal of Applied Physiology, vol. 26, no. 6, supplement, pp. S103-S119, 2001.

[121] M. A. Tarnopolsky, "Effect of caffeine on the neuromuscular system-potential as an ergogenic aid," Applied Physiology, Nutrition and Metabolism, vol. 33, no. 6, pp. 1284-1289, 2008.

[122] D. Laurent, K. E. Schneider, W. K. Prusaczyk et al., "Effects of caffeine on muscle glycogen utilization and the neuroendocrine axis during exercise," Journal of Clinical Endocrinology and Metabolism, vol. 85, no. 6, pp. 2170-2175, 2000.

[123] M. Doherty and P. M. Smith, "Effects of caffeine ingestion on exercise testing: a meta-analysis," International Journal of Sport Nutrition and Exercise Metabolism, vol. 14, no. 6, pp. 626-646, 2004.

[124] M. S. Ganio, J. F. Klau, D. J. Casa, L. E. Armstrong, and C. M. Maresh, "Effect of caffeine on sport-specific endurance performance: a systematic review," Journal of Strength and Conditioning Research, vol. 23, no. 1, pp. 315-324, 2009.

[125] T. A. Astorino and D. W. Roberson, "Efficacy of acute caffeine ingestion for short-term high-intensity exercise performance: a systematic review," Journal of Strength and Conditioning Research, vol. 24, no. 1, pp. 257-265, 2010.
[126] G. L. Warren, N. D. Park, R. D. Maresca, K. I. McKibans, and M. L. Millard-Stafford, "Effect of caffeine ingestion on muscular strength and endurance: a meta-analysis," Medicine and Science in Sports and Exercise, vol. 42, no. 7, pp. 1375-1387, 2010.

[127] A. Pérez-López, J. J. Salinero, J. Abian-Vicen et al., "Caffeinated energy drinks improve volleyball performance in elite female players," Medicine \& Science in Sports \& Exercise, vol. 47, no. 4, pp. 850-856, 2015.

[128] T. Nicholson, G. Middleton, and T. I. Gee, "Does caffeine have an ergogenic effect on sports-specific agility in competitive male racquet sport players?" in Proceedings of the UKSCA 9th Annual Conference, Nottingham, UK, 2013.

[129] J. Abian-Vicen, C. Puente, J. J. Salinero et al., "A caffeinated energy drink improves jump performance in adolescent basketball players," Amino Acids, vol. 46, no. 5, pp. 1333-1341, 2014.

[130] B. Lara, C. Gonzalez-Millán, J. J. Salinero et al., "Caffeinecontaining energy drink improves physical performance in female soccer players," Amino Acids, vol. 46, no. 5, pp. 1385$1392,2014$.

[131] J. del Coso, J. Portillo, G. Muñoz, J. Abián-Vicén, C. GonzalezMillán, and J. Muñoz-Guerra, "Caffeine-containing energy drink improves sprint performance during an international rugby sevens competition," Amino Acids, vol. 44, no. 6, pp. 15111519, 2013.

[132] J. del Coso, J. A. Ramírez, G. Muñoz et al., "Caffeine-containing energy drink improves physical performance of elite rugby players during a simulated match," Applied Physiology, Nutrition and Metabolism, vol. 38, no. 4, pp. 368-374, 2013.

[133] S. C. Lane, J. L. Areta, S. R. Bird et al., "Caffeine ingestion and cycling power output in a low or normal muscle glycogen state," Medicine and Science in Sports and Exercise, vol. 45, no. 8, pp. 1577-1584, 2013.

[134] M. J. Duncan, C. D. Thake, and P. J. Downs, "Effect of caffeine ingestion on torque and muscle activity during resistance exercise in men," Muscle \& Nerve, vol. 50, no. 4, pp. 523-527, 2014.

[135] M. D. Silva-Cavalcante, C. R. Correia-Oliveira, R. A. Santos et al., "Caffeine increases anaerobic work and restores cycling performance following a protocol designed to lower endogenous carbohydrate availability," PLOS ONE, vol. 8, no. 8, Article ID e72025, 2013

[136] T. E. Graham, E. Hibbert, and P. Sathasivam, "Metabolic and exercise endurance effects of coffee and caffeine ingestion," Journal of Applied Physiology, vol. 85, no. 3, pp. 883-889, 1998.

[137] A. B. Hodgson, R. K. Randell, and A. E. Jeukendrup, "The metabolic and performance effects of caffeine compared to coffee during endurance exercise," PLoS ONE, vol. 8, no. 4, Article ID e59561, 2013.

[138] B. Sökmen, L. E. Armstrong, W. J. Kraemer et al., "Caffeine use in sports: considerations for the athlete," Journal of Strength and Conditioning Research, vol. 22, no. 3, pp. 978-986, 2008.

[139] K. Vandenberghe, N. Gillis, M. van Leemputte, P. van Hecke, F. Vanstapel, and P. Hespel, "Caffeine counteracts the ergogenic action of muscle creatine loading," Journal of Applied Physiology, vol. 80, no. 2, pp. 452-457, 1996.

[140] C. L. Camic, T. J. Housh, J. M. Zuniga et al., "The effects of polyethylene glycosylated creatine supplementation on anaerobic performance measures and body composition," The Journal of Strength \& Conditioning Research, vol. 28, no. 3, pp. 825-833, 2014.

[141] J. M. Zuniga, T. J. Housh, C. L. Camic et al., "The effects of creatine monohydrate loading on anaerobic performance and 
one-repetition maximum strength," Journal of Strength and Conditioning Research, vol. 26, no. 6, pp. 1651-1656, 2012.

[142] J. M. Oliver, D. P. Joubert, S. E. Martin, and S. F. Crouse, "Oral creatine supplementation's decrease of blood lactate during exhaustive, incremental cycling," International Journal of Sport Nutrition and Exercise Metabolism, vol. 23, no. 3, pp. 252-258, 2013.

[143] L. R. McNaughton, J. Siegler, and A. Midgley, "Ergogenic effects of sodium bicarbonate," Current Sports Medicine Reports, vol. 7, no. 4, pp. 230-236, 2008.

[144] B. Requena, M. Zabala, P. Padial, and B. Feriche, "Sodium bicarbonate and sodium citrate: ergogenic aids?" Journal of Strength and Conditioning Research, vol. 19, no. 1, pp. 213-224, 2005.

[145] S. P. Cairns, "Lactic acid and exercise performance: culprit or friend?” Sports Medicine, vol. 36, no. 4, pp. 279-291, 2006.

[146] R. A. Robergs, F. Ghiasvand, and D. Parker, "Biochemistry of exercise-induced metabolic acidosis," American Journal of Physiology: Regulatory Integrative and Comparative Physiology, vol. 287, no. 3, pp. R502-R516, 2004.

[147] D. G. Allen, G. D. Lamb, and H. Westerblad, "Skeletal muscle fatigue: cellular mechanisms," Physiological Reviews, vol. 88, no. 1, pp. 287-332, 2008.

[148] A. J. Carr, W. G. Hopkins, and C. J. Gore, "Effects of acute alkalosis and acidosis on performance: a meta-analysis," Sports Medicine, vol. 41, no. 10, pp. 801-814, 2011.

[149] L. G. Matson and Z. V. Tran, "Effects of sodium bicarbonate ingestion on anaerobic performance: a meta-analytic review," International Journal of Sport Nutrition, vol. 3, no. 1, pp. 2-28, 1993.

[150] D. Bishop, J. Edge, C. Davis, and C. Goodman, "Induced metabolic alkalosis affects muscle metabolism and repeatedsprint ability," Medicine and Science in Sports and Exercise, vol. 36, no. 5, pp. 807-813, 2004.

[151] M. G. Hollidge-Horvat, M. L. Parolin, D. Wong, N. L. Jones, and G. J. F. Heigenhauser, "Effect of induced metabolic alkalosis on human skeletal muscle metabolism during exercise," American Journal of Physiology: Endocrinology and Metabolism, vol. 278, no. 2, pp. E316-E329, 2000.

[152] S. A. Jubrias, G. J. Crowther, E. G. Shankland, R. K. Gronka, and K. E. Conley, "Acidosis inhibits oxidative phosphorylation in contracting human skeletal muscle in vivo," Journal of Physiology, vol. 553, no. 2, pp. 589-599, 2003.

[153] A. M. Hunter, G. de Vito, C. Bolger, H. Mullany, and S. D. R. Galloway, "The effect of induced alkalosis and submaximal cycling on neuromuscular response during sustained isometric contraction," Journal of Sports Sciences, vol. 27, no. 12, pp. 12611269, 2009.

[154] S. M. Mueller, S. M. Gehrig, S. Frese, C. A. Wagner, U. Boutellier, and M. Toigo, "Multiday acute sodium bicarbonate intake improves endurance capacity and reduces acidosis in men," Journal of the International Society of Sports Nutrition, vol. 10, no. 1, article 16, 2013.

[155] K. J. Ducker, B. Dawson, and K. E. Wallman, "Effect of beta alanine and sodium bicarbonate supplementation on repeatedsprint performance," Journal of Strength and Conditioning Research, vol. 27, no. 12, pp. 3450-3460, 2013.

[156] A. A. Mero, P. Hirvonen, J. Saarela, J. J. Hulmi, J. R. Hoffman, and J. R. Stout, "Effect of sodium bicarbonate and beta-alanine supplementation on maximal sprint swimming," Journal of the International Society of Sports Nutrition, vol. 10, no. 1, article 52, 2013.
[157] M. W. Driller, J. R. Gregory, A. D. Williams, and J. W. Fell, “The effects of chronic sodium bicarbonate ingestion and interval training in highly trained rowers," International Journal of Sport Nutrition and Exercise Metabolism, vol. 23, no. 1, pp. 40-47, 2013.

[158] J. Edge, D. Bishop, and C. Goodman, "Effects of chronic $\mathrm{NaHCO}_{3}$ ingestion during interval training on changes to muscle buffer capacity, metabolism, and short-term endurance performance," Journal of Applied Physiology, vol. 101, no. 3, pp. 918-925, 2006.

[159] D. C. McKenzie, K. D. Coutts, D. R. Stirling, H. H. Hoeben, and G. Kuzara, "Maximal work production following two levels of artificially induced metabolic alkalosis," Journal of sports sciences, vol. 4, no. 1, pp. 35-38, 1986.

[160] J. C. Siegler, P. W. M. Marshall, J. Bray, and C. Towlson, "Sodium bicarbonate supplementation and ingestion timing: does it matter?" The Journal of Strength \& Conditioning Research, vol. 26, no. 7, pp. 1953-1958, 2012.

[161] A. J. Carr, G. J. Slater, C. J. Gore, B. Dawson, and L. M. Burke, "Effect of sodium bicarbonate on [HCO3-], pH, and gastrointestinal symptoms," International Journal of Sport Nutrition and Exercise Metabolism, vol. 21, no. 3, pp. 189-194, 2011.

[162] L. M. Burke and D. B. Pyne, "Bicarbonate loading to enhance training and competitive performance," International Journal of Sports Physiology and Performance, vol. 2, no. 1, pp. 93-97, 2007.

[163] T. Buclin, M. Cosma, M. Appenzeller et al., "Diet acids and alkalis influence calcium retention in bone," Osteoporosis International, vol. 12, no. 6, pp. 493-499, 2001.

[164] I. Kurtz, T. Maher, H. N. Hulter, M. Schambelan, and A. Sebastian, "Effect of diet on plasma acid-base composition in normal humans," Kidney International, vol. 24, no. 5, pp. 670680, 1983.

[165] C. Demigné, H. Sabboh, C. Puel, C. Rémésy, and V. Coxam, "Organic anions and potassium salts in nutrition and metabolism," Nutrition Research Reviews, vol. 17, no. 2, pp. 249-258, 2004.

[166] L. A. Frassetto, K. M. Todd, R. C. Morris Jr., and A. Sebastian, "Estimation of net endogenous noncarbonic acid production in humans from diet potassium and protein contents," The American Journal of Clinical Nutrition, vol. 68, no. 3, pp. 576583, 1998.

[167] M. L. Halperin, "Metabolism and acid-base physiology," Artificial Organs, vol. 6, no. 4, pp. 357-362, 1982.

[168] T. Remer and F. Manz, "Potential renal acid load of foods and its influence on urine pH," Journal of the American Dietetic Association, vol. 95, no. 7, pp. 791-797, 1995.

[169] H. Boeing, A. Bechthold, A. Bub et al., "Critical review: vegetables and fruit in the prevention of chronic diseases," European Journal of Nutrition, vol. 51, no. 6, pp. 637-663, 2012.

[170] F. J. He and G. A. MacGregor, "Beneficial effects of potassium on human health," Physiologia Plantarum, vol. 133, no. 4, pp. 725$735,2008$.

[171] E.-M. Hietavala, J. R. Stout, J. J. Hulmi et al., "Effect of diet composition on acid-base balance in adolescents, young adults and elderly at rest and during exercise," European Journal of Clinical Nutrition, vol. 69, no. 3, pp. 399-404, 2014.

[172] M. van der Aa, "Classification of mineral water types and comparison with drinking water standards," Environmental Geology, vol. 44, no. 5, pp. 554-563, 2003.

[173] G. Paulsen, U. R. Mikkelsen, T. Raastad, and J. M. Peake, "Leucocytes, cytokines and satellite cells: what role do they play in muscle damage and regeneration following eccentric exercise?" Exercise Immunology Review, vol. 18, pp. 42-97, 2012. 
[174] J. L. Ziltener, S. Leal, and P. E. Fournier, "Non-steroidal antiinflammatory drugs for athletes: an update," Annals of Physical and Rehabilitation Medicine, vol. 53, no. 4, pp. 278-288, 2010.

[175] F. Bieuzen, C. M. Bleakley, and J. T. Costello, "Contrast water therapy and exercise induced muscle damage: a systematic review and meta-analysis," PLoS ONE, vol. 8, no. 4, Article ID e62356, 2013.

[176] G. Howatson, M. Hoad, S. Goodall, J. Tallent, P. G. Bell, and D. N. French, "Exercise-induced muscle damage is reduced in resistance-trained males by branched chain amino acids: a randomized, double-blind, placebo controlled study," Journal of the International Society of Sports Nutrition, vol. 9, article 20, 2012.

[177] C. D. Black, M. P. Herring, D. J. Hurley, and P. J. O'Connor, "Ginger (Zingiber officinale) reduces muscle pain caused by eccentric exercise," The Journal of Pain, vol. 11, no. 9, pp. 894903, 2010

[178] S. Chuengsamarn, S. Rattanamongkolgul, B. Phonrat, R. Tungtrongchitr, and S. Jirawatnotai, "Reduction of atherogenic risk in patients with type 2 diabetes by curcuminoid extract: a randomized controlled trial," Journal of Nutritional Biochemistry, vol. 25, no. 2, pp. 144-150, 2014.

[179] E. Ernst, T. Saradeth, and G. Achhammer, "n-3 fatty acids and acute-phase proteins," European Journal of Clinical Investigation, vol. 21, no. 1, pp. 77-82, 1991.

[180] D. A. J. Connolly, M. P. McHugh, and O. I. Padilla-Zakour, "Efficacy of a tart cherry juice blend in preventing the symptoms of muscle damage," British Journal of Sports Medicine, vol. 40, no. 8, pp. 679-683, 2006.

[181] P. G. Bell, I. H. Walshe, G. W. Davison, E. Stevenson, and G. Howatson, "Montmorency cherries reduce the oxidative stress and inflammatory responses to repeated days high-intensity stochastic cycling," Nutrients, vol. 6, no. 2, pp. 829-843, 2014.

[182] S. Bent, "Herbal medicine in the United States: review of efficacy, safety, and regulation-grand Rounds at University of California, San Francisco Medical Center," Journal of General Internal Medicine, vol. 23, no. 6, pp. 854-859, 2008.

[183] J. A. O. Ojewole, "Analgesic, antiinflammatory and hypoglycaemic effects of ethanol extract of Zingiber officinale (Roscoe) rhizomes (Zingiberaceae) in mice and rats," Phytotherapy Research, vol. 20, no. 9, pp. 764-772, 2006.

[184] H.-Y. Young, Y.-L. Luo, H.-Y. Cheng, W.-C. Hsieh, J.-C. Liao, and W.-H. Peng, "Analgesic and anti-inflammatory activities of [6]-gingerol," Journal of Ethnopharmacology, vol. 96, no. 1-2, pp. 207-210, 2005.

[185] W. G. Cho and J. G. Valtschanoff, "Vanilloid receptor TRPV1positive sensory afferents in the mouse ankle and knee joints," Brain Research, vol. 1219, pp. 59-65, 2008.

[186] D. A. Connolly, S. P. Sayers, and M. P. McHugh, "Treatment and prevention of delayed onset muscle soreness," The Journal of Strength \& Conditioning Research, vol. 17, no. 1, pp. 197-208, 2003.

[187] C. D. Black and P. J. O'Connor, "Acute effects of dietary ginger on quadriceps muscle pain during moderate-intensity cycling exercise," International Journal of Sport Nutrition and Exercise Metabolism, vol. 18, no. 6, pp. 653-664, 2008.

[188] B. B. Aggarwal, "Targeting lammation-induced obesity and metabolic diseases by curcumin and other nutraceuticals," Annual Review of Nutrition, vol. 30, pp. 173-199, 2010.

[189] S. C. Gupta, S. Patchva, W. Koh, and B. B. Aggarwal, "Discovery of curcumin, a component of golden spice, and its miraculous biological activities," Clinical and Experimental Pharmacology and Physiology, vol. 39, no. 3, pp. 283-299, 2012.

[190] F. Drobnic, J. Riera, G. Appendino et al., "Reduction of delayed onset muscle soreness by a novel curcumin delivery system (Meriva(R)): a randomised, placebo-controlled trial," Journal of the International Society of Sports Nutrition, vol. 11, no. 1, article 31, 2014.

[191] M. Takahashi, K. Suzuki, H. K. Kim et al., "Effects of curcumin supplementation on exercise-induced oxidative stress in humans," International Journal of Sports Medicine, vol. 35, no. 6, pp. 469-475, 2014.

[192] H. Sasaki, Y. Sunagawa, K. Takahashi et al., "Innovative preparation of curcumin for improved oral bioavailability," Biological and Pharmaceutical Bulletin, vol. 34, no. 5, pp. 660-665, 2011.

[193] M. B. Covington, “Omega-3 fatty acids," American Family Physician, vol. 70, no. 1, pp. 133-140, 2004.

[194] R. J. Bloomer, D. E. Larson, K. H. Fisher-Wellman, A. J. Galpin, and B. K. Schilling, "Effect of eicosapentaenoic and docosahexaenoic acid on resting and exercise-induced inflammatory and oxidative stress biomarkers: a randomized, placebo controlled, cross-over study," Lipids in Health and Disease, vol. 8, article 36, 2009.

[195] B. Tartibian, B. H. Maleki, and A. Abbasi, "The effects of ingestion of omega-3 fatty acids on perceived pain and external symptoms of delayed onset muscle soreness in untrained men," Clinical Journal of Sport Medicine, vol. 19, no. 2, pp. 115-119, 2009.

[196] K. B. Jouris, J. L. McDaniel, and E. P. Weiss, "The effect of omega-3 fatty acid supplementation on the inflammatory response to eccentric strength exercise," Journal of Sports Science and Medicine, vol. 10, no. 3, pp. 432-438, 2011.

[197] J. Lenn, T. Uhl, C. Mattacola et al., "The effects of fish oil and isoflavones on delayed onset muscle soreness," Medicine \& Science in Sports \& Exercise, vol. 34, no. 10, pp. 1605-1613, 2002.

[198] A. D. Toft, M. Thorn, K. Ostrowski et al., "N-3 polyunsaturated fatty acids do not affect cytokine response to strenuous exercise," Journal of Applied Physiology, vol. 89, no. 6, pp. 2401-2406, 2000.

[199] G. I. Smith, P. Atherton, D. N. Reeds et al., "Dietary omega3 fatty acid supplementation increases the rate of muscle protein synthesis in older adults: a randomized controlled trial," American Journal of Clinical Nutrition, vol. 93, no. 2, pp. 402412, 2011.

[200] A. P. Simopoulos, "Omega-3 fatty acids and athletics," Current Sports Medicine Reports, vol. 6, no. 4, pp. 230-236, 2007.

[201] U. S. Food and Drug Administration Center for Food Safety and Applied Nutrition, Agency Response Letter. GRAS Notice No. GRN 000105, 2002.

[202] P. G. Bell, M. P. Mchugh, E. Stevenson, and G. Howatson, "The role of cherries in exercise and health," Scandinavian Journal of Medicine and Science in Sports, vol. 24, no. 3, pp. 477-490, 2014.

[203] L. M. McCune, C. Kubota, N. R. Stendell-Hollis, and C. A. Thomson, "Cherries and health: a review," Critical Reviews in Food Science and Nutrition, vol. 51, no. 1, pp. 1-12, 2011.

[204] N. P. Seeram, R. A. Momin, M. G. Nair, and L. D. Bourquin, "Cyclooxygenase inhibitory and antioxidant cyanidin glycosides in cherries and berries," Phytomedicine, vol. 8, no. 5, pp. 362-369, 2001.

[205] J. L. Bowtell, D. P. Sumners, A. Dyer, P. Fox, and K. N. Mileva, "Montmorency cherry juice reduces muscle damage caused by intensive strength exercise," Medicine and Science in Sports and Exercise, vol. 43, no. 8, pp. 1544-1551, 2011. 
[206] G. Howatson, M. P. McHugh, J. A. Hill et al., "Influence of tart cherry juice on indices of recovery following marathon running," Scandinavian Journal of Medicine and Science in Sports, vol. 20, no. 6, pp. 843-852, 2010.

[207] K. S. Kuehl, E. T. Perrier, D. L. Elliot, and J. C. Chesnutt, "Efficacy of tart cherry juice in reducing muscle pain during running: a randomized controlled trial," Journal of the International Society of Sports Nutrition, vol. 7, article 17, 2010.

[208] D. S. Kelley, Y. Adkins, A. Reddy, L. R. Woodhouse, B. E. Mackey, and K. L. Erickson, "Sweet bing cherries lower circulating concentrations of markers for chronic inflammatory diseases in healthy humans," The Journal of Nutrition, vol. 143, no. 3, pp. 340-344, 2013.

[209] D. S. Kelley, R. Rasooly, R. A. Jacob, A. A. Kader, and B. E. Mackey, "Consumption of bing sweet cherries lowers circulating concentrations of inflammation markers in healthy men and women," Journal of Nutrition, vol. 136, no. 4, pp. 981-986, 2006.

[210] S. K. Powers, J. Duarte, A. N. Kavazis, and E. E. Talbert, "Reactive oxygen species are signalling molecules for skeletal muscle adaptation," Experimental Physiology, vol. 95, no. 1, pp. $1-9,2010$.

[211] K. Fisher-Wellman and R. J. Bloomer, "Acute exercise and oxidative stress: a 30 year history," Dynamic Medicine, vol. 8, article 1, 2009.

[212] B. J. Schoenfeld, "The use of nonsteroidal anti-inflammatory drugs for exercise-induced muscle damage: implications for skeletal muscle development," Sports Medicine, vol. 42, no. 12, pp. 1017-1028, 2012.

[213] S. J. Warden, "Prophylactic use of NSAIDs by athletes: a risk/benefit assessment," Physician and Sportsmedicine, vol. 38, no. 1, pp. 132-138, 2010.

[214] M. J. Ormsbee, J. Lox, and P. J. Arciero, "Beetroot juice and exercise performance," Nutrition and Dietary Supplements, vol. 5, pp. 27-35, 2013.

[215] "Nutrition business journal's supplement business report," Nutrition Business Journal, vol. 3, p. 28, 2010.

[216] K. E. Lansley, P. G. Winyard, S. J. Bailey et al., "Acute dietary nitrate supplementation improves cycling time trial performance," Medicine and Science in Sports and Exercise, vol. 43, no. 6, pp. 1125-1131, 2011.

[217] K. E. Lansley, P. G. Winyard, J. Fulford et al., "Dietary nitrate supplementation reduces the $\mathrm{O}_{2}$ cost of walking and running: a placebo-controlled study," Journal of Applied Physiology, vol. 110, no. 3, pp. 591-600, 2011.

[218] S. J. Bailey, P. Winyard, A. Vanhatalo et al., "Dietary nitrate supplementation reduces the $\mathrm{O}_{2}$ cost of low-intensity exercise and enhances tolerance to high-intensity exercise in humans," Journal of Applied Physiology, vol. 107, no. 4, pp. 1144-1155, 2009.

[219] A. Vanhatalo, S. J. Bailey, J. R. Blackwell et al., "Acute and chronic effects of dietary nitrate supplementation on blood pressure and the physiological responses to moderate-intensity and incremental exercise," American Journal of PhysiologyRegulatory Integrative and Comparative Physiology, vol. 299, no. 4, pp. R1121-R1131, 2010.

[220] N. G. Hord, Y. Tang, and N. S. Bryan, "Food sources of nitrates and nitrites: the physiologic context for potential health benefits," The American Journal of Clinical Nutrition, vol. 90, no. 1, pp. 1-10, 2009.

[221] F. J. Larsen, T. A. Schiffer, S. Borniquel et al., "Dietary inorganic nitrate improves mitochondrial efficiency in humans," Cell Metabolism, vol. 13, no. 2, pp. 149-159, 2011.
[222] A. J. Webb, N. Patel, S. Loukogeorgakis et al., "Acute blood pressure lowering, vasoprotective, and antiplatelet properties of dietary nitrate via bioconversion to nitrite," Hypertension, vol. 51, no. 3, pp. 784-790, 2008.

[223] R. C. Hickner, J. S. Fisher, A. A. Ehsani, and W. M. Kohrt, "Role of nitric oxide in skeletal muscle blood flow at rest and during dynamic exercise in humans," American Journal of PhysiologyHeart and Circulatory Physiology, vol. 273, no. 1, part 2, pp. H405-H410, 1997.

[224] D. M. Gilligan, J. A. Panza, C. M. Kilcoyne, M. A. Waclawiw, P. R. Casino, and A. A. Quyyumi, "Contribution of endotheliumderived nitric oxide to exercise-induced vasodilation," Circulation, vol. 90, no. 6, pp. 2853-2858, 1994.

[225] S. J. Bailey, J. Fulford, A. Vanhatalo et al., "Dietary nitrate supplementation enhances muscle contractile efficiency during knee-extensor exercise in humans," Journal of Applied Physiology, vol. 109, no. 1, pp. 135-148, 2010.

[226] M. Murphy, K. Eliot, R. M. Heuertz, and E. Weiss, "Whole beetroot consumption acutely improves running performance," Journal of the Academy of Nutrition and Dietetics, vol. 112, no. 4, pp. 548-552, 2012.

[227] J. Kelly, A. Vanhatalo, D. P. Wilkerson, L. J. Wylie, and A. M. Jones, "Effects of nitrate on the power-duration relationship for severe-intensity exercise," Medicine and Science in Sports and Exercise, vol. 45, no. 9, pp. 1798-1806, 2013.

[228] D. J. Muggeridge, C. C. F. Howe, O. Spendiff, C. Pedlar, P. E. James, and C. Easton, "A single dose of beetroot juice enhances cycling performance in simulated altitude," Medicine and Science in Sports and Exercise, vol. 46, no. 1, pp. 143-150, 2014.

[229] L. J. Wylie, J. Kelly, S. J. Bailey et al., "Beetroot juice and exercise: pharmacodynamic and dose-response relationships," Journal of Applied Physiology, vol. 115, no. 3, pp. 325-336, 2013.

[230] P. M. Christensen, M. Nyberg, and J. Bangsbo, "Influence of nitrate supplementation on $\mathrm{VO}_{2}$ kinetics and endurance of elite cyclists," Scandinavian Journal of Medicine \& Science in Sports, vol. 23, no. 1, pp. e21-e31, 2013.

[231] A. A. Kenjale, K. L. Ham, T. Stabler et al., "Dietary nitrate supplementation enhances exercise performance in peripheral arterial disease," Journal of Applied Physiology, vol. 110, no. 6, pp. 1582-1591, 2011.

[232] H. K. Stadheim, B. Kvamme, R. Olsen, C. A. Drevon, J. L. Ivy, and J. Jensen, "Caffeine increases performance in crosscountry double-poling time trial exercise," Medicine and Science in Sports and Exercise, vol. 45, no. 11, pp. 2175-2183, 2013.

[233] A. L. Spence, M. Sim, G. Landers, and P. Peeling, "A comparison of caffeine versus pseudoephedrine on cycling time-trial performance," International Journal of Sport Nutrition and Exercise Metabolism, vol. 23, no. 5, pp. 507-512, 2013.

[234] N. W. Pitchford, J. W. Fell, M. D. Leveritt, B. Desbrow, and C. M. Shing, "Effect of caffeine on cycling time-trial performance in the heat," Journal of Science and Medicine in Sport, vol. 17, no. 4, pp. 445-449, 2014.

[235] G. L. Dohm, "Protein as a fuel for endurance exercise," Exercise and Sport Sciences Reviews, vol. 14, pp. 143-173, 1986.

[236] J. P. Flatt, "Use and storage of carbohydrate and fat," The American Journal of Clinical Nutrition, vol. 61, no. 4, supplement, pp. 952S-959S, 1995.

[237] R. K. Conlee, "Muscle glycogen and exercise endurance: a twenty-year perspective," Exercise and Sport Sciences Reviews, vol. 15, pp. 1-28, 1987. 
[238] A. D. Karelis, J. E. W. Smith, D. H. Passe, and F. Pronnet, "Carbohydrate administration and exercise performance: what are the potential mechanisms involved?" Sports Medicine, vol. 40, no. 9, pp. 747-763, 2010.

[239] N. Ørtenblad, H. Westerblad, and J. Nielsen, "Muscle glycogen stores and fatigue," The Journal of Physiology, vol. 591, no. 18, pp. 4405-4413, 2013.

[240] A. M. Prentice, "Manipulation of dietary fat and energy density and subsequent effects on substrate flux and food intake," The American Journal of Clinical Nutrition, vol. 67, no. 3, supplement, pp. 535S-541S, 1998.

[241] L. S. Sidossis, C. A. Stuart, G. I. Shulman, G. D. Lopaschuk, and R. R. Wolfe, "Glucose plus insulin regulate fat oxidation by controlling the rate of fatty acid entry into the mitochondria," Journal of Clinical Investigation, vol. 98, no. 10, pp. 2244-2250, 1996.

[242] B. B. Rasmussen, U. C. Holmbäck, E. Volpi, B. Morio-Liondore, D. Paddon-Jones, and R. R. Wolfe, "Malonyl coenzyme A and the regulation of functional carnitine palmitoyltransferase-1 activity and fat oxidation in human skeletal muscle," The Journal of Clinical Investigation, vol. 110, no. 11, pp. 1687-1693, 2002.

[243] V. A. Zammit, "The malonyl-CoA-long-chain acyl-CoA axis in the maintenance of mammalian cell function," Biochemical Journal, vol. 343, no. 3, pp. 505-515, 1999.

[244] L. A. Witters and B. E. Kemp, "Insulin activation of acetyl-CoA carboxylase accompanied by inhibition of the 5'-AMP-activated protein kinase," The Journal of Biological Chemistry, vol. 267, no. 5, pp. 2864-2867, 1992.

[245] J. Denis McGarry, "Dysregulation of fatty acid metabolism in the etiology of type 2 diabetes," Diabetes, vol. 51, no. 1, pp. 7-18, 2002.

[246] D. Cameron-Smith, L. M. Burke, D. J. Angus et al., "A shortterm, high-fat diet up-regulates lipid metabolism and gene expression in human skeletal muscle," The American Journal of Clinical Nutrition, vol. 77, no. 2, pp. 313-318, 2003.

[247] M. J. Arkinstall, R. J. Tunstall, D. Cameron-Smith, and J. A. Hawley, "Regulation of metabolic genes in human skeletal muscle by short-term exercise and diet manipulation," The American Journal of Physiology-Endocrinology and Metabolism, vol. 287, no. 1, pp. E25-E31, 2004.

[248] A. E. Civitarese, M. K. C. Hesselink, A. P. Russell, E. Ravussin, and P. Schrauwen, "Glucose ingestion during exercise blunts exercise-induced gene expression of skeletal muscle fat oxidative genes," The American Journal of Physiology - Endocrinology and Metabolism, vol. 289, no. 6, pp. E1023-E1029, 2005.

[249] N. A. Johnson, S. R. Stannard, K. Mehalski et al., "Intramyocellular triacylglycerol in prolonged cycling with high- and lowcarbohydrate availability," Journal of Applied Physiology, vol. 94, no. 4, pp. 1365-1372, 2003.

[250] M. Vogt, A. Puntschart, H. Howald et al., "Effects of dietary fat on muscle substrates, metabolism, and performance in athletes," Medicine and Science in Sports and Exercise, vol. 35, no. 6, pp. 952-960, 2003.

[251] T. W. Zderic, C. J. Davidson, S. Schenk, L. O. Byerley, and E. F. Coyle, "High-fat diet elevates resting intramuscular triglyceride concentration and whole body lipolysis during exercise," American Journal of Physiology-Endocrinology and Metabolism, vol. 286, no. 2, pp. E217-E225, 2004.

[252] J. W. Helge, B. Wulff, and B. Kiens, "Impact of a fat-rich diet on endurance in man: role of the dietary period," Medicine and Science in Sports and Exercise, vol. 30, no. 3, pp. 456-461, 1998.
[253] M. J. Ormsbee, C. W. Bach, and D. A. Baur, "Pre-exercise nutrition: the role of macronutrients, modified starches and supplements on metabolism and endurance performance," Nutrients, vol. 6, no. 5, pp. 1782-1808, 2014.

[254] J. Temesi, N. A. Johnson, J. Raymond, C. A. Burdon, and H. T. O'Connor, "Carbohydrate ingestion during endurance exercise improves performance in adults," Journal of Nutrition, vol. 141, no. 5, pp. 890-897, 2011.

[255] T. J. Vandenbogaerde and W. G. Hopkins, "Effects of acute carbohydrate supplementation on endurance performance: A meta-analysis," Sports Medicine, vol. 41, no. 9, pp. 773-792, 2011.

[256] L. M. Burke, D. J. Angus, G. R. Cox et al., "Effect of fat adaptation and carbohydrate restoration on metabolism and performance during prolonged cycling," Journal of Applied Physiology, vol. 89, no. 6, pp. 2413-2421, 2000.

[257] J. Fleming, M. J. Sharman, N. G. Avery et al., "Endurance capacity and high-intensity exercise performance responses to a high fat diet," International Journal of Sport Nutrition and Exercise Metabolism, vol. 13, no. 4, pp. 466-478, 2003.

[258] J. H. Goedecke, C. Christie, G. Wilson et al., "Metabolic adaptations to a high-fat diet in endurance cyclists," Metabolism: Clinical and Experimental, vol. 48, no. 12, pp. 1509-1517, 1999.

[259] E. V. Lambert, D. P. Speechly, S. C. Dennis, and T. D. Noakes, "Enhanced endurance in trained cyclists during moderate intensity exercise following 2 weeks adaptation to a high fat diet," European Journal of Applied Physiology and Occupational Physiology, vol. 69, no. 4, pp. 287-293, 1994.

[260] D. M. Muoio, J. J. Leddy, P. J. Horvath, A. B. Awad, and D. R. Pendergast, "Effect of dietary fat on metabolic adjustments to maximal $\mathrm{VO}_{2}$ and endurance in runners," Medicine \& Science in Sports \& Exercise, vol. 26, no. 1, pp. 81-88, 1994.

[261] K. A. O'Keeffe, R. E. Keith, G. D. Wilson, and D. L. Blessing, "Dietary carbohydrate intake and endurance exercise performance of trained female cyclists," Nutrition Research, vol. 9, no. 8, pp. 819-830, 1989.

[262] S. D. Phinney, B. R. Bistrian, W. J. Evans, E. Gervino, and G. L. Blackburn, "The human metabolic response to chronic ketosis without caloric restriction: preservation of submaximal exercise capability with reduced carbohydrate oxidation," Metabolism, vol. 32, no. 8, pp. 769-776, 1983.

[263] S. D. Phinney, E. S. Horton, E. A. H. Sims, J. S. Hanson, E. Danforth Jr., and B. M. LaGrange, "Capacity for moderate exercise in obese subjects after adaptation to a hypocaloric, ketogenic diet," The Journal of Clinical Investigation, vol. 66, no. 5, pp. 1152-1161, 1980.

[264] A. L. Robins, D. M. Davies, and G. E. Jones, "The effect of nutritional manipulation on ultra-endurance performance: a case study," Research in Sports Medicine, vol. 13, no. 3, pp. 199215, 2005.

[265] D. S. Rowlands and W. G. Hopkins, "Effects of high-fat and high-carbohydrate diets on metabolism and performance in cycling," Metabolism: Clinical and Experimental, vol. 51, no. 6, pp. 678-690, 2002.

[266] N. K. Stepto, A. L. Carey, H. M. Staudacher, N. K. Cummings, L. M. Burke, and J. A. Hawley, "Effect of short-term fat adaptation on high-intensity training," Medicine \& Science in Sports \& Exercise, vol. 34, no. 3, pp. 449-455, 2002.

[267] J. L. Walberg, V. K. Ruiz, S. L. Tarlton, D. E. Hinkle, and R. W. Thye, "Exercise capacity and nitrogen loss during a high or low carbohydrate diet," Medicine and Science in Sports and Exercise, vol. 20, no. 1, pp. 34-43, 1988. 
[268] M. Erlenbusch, M. Haub, K. Munoz, S. MacConnie, and B. Stillwell, "Effect of high-fat or high-carbohydrate diets on endurance exercise: a meta-analysis," International Journal of Sport Nutrition and Exercise Metabolism, vol. 15, no. 1, pp. 1-14, 2005.

[269] E. Hultman and J. Bergström, "Muscle glycogen synthesis in relation to diet studied in normal subjects.," Acta Medica Scandinavica, vol. 182, no. 1, pp. 109-117, 1967.

[270] J. D. Symons and I. Jacobs, "High-intensity exercise performance is not impaired by low intramuscular glycogen," Medicine and Science in Sports and Exercise, vol. 21, no. 5, pp. 550-557, 1989.

[271] A. Paoli, K. Grimaldi, D. D’Agostino et al., "Ketogenic diet does not affect strength performance in elite artistic gymnasts," Journal of the International Society of Sports Nutrition, vol. 9, no. 1, article 34, 2012.

[272] J. C. Sawyer, R. J. Wood, P. W. Davidson et al., "Effects of a short-term carbohydrate restricted diet on strength and power performance," The Journal of Strength \& Conditioning Research, vol. 27, no. 8, pp. 2255-2262, 2013.

[273] L. M. Burke, "Fueling strategies to optimize performance: training high or training low?" Scandinavian Journal of Medicine and Science in Sports, vol. 20, supplement 2, pp. 48-58, 2010.

[274] L. M. Burke and J. A. Hawley, "Effects of short-term fat adaptation on metabolism and performance of prolonged exercise," Medicine and Science in Sports and Exercise, vol. 34, no. 9, pp. 1492-1498, 2002.

[275] J. S. Volek and S. D. Phinney, The Art and Science of Low Carbohydrate Performance. A Revolutionary Program to Extend Your Physical and Mental Performance Envelope, Beyond Obesity LLC, Miami, Fla, USA, 2012.

[276] L. M. Burke and B. Kiens, "Fat adaptation' for athletic performance: the nail in the coffin?" Journal of Applied Physiology, vol. 100, no. 1, pp. 7-8, 2006.

[277] J. W. Helge, "Adaptation to a fat-rich diet: effects on endurance performance in humans," Sports Medicine, vol. 30, no. 5, pp. 347-357, 2000.

[278] J. W. Helge, "Long-term fat diet adaptation effects on performance, training capacity, and fat utilization," Medicine \& Science in Sports \& Exercise, vol. 34, no. 9, pp. 1499-1504, 2002.

[279] C. D. Gardner, A. Kiazand, S. Alhassan et al., "Comparison of the Atkins, Zone, Ornish, and LEARN diets for change in weight and related risk factors among overweight premenopausal women: the $\mathrm{A}$ to $\mathrm{Z}$ weight loss study: a randomized trial," Journal of the American Medical Association, vol. 297, no. 9, pp. 969-977, 2007.

[280] S. S. Summer, B. J. Brehm, S. C. Benoit, and D. A. D’Alessio, "Adiponectin changes in relation to the macronutrient composition of a weight-loss diet," Obesity, vol. 19, no. 11, pp. 21982204, 2011.

[281] P. T. Jabekk, I. A. Moe, S. E. Tomten, and A. T. Høstmark, "Resistance training in overweight women on a ketogenic diet conserved lean body mass while reducing body fat," Nutrition and Metabolism, vol. 7, article 17, 2010.

[282] D. K. Layman, E. Evans, J. I. Baum, J. Seyler, D. J. Erickson, and R. A. Boileau, "Dietary protein and exercise have additive effects on body composition during weight loss in adult women," Journal of Nutrition, vol. 135, no. 8, pp. 1903-1910, 2005.

[283] J. S. Volek, E. E. Quann, and C. E. Forsythe, "Low-carbohydrate diets promote a more favorable body composition than low-fat diets," Strength and Conditioning Journal, vol. 32, no. 1, pp. 4247, 2010.
[284] O. Ajala, P. English, and J. Pinkney, "Systematic review and meta-analysis of different dietary approaches to the management of type 2 diabetes," American Journal of Clinical Nutrition, vol. 97, no. 3, pp. 505-516, 2013.

[285] R. D. Feinman and J. S. Volek, "Carbohydrate restriction as the default treatment for type 2 diabetes and metabolic syndrome," Scandinavian Cardiovascular Journal, vol. 42, no. 4, pp. 256263, 2008.

[286] T. Hu, K. T. Mills, L. Yao et al., "Effects of low-carbohydrate diets versus low-fat diets on metabolic risk factors: a meta-analysis of randomized controlled clinical trials," American Journal of Epidemiology, vol. 176, supplement 7, pp. S44-S54, 2012.

[287] A. J. Nordmann, A. Nordmann, M. Briel et al., "Effects of lowcarbohydrate vs low-fat diets on weight loss and cardiovascular risk factors: a meta-analysis of randomized controlled trials," Archives of Internal Medicine, vol. 166, no. 3, pp. 285-293, 2006.

[288] F. L. Santos, S. S. Esteves, A. D. C. Pereira, W. S. Yancy Jr., and J. P. L. Nunes, "Systematic review and meta-analysis of clinical trials of the effects of low carbohydrate diets on cardiovascular risk factors," Obesity Reviews, vol. 13, no. 11, pp. 1048-1066, 2012.

[289] J. S. Volek and R. D. Feinman, "Carbohydrate restriction improves the features of Metabolic Syndrome. Metabolic Syndrome may be defined by the response to carbohydrate restriction," Nutrition and Metabolism, vol. 2, article 31, pp. 1-17, 2005.

[290] J. Guo, X. Zhang, L. Wang, Y. Guo, and M. Xie, "Prevalence of metabolic syndrome and its components among Chinese professional athletes of strength sports with different body weight categories," PLoS ONE, vol. 8, no. 11, Article ID e79758, 2013.

[291] G. D. Steffes, A. E. Megura, J. Adams et al., "Prevalence of metabolic syndrome risk factors in high school and NCAA division I football players," Journal of Strength \& Conditioning Research, vol. 27, no. 7, pp. 1749-1757, 2013.

[292] K. Baar and S. McGee, "Optimizing training adaptations by manipulating glycogen," European Journal of Sport Science, vol. 8, no. 2, pp. 97-106, 2008.

[293] J. A. Hawley, K. D. Tipton, and M. L. Millard-Stafford, "Promoting training adaptations through nutritional interventions," Journal of Sports Sciences, vol. 24, no. 7, pp. 709-721, 2006.

[294] S. D. Phinney, "Ketogenic diets and physical performance," Nutrition and Metabolism, vol. 1, article 2, 2004.

[295] S. D. Phinney, B. R. Bistrian, R. R. Wolfe, and G. L. Blackburn, "The human metabolic response to chronic ketosis without caloric restriction: physical and biochemical adaptation," Metabolism, vol. 32, no. 8, pp. 757-768, 1983.

[296] W. K. Yeo, A. L. Carey, L. Burke, L. L. Spriet, and J. A. Hawley, "Fat adaptation in well-trained athletes: effects on cell metabolism," Applied Physiology, Nutrition \& Metabolism, vol. 36, no. 1, pp. 12-22, 2011.

[297] American College of Sports Medicine, M. N. Sawka, L. M. Burke et al., "American College of Sports Medicine position stand. Exercise and fluid replacement," Medicine \& Science in Sport \& Exercise, vol. 39, no. 2, pp. 377-390, 2007.

[298] M. R. Naghii, "The significance of water in sport and weight control," Nutrition and Health, vol. 14, no. 2, pp. 127-132, 2000.

[299] S. K. Powers, J. Lawler, S. Dodd, R. Tulley, G. Landry, and $\mathrm{K}$. Wheeler, "Fluid replacement drinks during high intensity exercise effects on minimizing exercise-induced disturbances in homeostasis," European Journal of Applied Physiology and Occupational Physiology, vol. 60, no. 1, pp. 54-60, 1990.

[300] E. F. Coyle, "Fluid and fuel intake during exercise," Journal of Sports Sciences, vol. 22, no. 1, pp. 39-55, 2004. 
[301] S. P. von Duvillard, W. A. Braun, M. Markofski, R. Beneke, and R. Leithäuser, "Fluids and hydration in prolonged endurance performance," Nutrition, vol. 20, no. 7-8, pp. 651-656, 2004.

[302] T. D. Noakes, "Drinking guidelines for exercise: what evidence is there that athletes should drink 'as much as tolerable', 'to replace the weight lost during exercise' or 'ad libitum'?" Journal of Sports Sciences, vol. 25, no. 7, pp. 781-796, 2007.

[303] B. Sanders, T. D. Noakes, and S. C. Dennis, "Sodium replacement and fluid shifts during prolonged exercise in humans," European Journal of Applied Physiology, vol. 84, no. 5, pp. 419425, 2001.

[304] D. Bernardot, Advanced Sports Nutrition, Human Kinetics, Champaign, Ill, USA, 2006.

[305] S. M. Shirreffs, L. E. Armstrong, and S. N. Cheuvront, "Fluid and electrolyte needs for preparation and recovery from training and competition," Journal of Sports Sciences, vol. 22, no. 1, pp. 57-63, 2004.

[306] S. D. R. Galloway and R. J. Maughan, "The effects of substrate and fluid provision on thermoregulatory, cardiorespiratory and metabolic responses to prolonged exercise in a cold environment in man," Experimental Physiology, vol. 83, no. 3, pp. 419430, 1998.

[307] S. A. Kavouras, L. E. Armstrong, C. M. Maresh et al., "Rehydration with glycerol: endocrine, cardiovascular, and thermoregulatory responses during exercise in the heat," Journal of Applied Physiology, vol. 100, no. 2, pp. 442-450, 2006.

[308] J. L. J. Bilzon, J. L. Murphy, A. J. Allsopp, S. A. Wootton, and C. Williams, "Influence of glucose ingestion by humans during recovery from exercise on substrate utilisation during subsequent exercise in a warm environment," European Journal of Applied Physiology, vol. 87, no. 4-5, pp. 318-326, 2002.

[309] D. M. J. Vrijens and N. J. Rehrer, "Sodium-free fluid ingestion decreases plasma sodium during exercise in the heat," Journal of Applied Physiology, vol. 86, no. 6, pp. 1847-1851, 1999.

[310] R. J. Maughan, L. R. Bethell, and J. B. Leiper, "Effects of ingested fluids on exercise capacity and on cardiovascular and metabolic responses to prolonged exercise in man," Experimental Physiology, vol. 81, no. 5, pp. 847-859, 1996.

[311] J. L. Azevedo Jr., E. Tietz, T. Two-Feathers, J. Paull, and K. Chapman, "Lactate, fructose and glucose oxidation profiles in sports drinks and the effect on exercise performance," PLoS ONE, vol. 2, no. 9, article e927, 2007.

[312] M. J. Anderson, J. D. Cotter, A. P. Garnham, D. J. Casley, and M. A. Febbraio, "Effect of glycerol-induced hyperhydration on thermoregulation and metabolism during exercise in the heat," International Journal of Sport Nutrition, vol. 11, no. 3, pp. 315333, 2001.

[313] S. Hitchins, D. T. Martin, L. Burke et al., "Glycerol hyperhydration improves cycle time trial performance in hot humid conditions," European Journal of Applied Physiology and Occupational Physiology, vol. 80, no. 5, pp. 494-501, 1999.

[314] W. A. Latzka, M. N. Sawka, S. J. Montain et al., "Hyperhydration: thermoregulatory effects during compensable exercise-heat stress," Journal of Applied Physiology, vol. 83, no. 3, pp. 860-866, 1997.

[315] W. A. Latzka, M. N. Sawka, S. J. Montain et al., "Hyperhydration: tolerance and cardiovascular effects during uncompensable exercise-heat stress," Journal of Applied Physiology, vol. 84, no. 6, pp. 1858-1864, 1998.

[316] F. E. Marino, D. Kay, and J. Cannon, "Glycerol hyperhydration fails to improve endurance performance and thermoregulation in humans in a warm humid environment," Pflugers Archiv, vol. 446, no. 4, pp. 455-462, 2003.

[317] R. W. Kenefick, C. M. Maresh, L. E. Armstrong, D. Riebe, M. E. Echegaray, and J. W. Castellani, "Rehydration with fluid of varying tonicities: effects on fluid regulatory hormones and exercise performance in the heat," Journal of Applied Physiology, vol. 102, no. 5, pp. 1899-1905, 2007.

[318] N. M. Cermak and L. J. C. van Loon, "The use of carbohydrates during exercise as an ergogenic aid," Sports Medicine, vol. 43, no. 11, pp. 1139-1155, 2013.

[319] R. F. Tester, J. Karkalas, and X. Qi, "Starch-composition, fine structure and architecture," Journal of Cereal Science, vol. 39, no. 2, pp. 151-165, 2004.

[320] F. Stephens, M. Roig, G. Armstrong, and P. L. Greenhaff, "Postexercise ingestion of a unique, high molecular weight glucose polymer solution improves performance during a subsequent bout of cycling exercise," Journal of Sports Sciences, vol. 26, no. 2, pp. 149-154, 2008.

[321] A. C. Jozsi, T. A. Trappe, R. D. Starling et al., “The influence of starch structure on glycogen resynthesis and subsequent cycling performance," International Journal of Sports Medicine, vol. 17, no. 5, pp. 373-378, 1996.

[322] M. D. Roberts, C. Lockwood, V. J. Dalbo, J. Volek, and C. M. Kerksick, "Ingestion of a high-molecular-weight hydrothermally modified waxy maize starch alters metabolic responses to prolonged exercise in trained cyclists," Nutrition, vol. 27, no. 6, pp. 659-665, 2011.

[323] R. Hursel, W. Viechtbauer, A. G. Dulloo et al., "The effects of catechin rich teas and caffeine on energy expenditure and fat oxidation: a meta-analysis," Obesity Reviews, vol. 12, no. 7, pp. e573-e581, 2011.

[324] P. J. Arciero, A. W. Gardner, J. Calles-Escandon, N. L. Benowitz, and E. T. Poehlman, "Effects of caffeine ingestion on NE kinetics, fat oxidation, and energy expenditure in younger and older men," The American Journal of Physiology - Endocrinology and Metabolism, vol. 268, no. 6, pp. E1192-E1198, 1995.

[325] P. J. Arciero, C. L. Bougopoulos, B. C. Nindl, and N. L. Benowitz, "Influence of age on the thermic response to caffeine in women," Metabolism: Clinical and Experimental, vol. 49, no. 1, pp. 101-107, 2000.

[326] P. B. Júdice, J. P. Magalhães, D. A. Santos et al., "A moderate dose of caffeine ingestion does not change energy expenditure but decreases sleep time in physically active males: a double-blind randomized controlled trial," Applied Physiology, Nutrition and Metabolism, vol. 38, no. 1, pp. 49-56, 2013.

[327] P. B. Júdice, C. N. Matias, D. A. Santos et al., "Caffeine intake, short bouts of physical activity, and energy expenditure: a double-blind randomized crossover trial," PLoS ONE, vol. 8, no. 7, Article ID e68936, 2013.

[328] R. Hursel and M. S. Westerterp-Plantenga, "Thermogenic ingredients and body weight regulation," International Journal of Obesity, vol. 34, no. 4, pp. 659-669, 2010.

[329] M. J. Ludy and R. D. Mattes, "The effects of hedonically acceptable red pepper doses on thermogenesis and appetite," Physiology and Behavior, vol. 102, no. 3-4, pp. 251-258, 2011.

[330] K. Lim, M. Yoshioka, S. Kikuzato et al., "Dietary red pepper ingestion increases carbohydrate oxidation at rest and during exercise in runners," Medicine and Science in Sports and Exercise, vol. 29, no. 3, pp. 355-361, 1997.

[331] M. Yoshioka, S. St-Pierre, V. Drapeau et al., "Effects of red pepper on appetite and energy intake," British Journal of Nutrition, vol. 82, no. 2, pp. 115-123, 1999. 
[332] M. Yoshioka, M. Imanaga, H. Ueyama et al., "Maximum tolerable dose of red pepper decreases fat intake independently of spicy sensation in the mouth," British Journal of Nutrition, vol. 91, no. 6, pp. 991-995, 2004.

[333] T. Matsumoto, C. Miyawaki, H. Ue, T. Yuasa, A. Miyatsuji, and T. Moritani, "Effects of capsaicin-containing yellow curry sauce on sympathetic nervous system activity and diet-induced thermogenesis in lean and obese young women," Journal of Nutritional Science and Vitaminology, vol. 46, no. 6, pp. 309$315,2000$.

[334] S. Hachiya, F. Kawabata, K. Ohnuki et al., "Effects of CH-19 Sweet, a non-pungent cultivar of red pepper, on sympathetic nervous activity, body temperature, heart rate, and blood pressure in humans," Bioscience, Biotechnology and Biochemistry, vol. 71, no. 3, pp. 671-676, 2007.

[335] M. Yoshioka, S. St-Pierre, M. Suzuki, and A. Tremblay, "Effects of red pepper added to high-fat and high-carbohydrate meals on energy metabolism and substrate utilization in Japanese women," British Journal of Nutrition, vol. 80, no. 6, pp. 503-510, 1998.

[336] M. P. G. M. Lejeune, E. M. R. Kovacs, and M. S. WesterterpPlantenga, "Effect of capsaicin on substrate oxidation and weight maintenance after modest body-weight loss in human subjects," British Journal of Nutrition, vol. 90, no. 3, pp. 651-659, 2003.

[337] T. Yoneshiro, S. Aita, Y. Kawai, T. Iwanaga, and M. Saito, "Nonpungent capsaicin analogs (capsinoids) increase energy expenditure through the activation of brown adipose tissue in humans," The American Journal of Clinical Nutrition, vol. 95, no. 4, pp. 845-850, 2012.

[338] S. Snitker, Y. Fujishima, H. Shen et al., "Effects of novel capsinoid treatment on fatness and energy metabolism in humans: possible pharmacogenetic implications," The American Journal of Clinical Nutrition, vol. 89, no. 1, pp. 45-50, 2009.

[339] K. D. K. Ahuja, I. K. Robertson, D. P. Geraghty, and M. J. Ball, "Effects of chili consumption on postprandial glucose, insulin, and energy metabolism," The American Journal of Clinical Nutrition, vol. 84, no. 1, pp. 63-69, 2006.

[340] A. J. Smeets and M. S. Westerterp-Plantenga, "The acute effects of a lunch containing capsaicin on energy and substrate utilisation, hormones, and satiety," European Journal of Nutrition, vol. 48, no. 4, pp. 229-234, 2009.

[341] K. Iwai, A. Yazawa, and T. Watanabe, "Roles as metabolic regulators of the non-nutrients, capsaicin and capsiate, supplemented to diets," Proceedings of the Japan Academy Series B: Physical and Biological Sciences, vol. 79, no. 7, pp. 207-212, 2003.

[342] A. R. Josse, S. S. Sherriffs, A. M. Holwerda, R. Andrews, A. W. Staples, and S. M. Phillips, "Effects of capsinoid ingestion on energy expenditure and lipid oxidation at rest and during exercise," Nutrition and Metabolism, vol. 7, article 65, 2010.

[343] N. Inoue, Y. Matsunaga, H. Satoh, and M. Takahashi, "Enhanced energy expenditure and fat oxidation in humans with high BMI scores by the ingestion of novel and non-pungent capsaicin analogues (capsinoids)," Bioscience, Biotechnology and Biochemistry, vol. 71, no. 2, pp. 380-389, 2007.

[344] T. A. Lee, Z. Li, A. Zerlin, and D. Heber, "Effects of dihydrocapsiate on adaptive and diet-induced thermogenesis with a high protein very low calorie diet: a randomized control trial," Nutrition and Metabolism, vol. 7, article 78, 2010.

[345] J. E. Galgani and E. Ravussin, "Effect of dihydrocapsiate on resting metabolic rate in humans," The American Journal of Clinical Nutrition, vol. 92, no. 5, pp. 1089-1093, 2010.
[346] M. N. Opheim and J. W. Rankin, "Effect of capsaicin supplementation on repeated sprinting performance," Journal of Strength and Conditioning Research, vol. 26, no. 2, pp. 319-326, 2012.

[347] J. Bremer, "Carnitine-metabolism and functions," Physiological Reviews, vol. 63, no. 4, pp. 1420-1480, 1983.

[348] F. B. Stephens, B. T. Wall, K. Marimuthu et al., "Skeletal muscle carnitine loading increases energy expenditure, modulates fuel metabolism gene networks and prevents body fat accumulation in humans," Journal of Physiology, vol. 591, no. 18, pp. 46554666, 2013.

[349] I. B. Fritz and K. T. Yue, "Acyltransferase and the role of acylcarnitine derivatives in the catalytic increase of fatty acid oxidation induced by carnitine," Journal of Lipid Research, vol. 4, pp. 279-288, 1963.

[350] B. T. Wall, F. B. Stephens, D. Constantin-Teodosiu, K. Marimuthu, I. A. Macdonald, and P. L. Greenhaff, "Chronic oral ingestion of L-carnitine and carbohydrate increases muscle carnitine content and alters muscle fuel metabolism during exercise in humans," Journal of Physiology, vol. 589, part 4, pp. 963-973, 2011.

[351] G. E. Orer and N. A. Guzel, "The effects of acute l-carnitine supplementation on endurance performance of athletes," Journal of Strength and Conditioning Research, vol. 28, no. 2, pp. 514-519, 2014.

[352] C. J. Rebouche, "Carnitine function and requirements during the life cycle," The FASEB Journal, vol. 6, no. 15, pp. 3379-3386, 1992.

[353] M. R. Rubin, J. S. Volek, A. L. Gomez et al., "Safety measures of L-carnitine L-tartrate supplementation in healthy men," The Journal of Strength and Conditioning Research, vol. 15, no. 4, pp. 486-490, 2001.

[354] J. A. Higgins, "Resistant starch and energy balance: impact on weight loss and maintenance," Critical Reviews in Food Science and Nutrition , vol. 54, no. 9, pp. 1158-1166, 2014.

[355] M. D. Haub, K. L. Hubach, E. K. Al-Tamimi, S. Ornelas, and P. A. Seib, "Different types of resistant starch elicit different glucose reponses in humans," Journal of Nutrition and Metabolism, vol. 2010, Article ID 230501, 4 pages, 2010.

[356] K. N. Englyst, S. Liu, and H. N. Englyst, "Nutritional characterization and measurement of dietary carbohydrates," European Journal of Clinical Nutrition, vol. 61, supplement 1, pp. S19-S39, 2007.

[357] C. L. Bodinham, G. S. Frost, and M. D. Robertson, "Acute ingestion of resistant starch reduces food intake in healthy adults," British Journal of Nutrition, vol. 103, no. 6, pp. 917-922, 2010.

[358] A. Raben, A. Tagliabue, N. J. Christensen, J. Madsen, J. J. Holst, and A. Astrup, "Resistant starch: the effect on postprandial glycemia, hormonal response, and satiety," American Journal of Clinical Nutrition, vol. 60, no. 4, pp. 544-551, 1994.

[359] J. A. Higgins, D. R. Higbee, W. T. Donahoo, I. L. Brown, M. L. Bell, and D. H. Bessesen, "Resistant starch consumption promotes lipid oxidation," Nutrition \& Metabolism, vol. 1, article 8, 2004.

[360] A. S. Klosterbuer, W. Thomas, and J. L. Slavin, "Resistant starch and pullulan reduce postprandial glucose, insulin, and GLP1 , but have no effect on satiety in healthy humans," Journal of Agricultural and Food Chemistry, vol. 60, no. 48, pp. 1192811934, 2012.

[361] M. D. Haub, J. A. Louk, and T. C. Lopez, "Novel resistant potato starches on glycemia and satiety in humans," Journal of 
Nutrition and Metabolism, vol. 2012, Article ID 478043, 4 pages, 2012.

[362] P. M. Heacock, S. R. Hertzler, and B. Wolf, "The glycemic, insulinemic, and breath hydrogen responses in humans to a food starch esterified by 1-octenyl succinic anhydride," Nutrition Research, vol. 24, no. 8, pp. 581-592, 2004.

[363] A. Shimotoyodome, J. Suzuki, Y. Kameo, and T. Hase, "Dietary supplementation with hydroxypropyl-distarch phosphate from waxy maize starch increases resting energy expenditure by lowering the postprandial glucose-dependent insulinotropic polypeptide response in human subjects," British Journal of Nutrition, vol. 106, no. 1, pp. 96-104, 2011.

[364] N. de Roos, M. L. Heijnen, C. de Graaf, G. Woestenenk, and E. Hobbel, "Resistant starch has little effect on appetite, food intake and insulin secretion of healthy young men," European Journal of Clinical Nutrition, vol. 49, no. 7, pp. 532-541, 1995.

[365] S. Ranganathan, M. Champ, C. Pechard et al., "Comparative study of the acute effects of resistant starch and dietary fibers on metabolic indexes in men," The American Journal of Clinical Nutrition, vol. 59, no. 4, pp. 879-883, 1994.

[366] A. Tagliabue, A. Raben, M. L. Heijnen, P. Deurenberg, E. Pasquali, and A. Astrup, "The effect of raw potato starch on energy expenditure and substrate oxidation," American Journal of Clinical Nutrition, vol. 61, no. 5, pp. 1070-1075, 1995.

[367] E. K. Al-Tamimi, P. A. Seib, B. S. Snyder, and M. D. Haub, "Consumption of cross-linked resistant starch $\left(\mathrm{RS} 4_{X L}\right)$ on glucose and insulin responses in humans," Journal of Nutrition and Metabolism, vol. 2010, Article ID 651063, 6 pages, 2010.

[368] A. C. Bach and V. K. Babayan, "Medium-chain triglycerides: an update," The American Journal of Clinical Nutrition, vol. 36, no. 5, pp. 950-962, 1982.

[369] M. E. Clegg, "Medium-chain triglycerides are advantageous in promoting weight loss although not beneficial to exercise performance," International Journal of Food Sciences and Nutrition, vol. 61, no. 7, pp. 653-679, 2010.

[370] S. S. Gropper and J. L. Smith, Advanced Nutrition and Human Metabolism, Wadsworth Publishing, Belmont, Calif, USA, 6th edition, 2013.

[371] A. C. Rego Costa, E. L. Rosado, and M. Soares-Mota, "Influence of the dietary intake of medium chain triglycerides on body composition, energy expenditure and satiety: a systematic review," Nutrición Hospitalaria, vol. 27, no. 1, pp. 103-108, 2012.

[372] A. G. Dulloo, M. Fathi, N. Mensi, and L. Girardier, "Twentyfour-hour energy expenditure and urinary catecholamines of humans consuming low-to-moderate amounts of mediumchain triglycerides: a dose-response study in a human respiratory chamber," European Journal of Clinical Nutrition, vol. 50, no. 3, pp. 152-158, 1996.

[373] N. J. Rothwell and M. J. Stock, "Stimulation of thermogenesis and brown fat activity in rats fed medium chain triglyceride," Metabolism, vol. 36, no. 2, pp. 128-130, 1987.

[374] M.-P. St-Onge, R. Ross, W. D. Parsons, and P. J. H. Jones, "Medium-chain triglycerides increase energy expenditure and decrease adiposity in overweight men," Obesity Research, vol. 11, no. 3, pp. 395-402, 2003.

[375] M.-P. St-Onge and P. J. H. Jones, "Physiological effects of medium-chain triglycerides: potential agents in the prevention of obesity," Journal of Nutrition, vol. 132, no. 3, pp. 329-332, 2002.

[376] M. P. St-Onge, C. Bourque, P. J. Jones, R. Ross, and W. E. Parsons, "Medium- versus long-chain triglycerides for 27 days increases fat oxidation and energy expenditure without resulting in changes in body composition in overweight women,"
International Journal of Obesity and Related Metabolic Disorders, vol. 27, no. 1, pp. 95-102, 2003.

[377] M.-P. St-Onge and P. J. H. Jones, "Greater rise in fat oxidation with medium-chain triglyceride consumption relative to longchain triglyceride is associated with lower initial body weight and greater loss of subcutaneous adipose tissue," International Journal of Obesity and Related Metabolic Disorders, vol. 27, no. 12, pp. 1565-1571, 2003.

[378] M. E. Clegg, M. Golsorkhi, and C. J. Henry, "Combined medium-chain triglyceride and chilli feeding increases dietinduced thermogenesis in normal-weight humans," European Journal of Nutrition, vol. 52, no. 6, pp. 1579-1585, 2013.

[379] H. Amagase, R. Handel, and D. Nance, "Impact of a combination of medium-chain triglycerides and dietary fiber in a form of meal replacement shake on postprandial energy expenditure," The FASEB Journal, vol. 27, no. 854, p. 1, 2013.

[380] V. K. Babayan, "Medium chain triglycerides and structured lipids," Lipids, vol. 22, no. 6, pp. 417-420, 1987. 


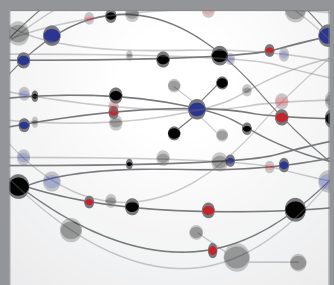

The Scientific World Journal
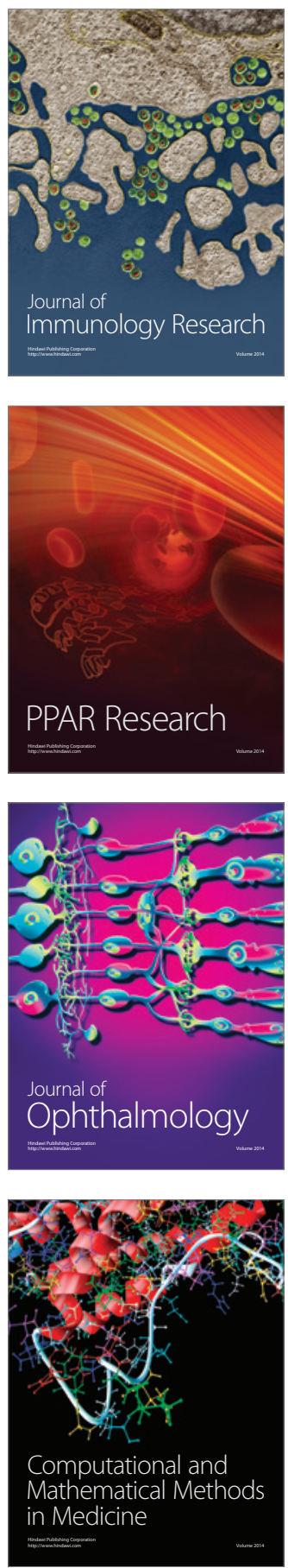

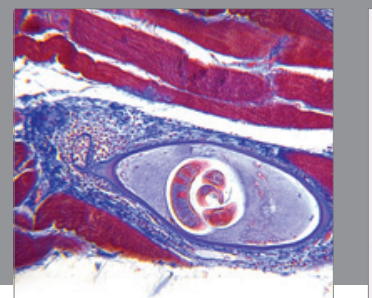

Gastroenterology

Research and Practice
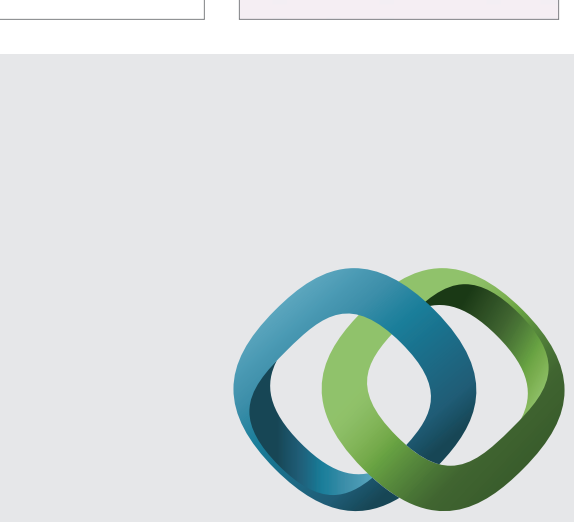

\section{Hindawi}

Submit your manuscripts at

http://www.hindawi.com
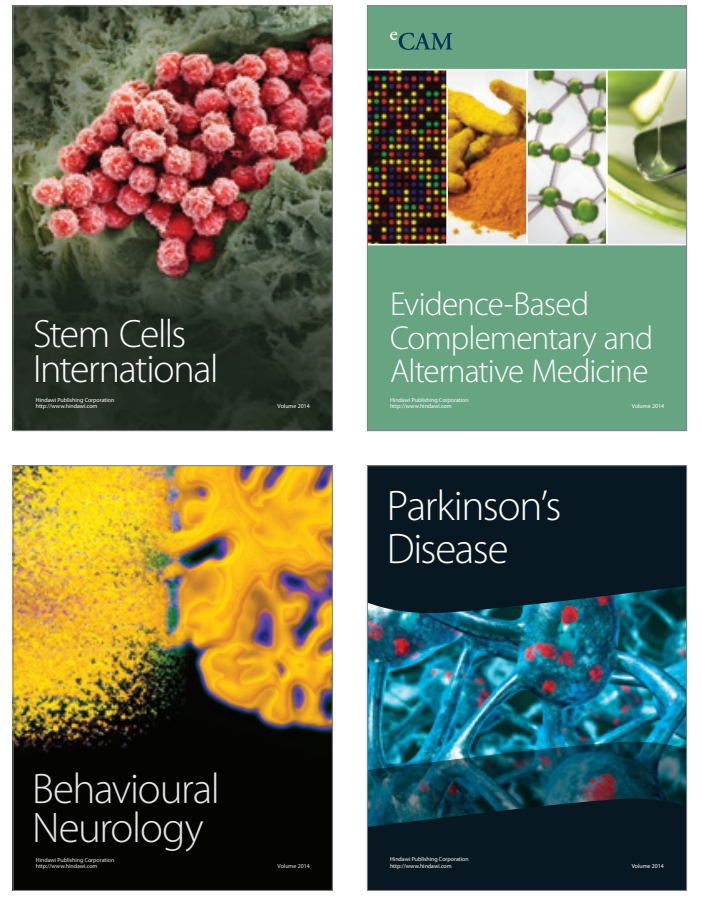
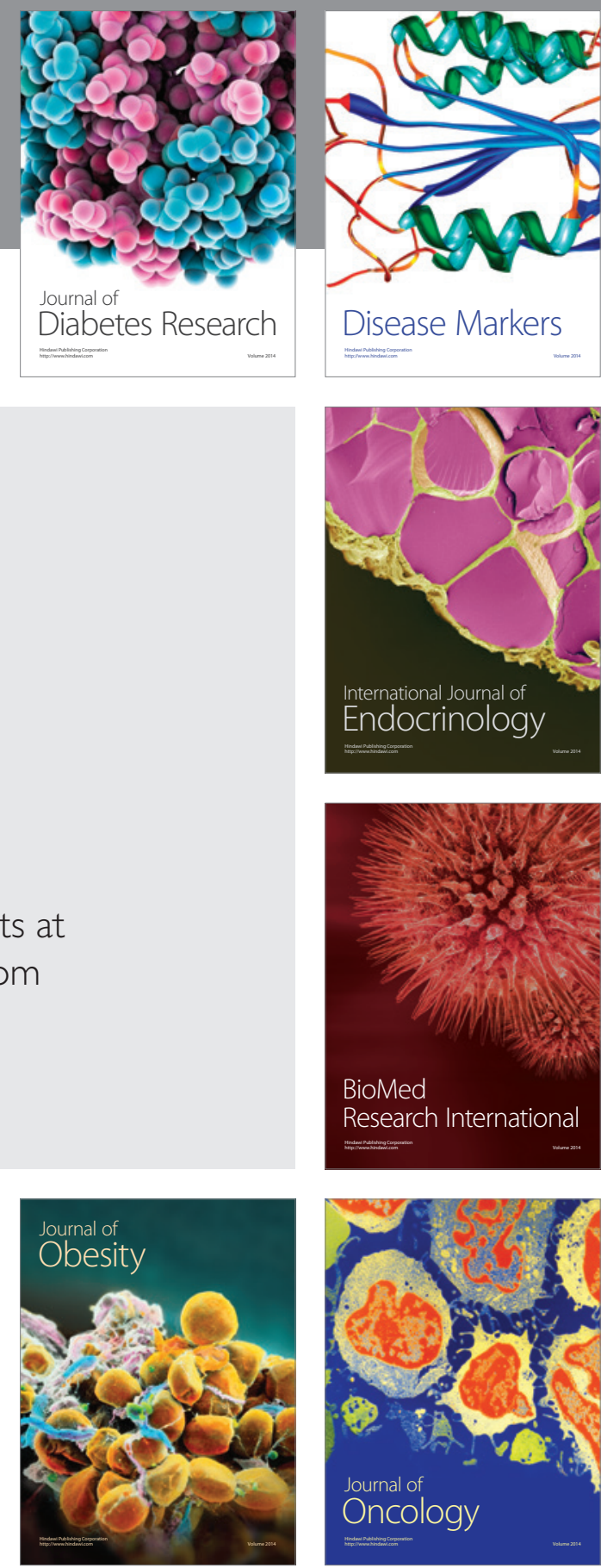

Disease Markers
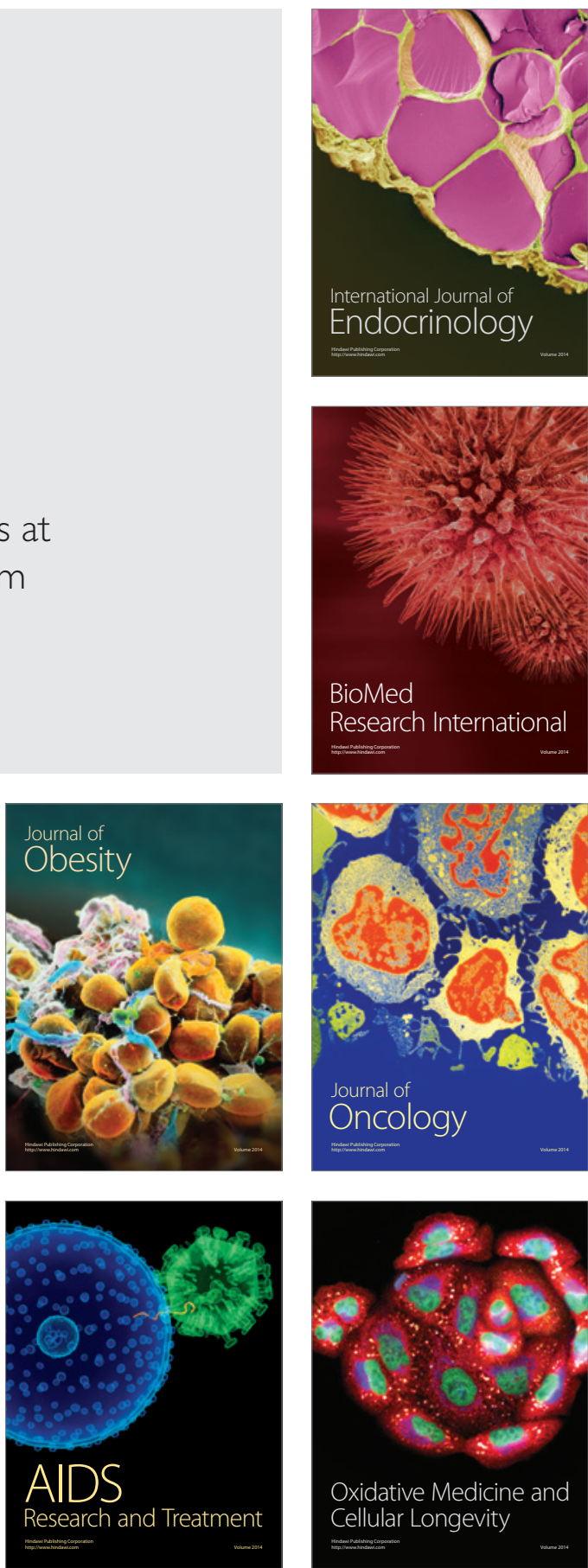